\title{
Development
}

\section{A Shared Transcriptional Identity for Forebrain and Dentate Gyrus Neural Stem Cells from Embryogenesis to Adulthood}

\author{
Michael J. Borrett, ${ }^{1,2}$ Brendan T. Innes, ${ }^{3,4}$ Nareh Tahmasian, ${ }^{1,2}$ Gary D. Bader, ${ }^{3,4}$ David R. Kaplan,, ${ }^{1,2,4}$ \\ and Freda D. Miller ${ }^{1,2,4,5,6,7}$
}

https://doi.org/10.1523/ENEURO.0271-21.2021

\begin{abstract}
${ }^{1}$ Program in Neuroscience and Mental Health, Hospital for Sick Children, Toronto, Ontario M5G 1L7, Canada, ${ }^{2}$ Institute of Medical Science, University of Toronto, Toronto, Ontario M5G 1A8, Canada, ${ }^{3}$ The Donnelly Centre, University of Toronto, Toronto, Ontario M5G 1A8, Canada, ${ }^{4}$ Department of Molecular Genetics, University of Toronto, Toronto, Ontario M5G 1A8, Canada, ${ }^{5}$ Department of Physiology, University of Toronto, Toronto, Ontario M5G 1A8, Canada, ${ }^{6}$ Michael Smith Laboratories, University of British Columbia, Vancouver, British Columbia V6T 1Z4, Canada, and ${ }^{7}$ Department of Medical Genetics, University of British Columbia, Vancouver, British Columbia V6T 1Z4, Canada
\end{abstract}

\begin{abstract}
Adult neural stem cells (NSCs) reside in two distinct niches in the mammalian brain, the ventricular-subventricular zone (V-SVZ) of the forebrain lateral ventricles and the subgranular zone (SGZ) of the hippocampal dentate gyrus. They are thought to be molecularly distinct since V-SVZ NSCs produce inhibitory olfactory bulb (OB) interneurons and SGZ NSCs excitatory dentate granule neurons. Here, we have asked whether this is so by directly comparing V-SVZ and SGZ NSCs from embryogenesis to adulthood using single-cell transcriptional data. We show that the embryonic radial glial precursor (RP) parents of these two NSC populations are very similar, but differentially express a small cohort of genes involved in glutamatergic versus GABAergic neurogenesis. These different RPs then undergo a similar gradual transition to a dormant adult NSC state over the first three postnatal weeks. This dormancy state involves transcriptional shutdown of genes that maintain an active, proliferative, prodifferentiation state and induction of genes involved in sensing and regulating their niche environment. Moreover, when reactivated to generate adult-born progeny, both populations reacquire a development-like state and re-express proneurogenic genes. Thus, V-SVZ and SGZ NSCs share a common transcriptional state throughout their lifespans and transition into and out of dormancy via similar trajectories.
\end{abstract}

Key words: forebrain neural stem cells; neurodevelopment; single-cell RNA-sequencing

\section{Significance Statement}

This work furthers our understanding of the molecular similarities and differences between the two major populations of adult neural stems [neural stem cell (NSC)] in the mammalian brain: ventricular-subventricular zone (V-SVZ) NSCs and subgranular zone (SGZ) NSCs. We have analyzed high throughput single-cell RNA-sequencing (scRNA-Seq) data for these two NSC populations from embryogenesis through to adulthood and show that while not identical, both populations exhibit a conserved forebrain NSC signature and are transcriptionally similar throughout their lifespans despite the different types of neurons they generate. Moreover, we show that both populations progress from active embryonic precursors to postnatal dormant NSCs along a similar timeframe, and that in both cases reactivation involves a transition back to a development-like state.

Received June 15, 2021; accepted November 15, 2021; First published January 13, 2022.

The authors declare no competing financial interests.
Author contributions: M.J.B., B.T.I., G.D.B., D.R.K., and F.D.M. designed research; N.T. performed research; M.J.B., B.T.I., D.R.K., and F.D.M. analyzed data; M.J.B., D.R.K., and F.D.M. wrote the paper. 


\section{Introduction}

Genesis of adult neural stem cells (NSCs) from embryonic neural precursors is an essential developmental process that ensures the continued production of newborn neurons and glia throughout postnatal and adult life. The adult murine brain contains at least two well-characterized NSC populations, one that resides in the ventricularsubventricular zone (V-SVZ) of the lateral ventricles and a second that resides in the subgranular zone (SGZ) of the hippocampal dentate gyrus. These V-SVZ and SGZ NSCs are functionally distinct and generate different types of neurons and glia; V-SVZ NSCs produce inhibitory olfactory bulb $(\mathrm{OB})$ interneurons and oligodendrocytes (Lois and Alvarez-Buylla, 1994; Lois et al., 1996; Menn et al., 2006), whereas SGZ NSCs produce excitatory granule neurons and astrocytes (Brandt et al., 2003; Bonaguidi et al., 2011). However, despite this differential cell genesis, these two NSC populations originate from embryonic neural precursors that reside in adjacent regions of the forebrain lateral ventricles (Young et al., 2007; Fuentealba et al., 2015; Berg et al., 2019). V-SVZ NSCs derive from embryonic cortical and ganglionic eminence (GE) radial glial precursor cells (RPs), whereas SGZ NSCs derive from a subpopulation of embryonic hippocampal precursors in the dentate neuroepithelium (Berg et al., 2018).

How similar are SGZ and V-SVZ NSCs, and what accounts for their functional differences? One idea is that these two NSC types are predetermined by morphogenic cues during early development. For example, lineage tracing and fate mapping studies suggested that V-SVZ NSCs originate from a subset of RPs that are set aside during mid-to-late embryogenesis (Fuentealba, et al., 2015; Furutachi et al., 2015), coincident with acquisition of a slowly-proliferating/quiescent-like cell cycle state (Fuentealba et al., 2015; Furutachi et al., 2015; Yuzwa et al., 2017). However, more recent studies suggest that these embryonic RPs transition to a dormant adult V-SVZ NSC transcriptional state over a relatively lengthy period of time that extends from late embryogenesis to the third postnatal week (Borrett et al., 2020). Similar findings have recently been reported for SGZ NSCs. Lineage tracing and clonal analysis showed that SGZ precursors enter a quiescent-like state by early postnatal development (Berg et al., 2019) and single-cell transcriptional profiling showed that newborn and three-week-old SGZ NSCs are transcriptionally distinct (Hochgerner et al., 2018). Thus, adult V-SVZ and SGZ NSC populations both apparently acquire their adult dormant states at similar times between birth and the third postnatal week. However, despite this similarity, we do not yet know whether the

This work was supported by the Canadian Institutes of Health Research (CIHR) and the Canada First Research Excellence Fund "Medicine by Design" (F.D.M., D.R.K., and G.D.B.). M.J.B. was supported by the CIHR.

Correspondence should be addressed to Freda D. Miller at freda. miller@msl.ubc.ca.

https://doi.org/10.1523/ENEURO.0271-21.2021

Copyright (C) 2022 Borrett et al.

This is an open-access article distributed under the terms of the Creative Commons Attribution 4.0 International license, which permits unrestricted use, distribution and reproduction in any medium provided that the original work is properly attributed. transition to dormancy is similar for these two adult NSC populations, and/or to what extent they or their embryonic precursor parents resemble each other.

Here, we have addressed these questions by computationally comparing the transcriptional profiles of V-SVZ and SGZ-derived NSCs from embryogenesis to adulthood. These analyses indicate that although these two NSC populations produce distinct cellular progeny, they share significant transcriptional commonalities from embryogenesis through to adulthood. Moreover, both populations display a similar developmental transition to dormancy, and reacquire their embryonic states when activated to generate adult-born progeny. These findings therefore support a model where forebrain NSCs are substantively similar at the transcriptional level, and where genesis of their distinct adult-born progeny may at least in part be determined by their adult niche environments.

\section{Materials and Methods}

\section{Tissue preparation, fluorescence in situ hybridization (FISH), and immunostaining}

Under RNase-free conditions, brains were harvested from postnatal day (P)5 CD1 mice, fixed in 4\% paraformaldehyde (PFA) for $24 \mathrm{~h}$ at $4^{\circ} \mathrm{C}$, washed in HBSS, transferred to $30 \%$ sucrose for $48 \mathrm{~h}$ at $4^{\circ} \mathrm{C}$, embedded in optimum cutting temperature (O.C.T.) mounting medium (Tissue-Tek) and stored at $-80^{\circ} \mathrm{C}$. Frozen embedded brains were sectioned coronally at $14-\mu \mathrm{m}$ thickness and stored at $-80^{\circ} \mathrm{C}$.

RNA was detected using the RNAscope Multiplex Fluorescent Assay kit (Advanced Cell Diagnostics) under RNase-free conditions. Sections were dried for $15 \mathrm{~min}$ at $37^{\circ} \mathrm{C}$, washed in PBS for $5 \mathrm{~min}$, then washed in $50 \%, 70 \%$, and $100 \%$ ethanol sequentially for 5,5 , and $2 \times 5 \mathrm{~min}$, respectively. After air drying at room temperature, sections were permeabilized using a 1:30 dilution of the RNA-scope Pretreatment-4 protease solution (Advanced Cell Diagnostics) for $10 \mathrm{~min}$ at $37^{\circ} \mathrm{C}$, washed, and maintained in PBS until probe addition. RNA probes were preheated at $40^{\circ} \mathrm{C}$ for $10 \mathrm{~min}$ and added to the sections and incubated for $2 \mathrm{~h}$ at $40^{\circ} \mathrm{C}$. Probes were used to target Ptprz1 (catalog \#460991, NM_001081306.1), Ttyh1 (504051-C3, NM_001001454.4), Rgs5 (catalog \#430181, NM_009063.3), Aldoc (429531-C3, NM_009657.3), and Mt3 (catalog \#504061, NM_013603.2) mRNAs. Following probe incubation, sections were washed as recommended by the manufacturer and incubated with RNAscope AMP1 solution for $30 \mathrm{~min}$ at $40^{\circ} \mathrm{C}$, washed, incubated with RNAscope AMP2 solution for $15 \mathrm{~min}$ at $40^{\circ} \mathrm{C}$, washed, incubated with RNAscope AMP3 solution for 30 min at $40^{\circ} \mathrm{C}$, washed, incubated with RNAscope AMP4 solution for $15 \mathrm{~min}$ at $40^{\circ} \mathrm{C}$, and washed. For concomitant immunostaining, sections were washed once with PBS, incubated in $5 \%$ BSA blocking buffer at room temperature for $1 \mathrm{~h}$, and incubated in primary antibody solution (goat anti-Sox2 diluted 1:1000 in 2.5\% BSA; R\&D Systems) overnight at $4^{\circ}$ $\mathrm{C}$ in a humidified chamber. Following primary antibody incubation, sections were washed three times with PBS and incubated in fluorescently labeled secondary antibody 
solution (diluted 1:1000 in PBS; Invitrogen) for $1 \mathrm{~h}$ at room temperature. Sections were then washed three times with PBS, incubated with $0.5 \mathrm{mg} / \mathrm{ml}$ Hoechst 33258 for $5 \mathrm{~min}$ at room temperature, washed three times with PBS, and mounted on glass slides using Aqua-Poly/Mount (Polysciences).

\section{Imaging and microscopy}

Images of FISH with immunostaining were collected using a Quorom spinning disk confocal microscope system. $Z$ stacks of confocal images were taken with an optical slice thickness of $0.3 \mu \mathrm{m}$, and projected z-stacked images are shown.

\section{Single-cell RNA-sequencing (scRNA-Seq) data analysis pipeline}

Hippocampal dentate gyrus scRNA-Seq data described in Hochgerner et al. (2018) was downloaded from GSE95753. 10× Genomics scRNA-Seq dataset in Hochgerner et al. (2018), termed "Dataset C" and consisting of 24,185 cells (GSE104323), was used for all described analyses below. Dataset count matrix was imported into Seurat version 3.1.1 and was normalized using Seurat's library size normalization method. Genes detected in fewer than three cells were removed from the dataset. PCA was performed using highly variable genes in the data. The Seurat function RunUMAP was used to generate two-dimensional UMAP projections using the top principal components detected in the dataset. UMAP visualization of all dentate gyrus cell types was subsequently overlaid with specific cell types annotated by Hochgerner et al. (2018) as shown in Figure $1 A$ to ensure reproducibility of data analysis. Annotations by Hochgerner et al. (2018) can be found at GSE104323. The P20, P34, P61 merged V-SVZ neural cell dataset described in Borrett et al. (2020) was also run through this computational pipeline as shown in Figure $2 E$ to more consistently compare the V-SVZ cell types with the dentate gyrus populations.

To generate the SGZ NSCs and V-SVZ NSCs merged dataset shown in Figure 3B, SGZ NSCs (also known as radial glial like cells; RGL) from all timepoints (885 total cells), annotated by Hochgerner et al. (2018) were extracted from the complete dentate gyrus dataset, and cell transcriptomes were merged with V-SVZ NSC transcriptomes described in Borrett et al. (2020) and subsequently run through a batch corrected version of the pipeline described above (methods described below) resulting in 2479 total forebrain NSCs. Cell cycle regression was performed on the same dataset (method described below). The same top principal components used to perform UMAP dimensionality reduction, were subsequently used to iteratively carry out SNN-Cliq-inspired clustering (FindClusters function in Seurat). Clusters were assigned at a resolution of 0.4 (nine clusters identified without cell cycle regression and eight clusters identified with cell cycle regression, presumably because of reduced cellcycle related clustering). To generate the E14 RP and embryonic day (E)16.5 dentate neuroepithelium RP merged dataset shown in Figure 5A, all E14 RP (cortical and GEderived) and E16.5 dentate neuroepithelium RP raw transcriptomes were extracted and run through the same batch corrected pipeline. To generate the P6/P7 V-SVZ NSC and P5 SGZ NSC merged dataset shown in Figure $5 E$, all P6/P7 RP (cortical and GE-derived) and P5 SGZ NSC raw transcriptomes were extracted and run through the same batch corrected pipeline. Juvenile and adult transit-amplifying precursors (TAPs)/intermediate progenitors (IPs) of both V-SVZ and SGZ origin were combined to the merged NSC dataset shown in Figure $3 B$ and were subsequently run through the batch corrected pipeline. SGZ IPs included all IPs annotated by Hochgerner et al. (2018) from P18 to P132 and V-SVZ TAPs included all nonproliferative TAPs at P20,P34,P61 identified in Borrett et al. (2020). This population of TAPs included a small number of activated NSCs at these ages as described in Borrett et al. (2020). Note that for all dataset merging, the union of all detected genes from each dataset was always used. tSNE gene overlays were generated using the Seurat FeaturePlot function, violin plots were generated using the Seurat VInPlot function, heatmaps were generated using the Seurat DoHeatmap function (using scaled expression values).

\section{Batch correction of merged V-SVZ and SGZ datasets}

V-SVZ and SGZ cell transcriptomes were corrected for batch differences using the R program Harmony (version 1.0; Korsunsky et al., 2019). Cells were categorized into two distinct batches based on their site of origin: all VSVZ cells were considered batch 1 and all SGZ cells were considered batch 2. Following PCA, a single iteration of Harmony-mediated correction was performed on the normalized cell transcriptomes based on the above batch categorization using the RunHarmony function. Following Harmony batch correction, both UMAP dimensionality reduction and SNN-Cliq inspired clustering were performed using the obtained "harmonized" principal component space as opposed to the original uncorrected principal component space. This same protocol was conducted for all datasets on which batch correction was performed.

\section{Trajectory inference and pseudotime ordering}

Single-cell pseudotime trajectories were constructed as described in Borrett et al. (2020) using a modified version of the dpFeature method in Monocle v2 (Trapnell et al., 2014) as previously published (Borrett et al., 2020; Storer et al., 2020). Briefly, cell barcodes from desired datasets were extracted from the raw digital gene expression matrices and merged before normalization using Monocle's size factor normalization method. PCA was performed using the same highly variable genes that were obtained from our custom-built pipeline as described above and the cells were projected into two-dimensional space using the tSNE algorithm. Cells were subsequently assigned into distinct clusters using Monocle's density peak clustering algorithm. A set of ordering genes was obtained by testing each gene for differential expression between the clusters in the dataset and selecting the top 

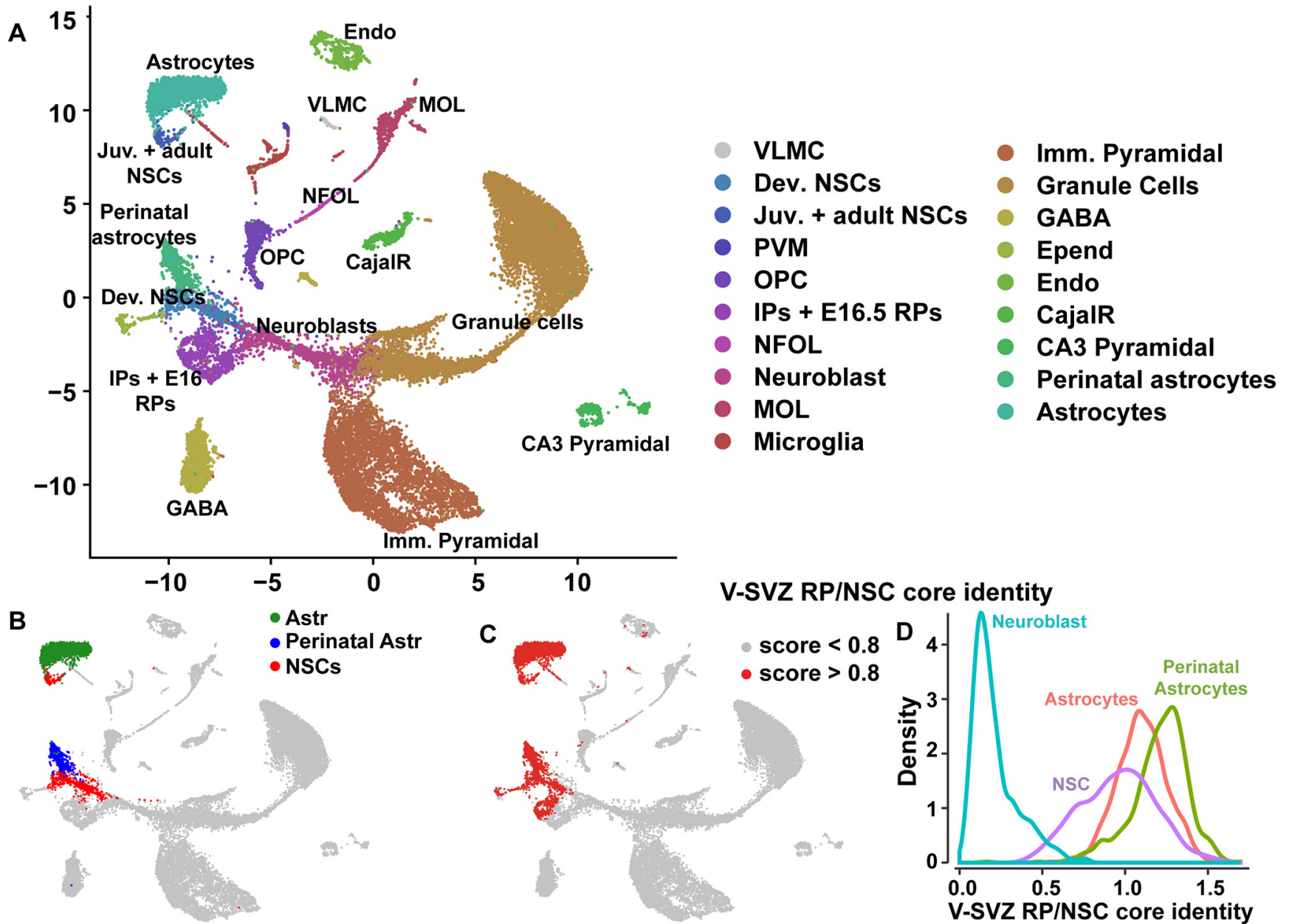

510

\section{V-SVZ RP/NSC core identity}

B

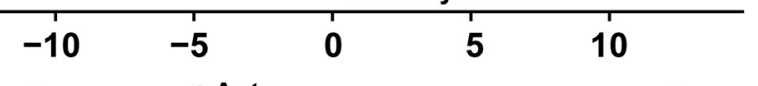

-SVZ RPINSC core identity

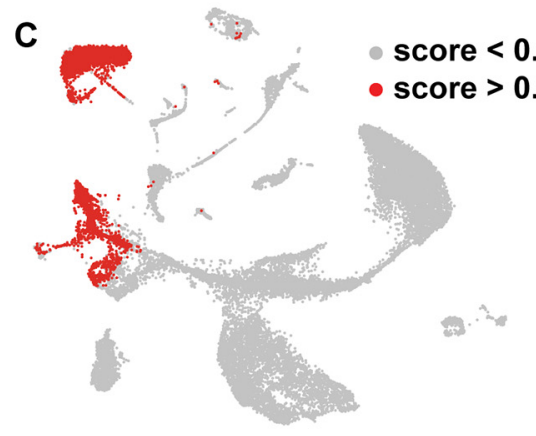

E Ptprz1/Ttyh1/Sox2/Hoechst
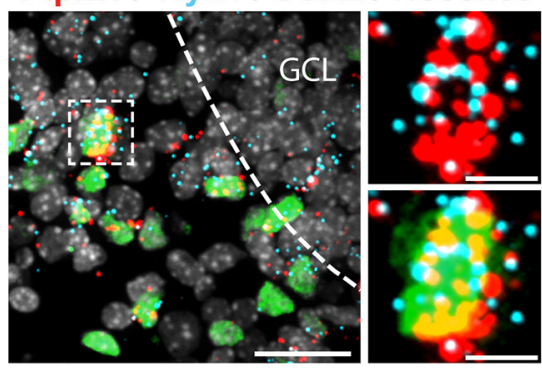

Rgs5 / Aldoc / SOX2 / Hoechst
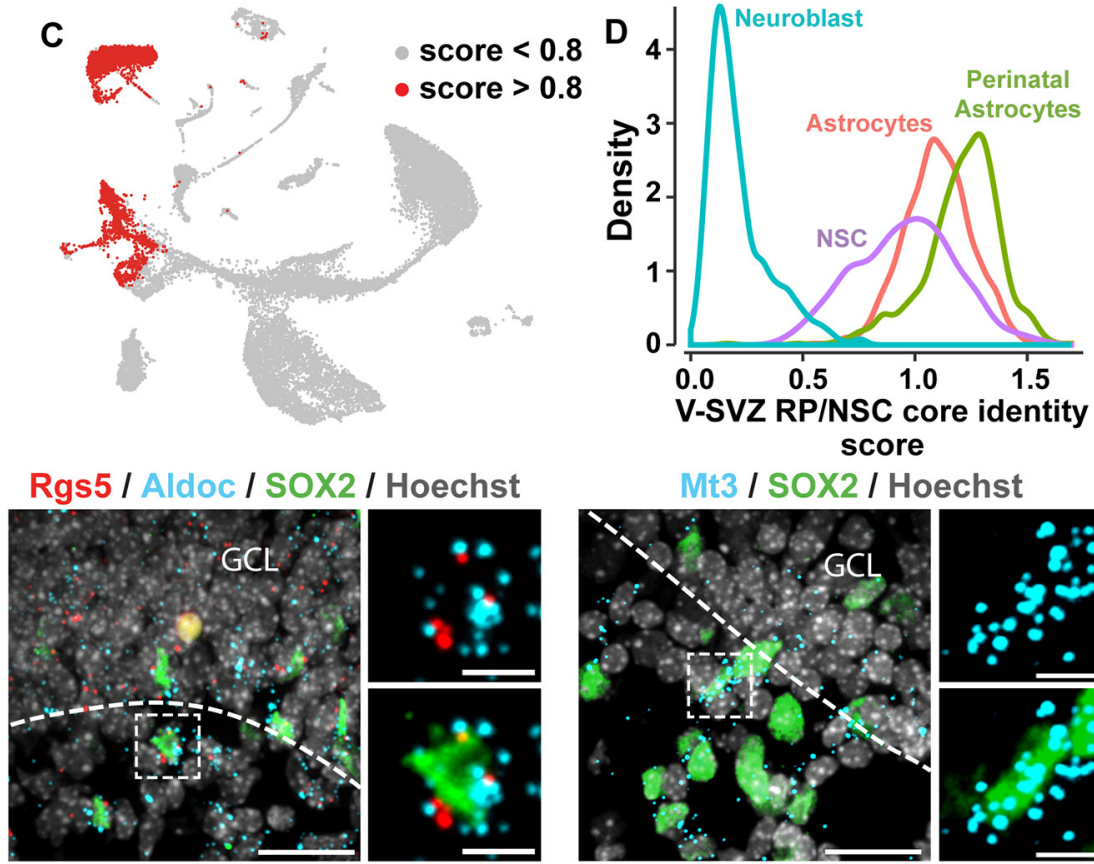

score

Mt3 / SOX2 / Hoechst

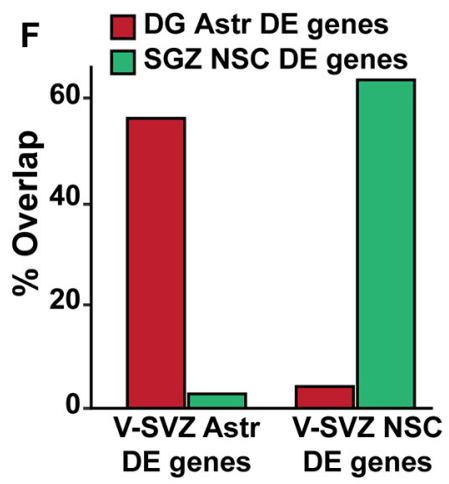

G

\section{Astrocyte signature}
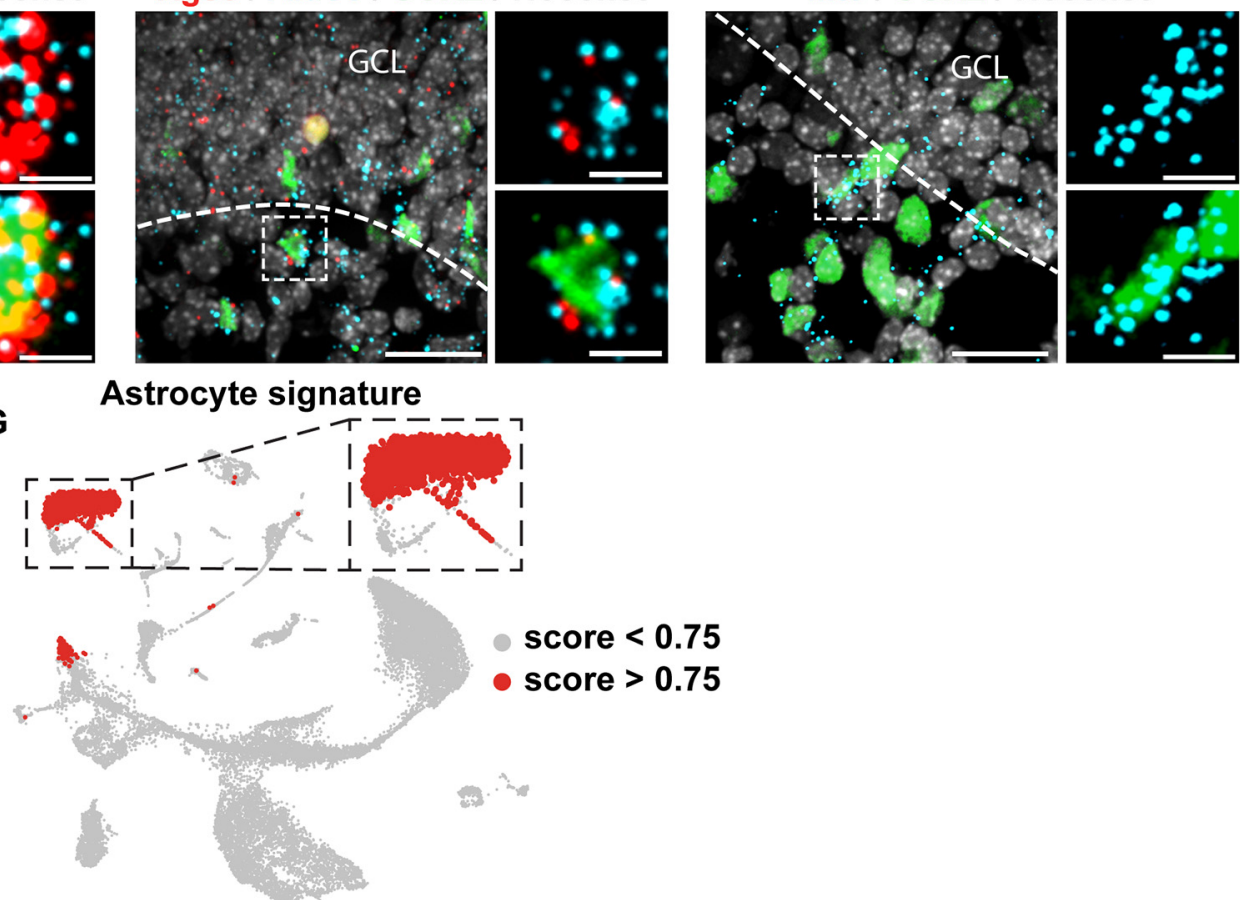

Figure 1. Analysis of single-cell transcriptomes of murine dentate gyrus cells from E16.5 to P132. A, UMAP visualization of dentate 
continued

gyrus cell transcriptomes from ages E16.5 to P132, colored by cell type using cell annotations described by Hochgerner et al. (2018). Annotations of cell types are shown on the right. VLMC: vascular and leptomeningeal cell; Dev. NSCs: developmental NSCs (E16.5, P0, P5); Juv. + adult NSCs: juvenile and adult NSCs (P18-P132); PVM: perivascular macrophage; OPC: oligodendrocyte precursor cell; IPs: intermediate progenitors (E16.5-P132); RP: radial precursors; NFOL: newly formed oligodendrocytes; MOL: mature oligodendrocytes; Imm. Pyramidal: immature pyramidal cells; GCs: granule cells; GABA: GABAergic neurons; CA3 Pyramidal: pyramidal cells of the hippocampal cornu Ammonis3. Data are not batch-corrected. $\boldsymbol{B}$, UMAP visualization as shown in $\boldsymbol{A}$ with the NSCs and astrocytes overlaid in different colors. NSCs at all ages (E16.5-P132) are highlighted in red, perinatal astrocytes (Astr; P0, P5) in blue and juvenile/adult astrocytes (Astr; P18-P132) in green. C, UMAP as shown in $\boldsymbol{A}$ overlaid with gene expression scores for a previously defined core identity for embryonic cortical RPs and V-SVZ NSCs (V-SVZ RP/NSC core identity; Yuzwa et al., 2017; Borrett et al., 2020). Red denotes cells with scores $>0.8$. D. Density plot showing the distribution of gene expression signature scores of the V-SVZ RP/NSC core identity as in $\mathbf{C}$ in distinct dentate gyrus populations. SGZ NSCs, perinatal astrocytes (P0, P5), juvenile/adult astrocytes (P18-P132) and neuroblasts are shown and are color coded. $\boldsymbol{E}$, Confocal z-stack images of coronal sections through the P5 dentate gyrus analyzed by FISH with probes for Ptprz1, Ttyh1, Rgs5, Aldoc, and Mt3 mRNAs (red or blue dots), combined with immunostaining for Sox2 (green) and counterstained with Hoechst (gray). Hatched white lines outline the border between the SGZ and the granule cell layer (GCL) and hatched boxes denote single labeled cells that are shown at higher magnification on the right. Scale bars represent $20 \mu \mathrm{m}$ in the lower magnification images and $5 \mu \mathrm{m}$ in the magnified images. $\boldsymbol{F}$, Bar graph showing the proportion of differentially expressed genes between V-SVZ astrocytes (V-SVZ Astr) and V-SVZ NSCs that are also differentially expressed between SGZ NSCs and dentate gyrus astrocytes (DG Astr); $64 \%$ of genes enriched in V-SVZ NSCs relative to V-SVZ astrocytes (V-SVZ NSC DE genes) were also enriched in SGZ NSCs relative to dentate gyrus astrocytes, while 56\% of genes enriched in V-SVZ astrocytes relative to V-SVZ NSCs (V-SVZ Astr DE genes) were also enriched in dentate gyrus astrocytes relative to SGZ NSCs. G, UMAP visualization as in $\boldsymbol{A}$ overlaid with gene expression scores for a 26 gene signature specific to astrocytes relative to NSCs in the V-SVZ and SGZ. These 26 genes are highlighted with asterisks in Table 2. The region shown in the hatched box includes juvenile/adult astrocytes and NSCs as identified in $\boldsymbol{B}$ and is shown at a larger size to the right. Red denotes cells with scores $>0.75$.

1000 significantly differentially expressed genes. Expression profiles were reduced to two dimensions using the DDRTree algorithm included in Monocle 2 and cells were ordered using these genes to obtain a trajectory. Cell cycle regression was performed as described below.

\section{Cell cycle regression analysis}

Cell cycle regression was conducted using the same method described in Borrett et al. (2020) by removing all cell cycle related genes from the highly variable genes used to perform PCA. All downstream steps were performed as previously described. In order to carry out cell cycle regression on the trajectory inference analysis performed using Monocle, the same list of cell cycle related genes was removed from the top 1000 differentially expressed genes used to order the cells along the inferred trajectory. In order to obtain a list of cell cycle related genes, we took the enriched genes from all G1, S, and G2/M marker gene pairs used by the Cyclone method (Scialdone et al., 2015) to assign cell cycle phase that were detected in our scRNA-Seq dataset. These genes were subsequently combined with an additional list of $S$ phase related and G2/M phase related genes described in Kowalczyk et al. (2015). Together, this resulted in a total of 678 cell cycle related genes that were used to perform cell cycle regression.

\section{Gene set enrichment analysis (GSEA)}

GSEA on the SGZ NSCs was performed using the same computational method described in Borrett et al. (2020). Gene correlation with time was performed by converting developmental day for each cell to an integer value, with birth at zero, then calculating Spearman rank correlation of normalized gene expression for each gene with time. GSEA was performed on the correlation coefficients as per the protocol in Reimand et al. (2019), using the quiescence gene set (Cheung and Rando, 2013) and gene sets defined here: http://download.baderlab.org/EM_Genesets/January_01_ 2020/Mouse/symbol/Mouse_GOBP_AllPathways_no_ GO_iea_January_01_2020_symbol.gmt. GSEA calculations were performed in $\mathrm{R}$ using the fast GSEA (fgsea) algorithm. Large gene set databases contain redundancy that makes interpretation difficult, so before reporting enriched gene sets, the results were collapsed into a non-redundant set (minimizing overlapping genes per set) using a Bayesian network construction approach (Korotkevich et al., 2021).

\section{Upregulation of quiescence genes over time}

Upregulation of quiescence genes over time shown in Figure $6 E$ was performed as described in Borrett et al. (2020). Gene correlation with time was performed by converting developmental day for each cell to an integer value, with birth at zero, then calculating Spearman rank correlation of normalized gene expression for each gene with time (same method as was done in the GSEA). Quiescence genes (defined in Cheung and Rando, 2013) were determined to be more correlated with time by comparing Spearman rank correlation coefficients versus all other detected genes using the Wilcoxon rank-sum test. Significance values are given in the figure legend and Results.

\section{Pearson correlation analysis}

Average Pearson correlation analysis was conducted by averaging the expression of each gene in a given cluster or cell type (i.e., population at a given age) and performing Pearson correlation using the cor.test function in R. Correlation coefficients between different populations were subsequently displayed as heatmaps using the pheatmap package in $R$. The single-cell Pearson 


\section{Dentate gyrus populations: timepoints overlaid}

A

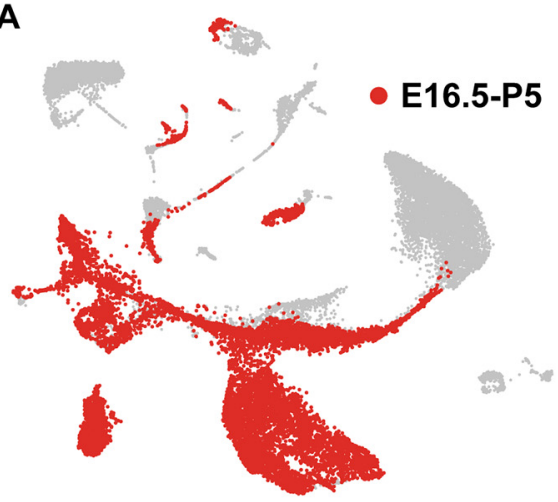

C

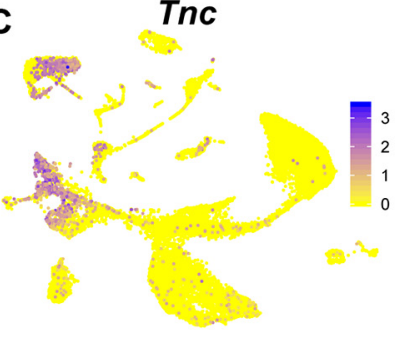

D

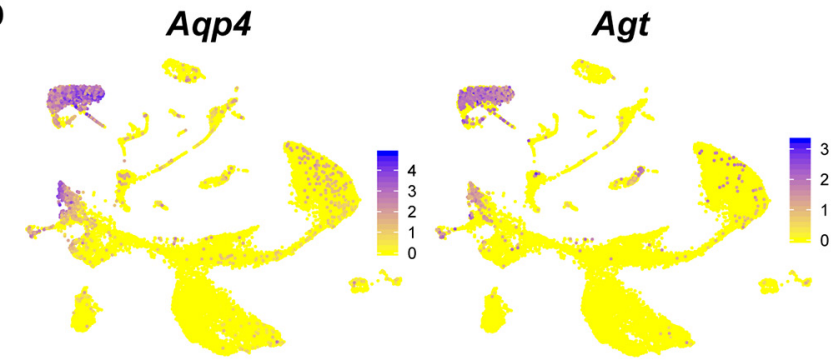

Agt

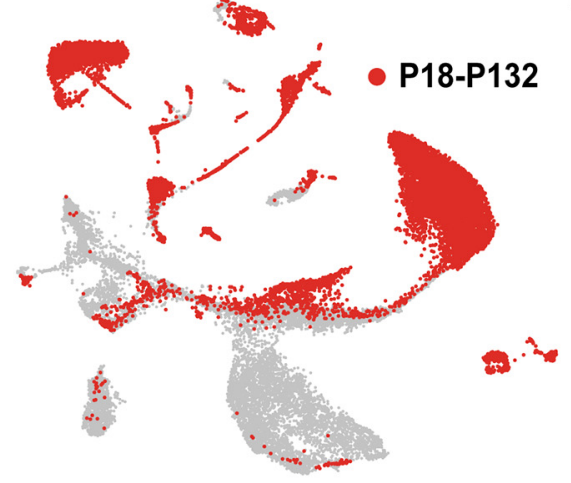

B

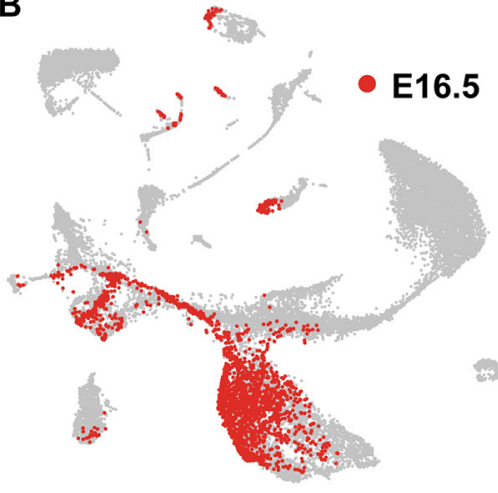

Tfap2c

Gas1
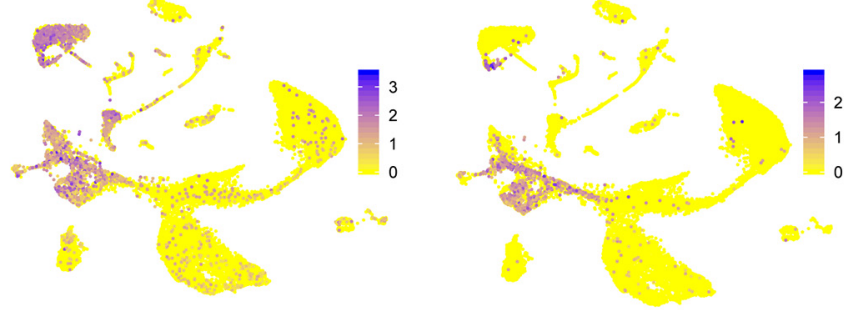

Ddah1

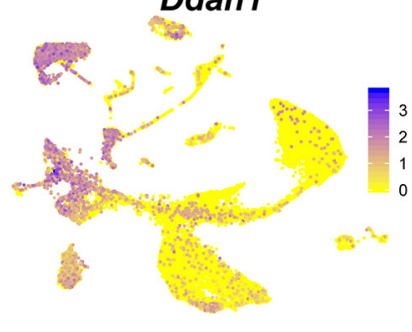

E Juvenile + Adult V-SVZ neural cell types

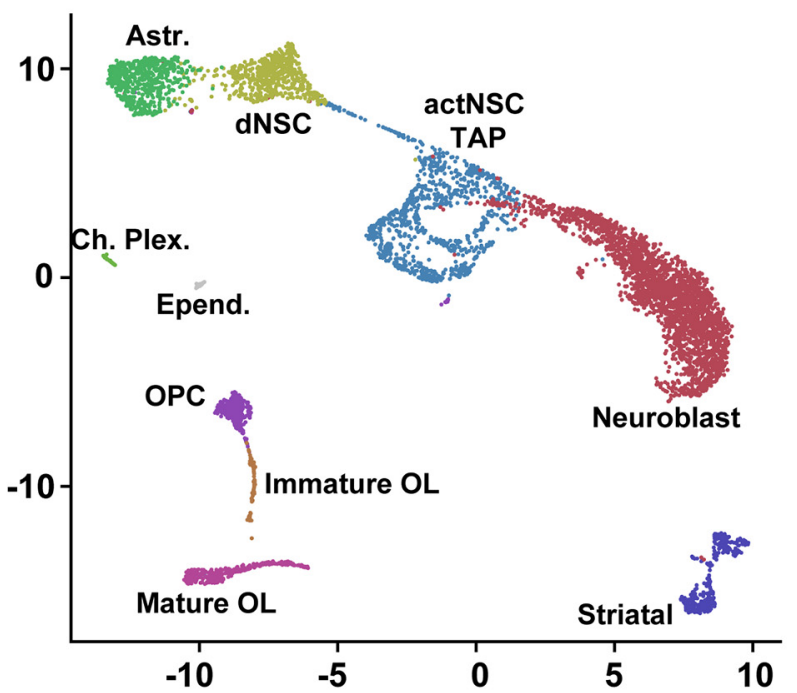

Astrocyte signature

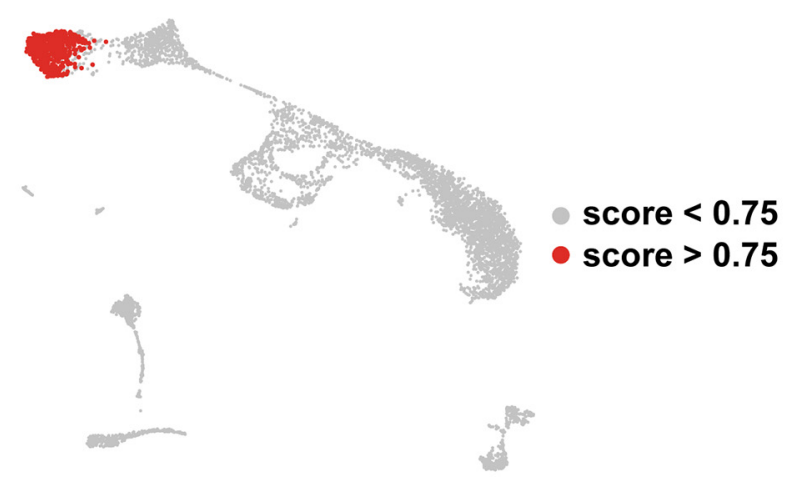

Figure 2. Molecular distinctions between NSCs and astrocytes are conserved in the V-SVZ and SGZ. A, B, UMAP visualizations of dentate gyrus cells from E16.5 to adulthood as in Figure $1 A$, overlaid to show cells from different age groups (red), including all developing cells from E16.5 to P5 (A, left panel), juvenile/adult cells from P18 to P132 (A, right panel), and E16.5 alone $(\boldsymbol{B})$. Data are not batch-corrected. C, UMAP visualizations as shown in Figure 1A, overlaid for expression of four V-SVZ RP/NSC core identity 
continued

genes. Cells are color-coded for levels of expression as per the adjacent color keys. $\boldsymbol{D}$, UMAP visualizations as in Figure $1 A$, overlaid for expression of two astrocyte-enriched mRNA from the astrocyte gene signature, Aqp4 and Agt. Cells are color-coded for levels of expression as per the adjacent color keys. E, UMAP visualization of transcriptomes of juvenile/adult (P20, P34, P61) neural V-SVZ cells from Borrett et al. (2020), annotated for cell types. Astrocytes: Astr.; dNSC: dormant NSCs; actNSC: activated NSC; transit amplifying cells: TAP; choroid plexus: Ch. Plex.; ependymal cells: Epend.; oligodendrocyte progenitor cells: OPC; oligodendrocyte: OL; striatal neurons; Striatal. UMAP on the right is overlaid for the 26 gene signature specific to niche astrocytes, where red denotes cells with scores $>0.75$. Data are not batch-corrected.

correlation analysis depicted in Figures $3 F, 7 A$ was conducted as described in previous studies (Borrett et al., 2020; Storer et al., 2020; Toma et al., 2020). Average transcriptomes were calculated for juvenile and adult V-SVZ dNSCs, E14 total cortical and GE RPs, juvenile and adult SGZ NSCs, and E16.5 dentate gyrus RPs by averaging the expression of the union of all detected genes in each of the four cell populations. Each cell depicted on the plot was subsequently correlated to each of the four average transcriptomes using Pearson correlation (cor function in R). $X$-coordinates represent the difference between the correlation of a cell with the juvenile and adult VSVZ dNSC average transcriptome and the correlation of the same cell with the E14 total RP average transcriptome. Y-coordinates represent the difference between the correlation of a cell with the E16.5 dentate gyrus RP average transcriptome and the correlation of the same cell with the juvenile and adult SGZ NSC average transcriptome.

\section{Differential gene expression statistical analysis}

Differential expression (DE) was performed as described in Borrett et al. (2020). Statistics used to test differential gene expression in the scRNA-Seq data were performed using the Seurat FindMarkers function using a Wilcox test (Seurat version 3.1.1). An adjusted $p$ value (Family-Wise Error Rate; FWER) smaller than 0.05 was considered statistically significant (Bonferroni correction).

\section{NSC versus astrocyte molecular comparison}

Differential gene expression analysis was performed between all SGZ NSCs at all ages with all dentate gyrus niche astrocytes at all ages as described above. These genes were compared with the differentially expressed genes between V-SVZ NSCs and V-SVZ niche astrocytes at P20, P34, and P61 (analysis previously performed in Borrett et al., 2020). The overlap of astrocyte-enriched genes and NSC-enriched genes in both regions was subsequently determined. The overlapping proportions are shown in Figure $1 F$. Of the overlapping astrocyte-enriched genes, 26 genes that exhibited the most specific expression to astrocytes were selected as a means to define a molecular signature that labels forebrain astrocytes and not forebrain NSCs. These genes included Aqp4, Slc4a4, Gjb6, Grin2c, Abhd3, Cxcl14, S100 $\beta$, Fgfr3, Cadm2, Slc39a12, Tril, Hapln1, Arxes2, Gabrg1, Car2, Pfkp, Lcat, Hsd11b1, Cryab, Vegfa, Timp4, Al464131, Omg, Syne1, Cd38, and Agt.

\section{Shared adult dormant NSC gene signature analysis}

In order to compute the shared adult NSC signature described in Figures 8, 9, differential expression analysis was conducted as described above between embryonic RPs, juvenile/adult dormant NSCs and juvenile/adult TAPs/IPs of both V-SVZ and SGZ origin. Genes upregulated $(>0.5$ avg log fold change, adj. $p$ value $<0.05$; FWER) in adult dormant NSCs relative to both embryonic RPs and adult TAPs/IPs were computed for both V-SVZ and SGZ populations. V-SVZ and SGZ genes identified by this analysis were compared and the overlap of both gene sets were termed the shared adult dormant NSC signature. This consisted of a total of 94 genes as shown in Tables 6, 7.

\section{Quantification of gene signature}

Quantification of gene signatures in cell types was performed as described in Borrett et al. (2020). Gene signature scores were computed by taking the average expression of all detected signature genes in each cell. Gene signature scores for each cell were subsequently overlaid on the tSNE plot to display cells with the highest signature scores. This analysis was conducted for three different gene signatures: (1) a cortical RP core identity signature identified in Yuzwa et al. (2017); (2) the astrocyte gene signature described above; and (3) the shared adult dormant NSC signature described above. Expression cutoffs are provided in the figures and legends. Density plots showing distribution of signature scores were performed using ggplot.

\section{Results}

\section{A V-SVZ NSC core transcriptional signature is conserved in developing and adult SGZ NSCs}

To compare V-SVZ and SGZ NSCs, we used two recently-published single-cell transcriptome datasets, one including forebrain V-SVZ cells from E14 to P61 (Borrett et al., 2020) and a second including dentate gyrus cells from E16.5 to P132 (Hochgerner et al., 2018). Since these datasets were generated using two different protocols, we ensured that they were comparable by analyzing both of them using a slightly modified version of a previously described scRNA-Seq computational pipeline (see Materials and Methods for details; Yuzwa et al., 2017; Carr et al., 2019; Borrett et al., 2020; Storer et al., 2020). This pipeline was originally described in Yuzwa et al. (2017) and incorporates extensive low level data quality analysis and evidence-based parameter selection to visualize and cluster transcriptomes from scRNA-Seq datasets. For the hippocampus, we used this pipeline to analyze the 24,185 dentate gyrus transcriptomes of all ages from Hochgerner et al. (2018; termed Dataset C in Hochgerner et al., 2018; GSE 95 753). Following analysis, 


\begin{tabular}{c|c|c} 
A & V-SVZ & SGZ \\
\hline Embryonic & E14 & E16.5 \\
\hline Perinatal & E17 & P0 \\
& P2 & \\
\hline Early & P6 & P5 \\
Postnatal & P7 & \\
\hline Juvenile & P20 & $\begin{array}{l}\text { P19 } \\
\text { P23 }\end{array}$ \\
\hline Adult & P34 & P120 \\
& P61 & P132
\end{tabular}

C Embryonic
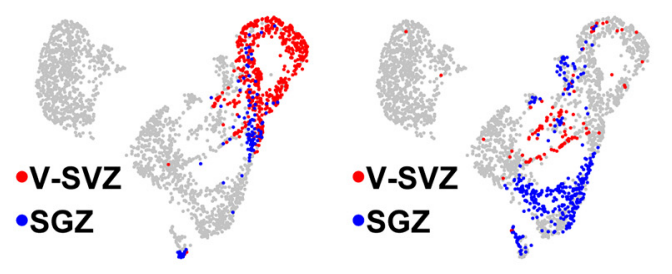

Perinatal
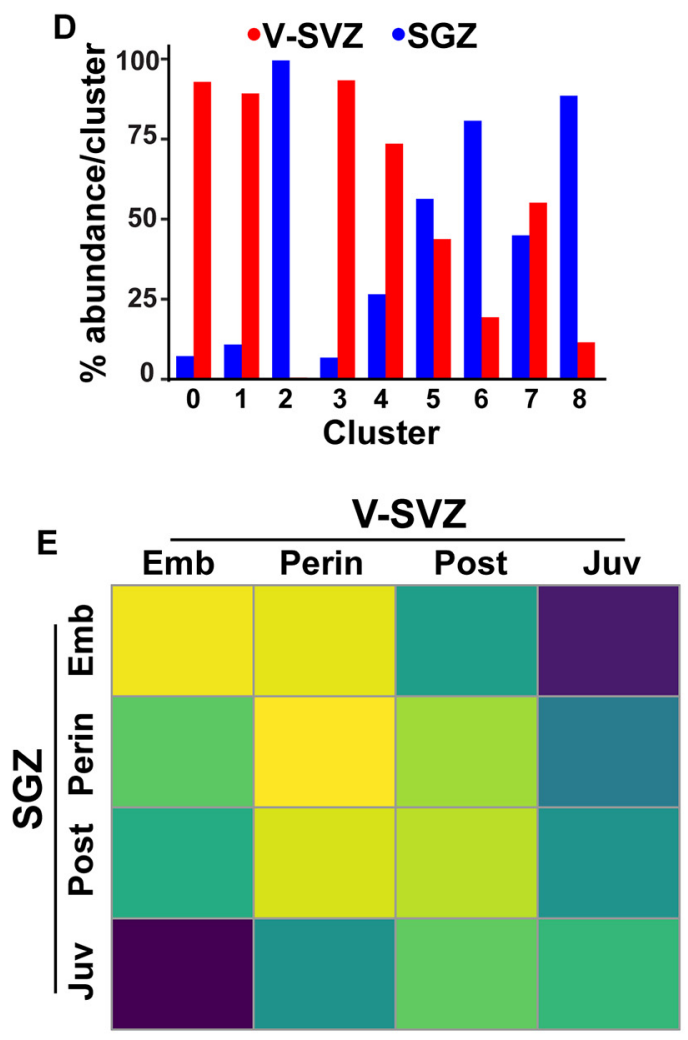

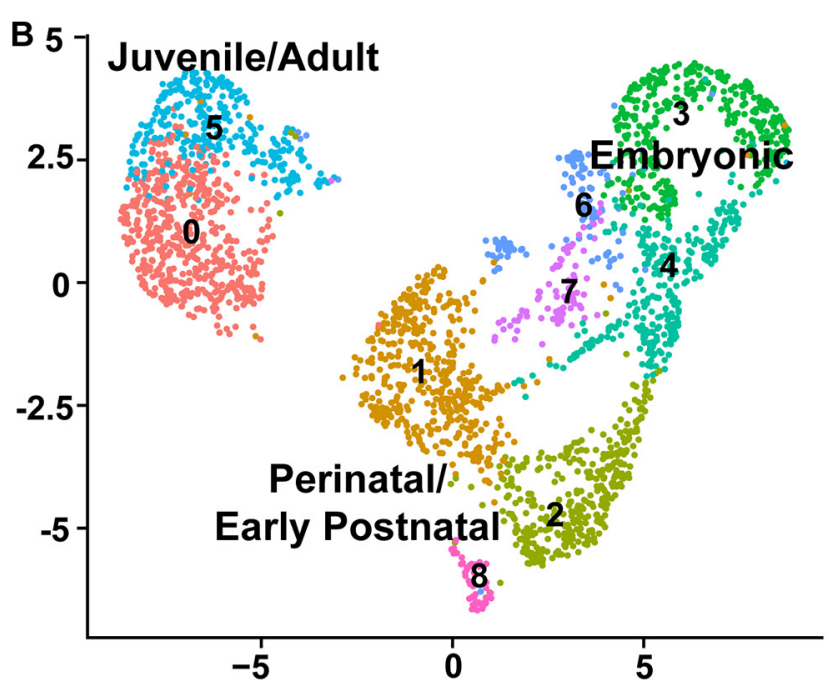

Early Postnatal

Juvenile
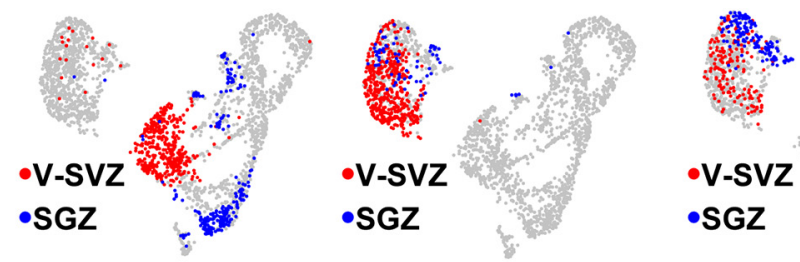

Adult

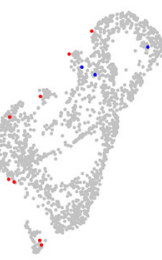

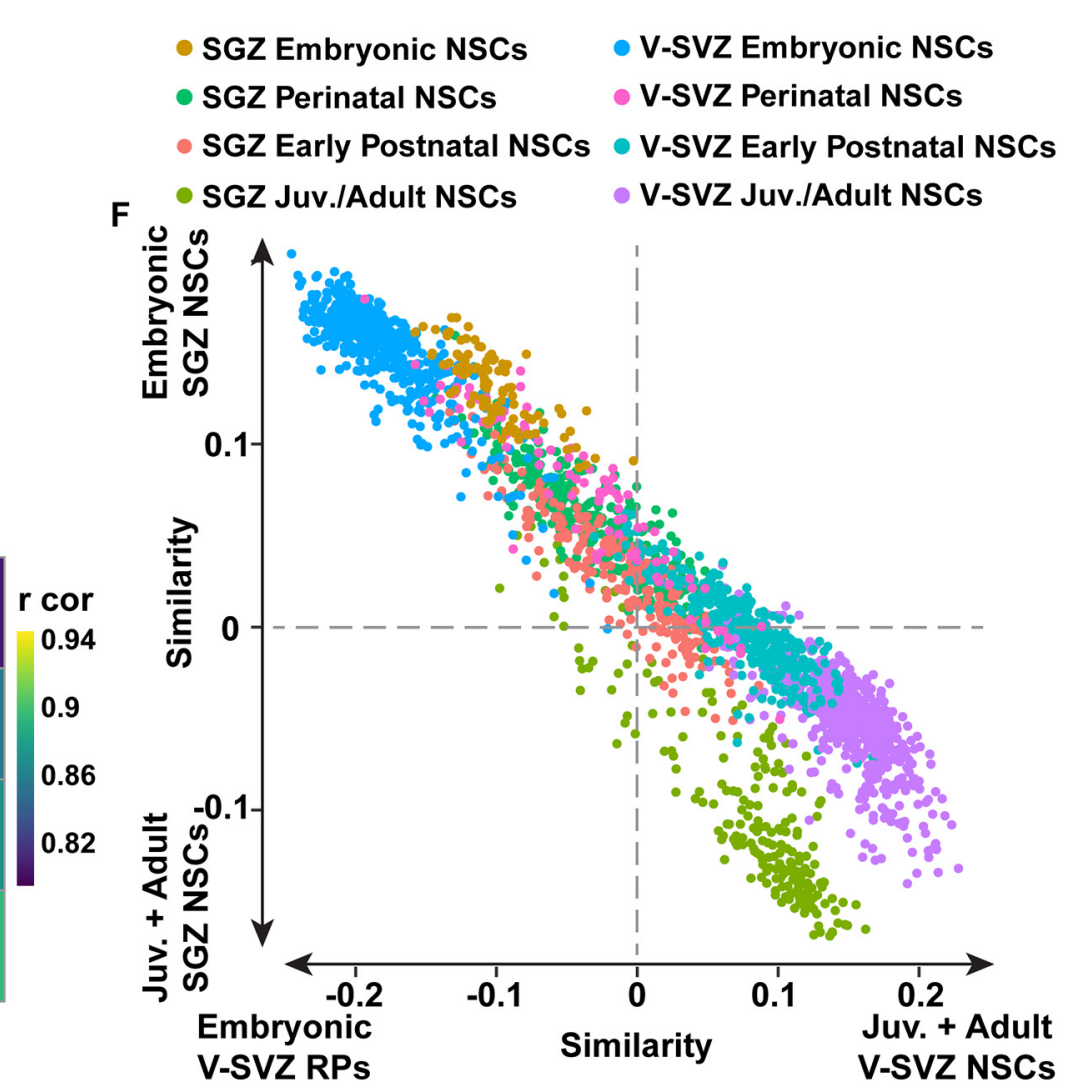

Figure 3. Comparison of V-SVZ and SGZ RP/NSCs from embryogenesis to adulthood. A, Table illustrating the assignment of agerelated categories to V-SVZ and SGZ derived RP/NSCs at various timepoints from E14 to P132. $\boldsymbol{B}$, Batch-corrected UMAP visualization of merged V-SVZ NSCs $(n=1594)$ and SGZ NSCs $(n=885)$ from all ages depicted in $\boldsymbol{A}$. Cells were grouped into color coded 
continued

and numbered clusters based on gene expression profiles. $\boldsymbol{C}$, UMAPs as in $\boldsymbol{B}$ showing V-SVZ and SGZ NSCs from the different age groups as defined in $\boldsymbol{A}$. V-SVZ NSCs are shown in red and SGZ NSCs are shown in blue. $\boldsymbol{D}$, Bar graph showing the percentages of V-SVZ and SGZ transcriptomes in each of the clusters shown in $\boldsymbol{B}$. V-SVZ proportions are shown in red and SGZ proportions are shown in blue. $\boldsymbol{E}$, Correlation heatmap showing Pearson correlation coefficients between V-SVZ and SGZ NSC average gene expression profiles from the different age groups shown in $\boldsymbol{A}$. Gene expression values are not batch-corrected. Correlation coefficients are color coded as per the adjacent color key. Emb: embryonic; Perin: perinatal; Post: early postnatal; Juv: juvenile. $\boldsymbol{F}$, Scatterplot showing single-cell correlation analysis of transcriptomes from embryonic, perinatal, early postnatal, juvenile and adult V-SVZ and SGZ RP/NSCs (as defined in $\boldsymbol{A}$ ), where the individual transcriptomes were each correlated with the averaged gene expression for E14 V-SVZ RPs versus juvenile/adult V-SVZ dormant NSCs (P20, P34, P61; $x$-axis) and with the averaged gene expression for E16.5 SGZ RPs versus juvenile/adult SGZ NSCs (P18, P19, P23, P120, P132; $y$-axis). Gene expression values are not batch-corrected. Cells are color coded for their dataset and age of origin. Juvenile and adult SGZ NSCs are represented in the same color. Juvenile and adult V-SVZ NSCs are represented by the same color.

we used UMAPs to visualize clustering and were able to identify transcriptome clusters corresponding to both neural and nonneural cell types (Figs. $1 A, 2 A$ ), as previously described (Hochgerner et al., 2018). Of particular relevance, we found that neonatal NSCs (P0 and P5) and nonproliferative E16.5 RPs (together labeled developing NSCs) were co-clustered and were distinct from clusters containing the P18 and older NSCs (P18, P19, P23, P120, and P132; labeled adult NSCs). There was also a population of proliferative E16.5 RPs that were co-clustered with $\mathrm{P} 0$ and $\mathrm{P} 5$ cells that were previously-defined as transitamplifying IPs (Figs. 1A, 2B; labeled IPs + E16 RPs). All of the precursor clusters were segregated from two additional distinct clusters containing perinatal astrocytes (P0 and P5) and juvenile/adult astrocytes (P18 and older; labeled Astrocytes; Fig. 1A,B). This clustering analysis therefore suggests that juvenile and adult SGZ NSCs are very similar to each other but are quite distinct from embryonic and perinatal SGZ NSCs, a finding previously reported in Hochgerner et al. (2018).

To start to ask about potential transcriptional similarities between SGZ and V-SVZ NSCs, we examined 79 genes that were first identified as highly enriched in embryonic cortical RPs relative to all other embryonic cortex cell types (Yuzwa et al., 2017) and then were shown to also be enriched in postnatal V-SVZ NSCs (Borrett et al., 2020; see Table 1 for a list of the differentially-expressed genes). We used these 79 genes to compute a single-cell gene expression score and applied this to all of the cells in the dentate gyrus dataset (Fig. 1C,D). The gene signature was enriched in developing and adult SGZ NSCs, and in all E16.5 hippocampal RPs. To confirm this result, we also analyzed average expression levels for these 79 genes. This analysis showed that 63 of the 79 genes were enriched in nonproliferative SGZ NSCs (cells highlighted in red in Fig. 1B; Table 1) relative to the collection of the remaining dentate gyrus cells (as shown in Fig. 1A; adjusted $p$ value $<0.05$; FWER). The genes that were not enriched were Ndel, Rgcc, Ednrb, Metrn, Kbtbd11, Gm11627, Acadl, Aldhl11, Bcan, Vit, Acss1, Acsbg1, Atp1a2, Clu, Pnp, and Rcn3.

These data suggest that a similar core gene signature is enriched in V-SVZ and SGZ precursors from embryogenesis through to adulthood. We validated expression of a subset of these genes in SGZ NSCs by performing FISH for Ptprz1, Ttyh1, Aldoc, and Mt3 on the neonatal P5 dentate gyrus. To identify NPCs, we combined the FISH with immunostaining for the precursor protein Sox2. As predicted by the scRNA-Seq analysis, there were Sox2positive cells within the developing SGZ that co-expressed these different mRNAs (Fig. 1E).

\section{Defining a gene signature that distinguishes niche astrocytes from NSCs}

One limitation of this analysis is that the V-SVZ RP/NSC gene signature, as well as many of the individual genes, were also enriched in SGZ niche astrocytes (Fig. 1C,D; Table 1), as previously observed in the V-SVZ (Borrett et al., 2020). For example, Tnc, Gas1, and Ddah1 mRNAs were enriched in both astrocytes and NSCs, although some mRNAs, such as Tfap2c, Vimentin (Vim), and Nestin (Nes) were more specific to the NSCs (Fig. 2C; Table 1). We therefore asked whether we could identify genes that more definitively distinguished NSCs from niche astrocytes in the SGZ by focusing on a gene set recently shown to be differentially expressed in these two cell types in the P20-P61 V-SVZ. This gene set included 537 mRNAs that were significantly higher in their expression in V-SVZ astrocytes versus NSCs, and 498 genes that were significantly lower (Borrett et al., 2020). Analysis of these same genes in the dentate gyrus dataset (Fig. 1F) showed that $64 \%$ of the genes that were expressed more highly in V-SVZ NSCs were also expressed at higher levels in SGZ NSCs than in SGZ astrocytes, while $56 \%$ of genes that were higher in V-SVZ astrocytes were also higher in SGZ astrocytes (Fig. 1F; Table 2).

This analysis suggests that the same genes that distinguish NSCs from astrocytes in the V-SVZ distinguish these two cell types in the dentate gyrus. To test this idea, we selected 26 of the genes in this dataset that were most highly enriched in astrocytes versus NSCs in both the VSVZ and SGZ (Table 2, asterisks), as exemplified by the patterns of expression of Aqp4 and Agt (Fig. 2D). A gene signature score computed using these 26 genes was specifically enriched in niche astrocytes relative to all other cells in the dentate gyrus dataset (Fig. 1G). This gene signature was similarly enriched in V-SVZ niche astrocytes, as shown by computing a similar signature score for the P20, P34, and P61 V-SVZ transcriptomes (Borrett et al., 2020 ) that had been put through the same computational pipeline (Fig. 2E). Thus, while niche astrocytes share many transcriptional commonalities with SGZ and V-SVZ 
Table 1: Expression of V-SVZ RP/NSC core identity genes in hippocampal SGZ NSCs and astrocytes (related to Fig. 1)

\begin{tabular}{|c|c|c|}
\hline Core genes & SGZ NSC abundance (\%) & SGZ Astr abundance (\%) \\
\hline Acaa2 & 21.6 & 17.3 \\
\hline Aldoc & 85.1 & 98.7 \\
\hline Apoe & 90.8 & 99.9 \\
\hline Asrgl1 & 42.9 & 63.4 \\
\hline Ccdc80 & 49.0 & 19.0 \\
\hline Cd63 & 65.6 & 64.2 \\
\hline Ckb & 87.7 & 94.6 \\
\hline Cyr61 & 34.5 & 12.2 \\
\hline Dbi & 99.2 & 92.8 \\
\hline Ddah1 & 72.4 & 59.3 \\
\hline Efhd2 & 40.7 & 36.4 \\
\hline Fabp7 & 94.7 & 75.3 \\
\hline Fgfbp3 & 28.9 & 16.7 \\
\hline Gas1 & 66.9 & 33.9 \\
\hline Gng12 & 51.2 & 53.6 \\
\hline Gpx8 & 30.4 & 12.1 \\
\hline Gsta4 & 29.3 & 11.6 \\
\hline Hes1 & 45.3 & 28.2 \\
\hline Hes5 & 63.6 & 47.9 \\
\hline Hopx & 58.0 & 42.1 \\
\hline Id1 & 34.0 & 26.8 \\
\hline Id3 & 54.6 & 62.0 \\
\hline Id4 & 36.4 & 59.1 \\
\hline Lfng & 32.2 & 26.5 \\
\hline Magt1 & 24.5 & 25.2 \\
\hline Mdk & 72.8 & 43.5 \\
\hline Mfge8 & 78.8 & 82.9 \\
\hline Mlc1 & 51.2 & 79.4 \\
\hline Mt1 & 94.5 & 98.3 \\
\hline Mt2 & 85.6 & 93.3 \\
\hline Mt3 & 94.0 & 99.8 \\
\hline Myo10 & 27.2 & 38.8 \\
\hline Nek6 & 28.4 & 9.2 \\
\hline Nes & 15.4 & 3.5 \\
\hline Nr2e1 & 29.5 & 20.4 \\
\hline Nrarp & 43.3 & 34.8 \\
\hline Oat & 37.6 & 45.2 \\
\hline Pax6 & 55.0 & 32.6 \\
\hline Pdpn & 37.5 & 34.0 \\
\hline Pea15a & 70.8 & 62.3 \\
\hline Phgdh & 66.8 & 53.0 \\
\hline Pon2 & 39.3 & 45.6 \\
\hline Psat1 & 57.3 & 46.0 \\
\hline Ptprz1 & 93.1 & 95.6 \\
\hline Rcn1 & 35.7 & 13.8 \\
\hline Rhoc & 32.0 & 18.3 \\
\hline Serpinh1 & 38.8 & 24.9 \\
\hline Sfrp1 & 33.9 & 6.2 \\
\hline Slc1a3 & 97.5 & 99.6 \\
\hline Slc9a3r1 & 47.3 & 54.2 \\
\hline Sox2 & 59.8 & 65.3 \\
\hline Sox21 & 20.7 & 29.2 \\
\hline Sox9 & 78.2 & 77.1 \\
\hline Sparc & 55.5 & 22.8 \\
\hline Tead2 & 31.3 & 7.0 \\
\hline Tfap2c & 38.6 & 0.7 \\
\hline Tgfb2 & 38.6 & 21.6 \\
\hline Tnc & 50.5 & 29.0 \\
\hline Ttyh1 & (Continued) & 96.5 \\
\hline
\end{tabular}

Table 1: Continued

\begin{tabular}{lll}
\hline Core genes & SGZ NSC abundance (\%) & SGZ Astr abundance (\%) \\
\hline Vcam1 & 33.2 & 48.3 \\
Veph1 & 24.6 & 1.7 \\
Vim & 66.4 & 18.0 \\
Zfp36I1 & 70.8 & 45.1 \\
\hline
\end{tabular}

Shown are 63 of the 79 embryonic cortical signature genes defined in Yuzwa et al. (2017) that are not cell cycle associated and are significantly enriched in SGZ NSCs (cells highlighted in red in Fig. 1B) relative to all other combined cell types in the dentate gyrus from embryogenesis through to adulthood (E16.5-P132; adjusted $p$ value, FWER $<0.05$ ). The relative proportions of SGZ NSCs (red cells in Fig. 1B) and all SGZ astrocytes (green and blue cells in Fig. $1 B$ ) that detectably express these mRNAs are also shown.

NSCs, astrocytes and NSCs can be readily distinguished at the transcriptional level.

\section{V-SVZ and SGZ precursors share transcriptional similarities as they progress from active embryonic to dormant adult NSCs}

It was previously reported that the transition from an embryonic to adult V-SVZ NSC reflects a switch from an active to a dormant stem cell state, involving a broad dampening of cell biological processes associated with an active state including cell division, transcription, RNA metabolism and protein translation, processing and trafficking (Borrett et al., 2020). The finding that a V-SVZ RP/ NSC gene signature is also enriched in SGZ RP/NSCs suggests that these two populations might be more transcriptionally similar than previously appreciated and thus might share similar transcriptional trajectories to a dormant state. To test this idea further, we extracted all nonproliferative SGZ RP and NSC transcriptomes (the red cells in Fig. 1B; 885 total cells) and combined them with the V-SVZ RP/NSC transcriptomes (as identified in Borrett et al., 2020), including P2, P6/7, P20, P34, and P61 dormant NSCs and E14 and E17 cortical and GE-derived RPs. This combined dataset was put through the computational pipeline and included V-SVZ and SGZ precursors of similar developmental stages from embryogenesis to adulthood (shown in Fig. 3A).

One potential caveat of combining the two datasets is that the SGZ and V-SVZ cells were prepared and sequenced in two different laboratories using different protocols, and thus apparent differences might derive from batch effects as opposed to biological heterogeneity. To correct for this possibility, we also included endothelial cells (P19 SGZ and P20 V-SVZ) and microglial cells (P23 SGZ and P20 V-SVZ) from both datasets with the assumption that V-SVZ endothelial cells and microglia should be similar enough to co-cluster with the same cell types from the SGZ. However, when the combined dataset was visualized on a two-dimensional UMAP plot, the endothelial cells and microglia from the two different regions/datasets were partially segregated from each other (Fig. 4A), indicating variability because of batch effects. We therefore corrected for these batch effects using Harmony, a computational method for data integration that iteratively removes batch-mediated technical variation within principal component space of high 
Table 2: Genes that are differentially expressed between NSCs and astrocytes in both the V-SVZ and SGZ (related to Fig. 1, 2)

\begin{tabular}{|c|c|}
\hline $\begin{array}{l}\text { Astr-enriched genes in V-SVZ } \\
+ \text { SGZ }\end{array}$ & $\begin{array}{l}\text { NSC-enriched genes in V-SVZ } \\
+ \text { SGZ }\end{array}$ \\
\hline Gpr37I1 & Dbi \\
\hline Sparcl1 & Sfrp1 \\
\hline Cxcl14* & Rpl41 \\
\hline Htra1 & Rplp0 \\
\hline Bcan & Rps27a \\
\hline Id2 & Rpl18a \\
\hline Aqp4* & Rps27 \\
\hline Tril $^{*}$ & Rpl35a \\
\hline Ntsr2 & Rps19 \\
\hline Atp1b2 & Rpl13a \\
\hline Timp4* & Rpl9 \\
\hline Car2* & Rpl3 \\
\hline Atp1a2 & Rps14 \\
\hline Eno1 & Eef1a1 \\
\hline Kcnk1 & Rpl13 \\
\hline S100b* & Rplp1 \\
\hline $\mathrm{Dbx} 2$ & Ptma \\
\hline Cldn10 & Rps 4x \\
\hline Btbd17 & Rpl10 \\
\hline Aplp1 & Marcksl1 \\
\hline Slc39a12* & Rpl23a \\
\hline Msmo1 & Rps24 \\
\hline Gja1 & Rpl17 \\
\hline Slc7a10 & Rps5 \\
\hline Lsamp & Rpl14 \\
\hline Pla2g7 & Vim \\
\hline Fjx1 & Rps9 \\
\hline Gria2 & Rps23 \\
\hline Plpp3 & Rps15a \\
\hline Abhd3* & Rps18 \\
\hline F3 & Rpl37 \\
\hline Gpm6a & Rpl11 \\
\hline Dclk1 & $\mathrm{Rpl27a}$ \\
\hline Clu & Rps16 \\
\hline Gjb6* & Rps8 \\
\hline Slc $4 a 4^{*}$ & Rpl26 \\
\hline Tmem100 & Rpl37a \\
\hline Omg* & Rps13 \\
\hline $\mathrm{Ntm}$ & Rps10 \\
\hline Eva1a & Gnas \\
\hline Grina & Rps20 \\
\hline Scg3 & Rpl32 \\
\hline Arxes2* & Rplp2 \\
\hline S1pr1 & Rpl8 \\
\hline Apoe & Rps2 \\
\hline Smpdl3a & Rpl34 \\
\hline Camk2n1 & Rpl38 \\
\hline $\mathrm{mt}-\mathrm{Co} 3$ & Rps21 \\
\hline Acsbg1 & Rps25 \\
\hline Agpat5 & Rpl23 \\
\hline Acsl6 & Rps12 \\
\hline Gpc5 & Riiad1 \\
\hline Hacd2 & Rps3a1 \\
\hline Cadm1 & Rpl7 \\
\hline Fgfr3* $^{*}$ & Sparc \\
\hline Aldoc & Rpl10a \\
\hline Hapln1* & Rps6 \\
\hline Mfge8 & Rpl22l1 \\
\hline \multirow[t]{2}{*}{ Hbegf } & Rps15 \\
\hline & tinued) \\
\hline
\end{tabular}

Table 2: Continued

\begin{tabular}{|c|c|}
\hline $\begin{array}{l}\text { Astr-enriched genes in V-SVZ } \\
+ \text { SGZ }\end{array}$ & $\begin{array}{l}\text { NSC-enriched genes in V-SVZ } \\
+ \text { SGZ }\end{array}$ \\
\hline Tuba4a & Rps28 \\
\hline Hsd11b1* & H2afv \\
\hline Grin2c* & Rps7 \\
\hline Tmem176a & Rps11 \\
\hline Grm3 & Rtn1 \\
\hline Chst1 & Fau \\
\hline Slc38a3 & Rpl21 \\
\hline Tspan7 & Rpl31 \\
\hline Macf.1 & Rpl39 \\
\hline Sepp1 & Ftl1 \\
\hline Lcat $^{*}$ & Rps17 \\
\hline Clmn & Tmsb4x \\
\hline Vegfa* & Hmgb1 \\
\hline Al464131* & Rpl30 \\
\hline Slc6a1 & Rpsa \\
\hline Pfkp* & Hsp90aa1 \\
\hline Paqr7 & Ccnd2 \\
\hline Eps8 & Rpl6 \\
\hline Slc9a3r1 & Rps3 \\
\hline Tagln3 & Ascl1 \\
\hline Fermt2 & Tpt1 \\
\hline mt-Nd1 & Rpl36a \\
\hline Oaf & Fxyd6 \\
\hline Vcam1 & Rpl15 \\
\hline Tlcd1 & Rpl36 \\
\hline Tmem176b & Fabp7 \\
\hline mt-Atp6 & Rpl19 \\
\hline mt-Cytb & Rpl4 \\
\hline mt-Nd2 & Bex4 \\
\hline Cryab* & Hmgn1 \\
\hline Serinc1 & Cd9 \\
\hline Cd81 & Rpl18 \\
\hline Phyhipl & Rpl24 \\
\hline Ptprz1 & Pebp1 \\
\hline Ppp1r3g & Psph \\
\hline Syne1* & Rps26 \\
\hline Cd38* & Ypel3 \\
\hline Mertk & Cnbp \\
\hline Appl2 & Rpl12 \\
\hline Mt1 & Rpl22 \\
\hline Mfsd2a & Swi5 \\
\hline Ank2 & Zbtb20 \\
\hline Fam20a & Ybx1 \\
\hline Tprkb & Sptssa \\
\hline Sept7. & Eef2 \\
\hline Pcdh7 & Tox3 \\
\hline Scrg1 & Slc38a1 \\
\hline Tmed5 & Rpl35 \\
\hline Ccdc88a & Naca \\
\hline Ugp2 & Ywhae \\
\hline mt-Nd4 & Plagl1 \\
\hline Cadm2* & Rpl29 \\
\hline mt-Co2 & Sept15. \\
\hline Ptn & Smim11 \\
\hline Mt2 & Arl4c \\
\hline Pmm1 & Rpl5 \\
\hline II18 & Fbln2 \\
\hline mt-Co1 & Bex2 \\
\hline 2900052N01Rik & H3f3a \\
\hline Apln & Rpl27 \\
\hline \multirow[t]{2}{*}{ Luzp2 } & Mif \\
\hline & tinued) \\
\hline
\end{tabular}


Table 2: Continued

\begin{tabular}{|c|c|}
\hline $\begin{array}{l}\text { Astr-enriched genes in V-SVZ } \\
+ \text { SGZ }\end{array}$ & $\begin{array}{l}\text { NSC-enriched genes in V-SVZ } \\
+ \text { SGZ }\end{array}$ \\
\hline Slc6a11 & Maged1 \\
\hline Slco1c1 & Marcks \\
\hline Rgcc & Mrfap1 \\
\hline Ncan & Snrpg \\
\hline Slc1a3 & Mfap2 \\
\hline Id3 & Rpl7a \\
\hline Acsl3 & Snrpd2 \\
\hline Phactr3 & Veph1 \\
\hline Serpine2 & Tuba1a \\
\hline P4 ha1 & Chchd2 \\
\hline Tmem44 & Ppia \\
\hline $\mathrm{Agt}^{\star}$ & Tomm7 \\
\hline Enho & Jund \\
\hline Adora2b & Ubl5 \\
\hline Hacd3 & Acot1 \\
\hline Tsc22d4 & H1fO \\
\hline Cdh10 & Anapc11 \\
\hline Dhcr7 & Btf3 \\
\hline Gabrg1* & Hdgf \\
\hline Ctsd & Pfdn5 \\
\hline Cystm1 & Gnb2l1 \\
\hline Phkg1 & Trim2 \\
\hline Slc7a11 & Tead2 \\
\hline Usp53 & Psip1 \\
\hline Pcdh10 & Ifitm2 \\
\hline Arhgap5 & Pdlim4 \\
\hline Sec14l2 & Ap1s2 \\
\hline Nptn & Ren1 \\
\hline Thy1 & Eif3f \\
\hline Cmtm5 & Rpl28 \\
\hline Atp13a4 & Cetn2 \\
\hline Elovl2 & Clic1 \\
\hline Rorb & Ndn \\
\hline Fut9 & Nenf \\
\hline Sat1 & Snrpe \\
\hline Pcdh9 & Gabarap \\
\hline Ttyh1 & Dek \\
\hline mt-Nd4I & Prdx2 \\
\hline Pfkm & Eef1d \\
\hline Gabrb1 & Idh2 \\
\hline Fam21 & Stra13 \\
\hline Cpeb4 & Sh3bgrl3 \\
\hline Prex1 & Atpif1 \\
\hline Pmp22 & Srp9 \\
\hline Gatm & Nsg1 \\
\hline Csrp1 & Hsbp1 \\
\hline Smpd1 & Eef1g \\
\hline Сур7b1 & Serf1 \\
\hline Pcdh17 & Myl9 \\
\hline TIr3 & Fam210b \\
\hline Metrn & Aif1I \\
\hline Lgr4 & Cox7a2l \\
\hline Chchd10 & Bex1 \\
\hline Slc14a1 & Dstn \\
\hline Rrbp1 & Tuba1b \\
\hline Gpr162 & Rps27I \\
\hline Abcd2 & Ap2m1 \\
\hline Gpr37 & Stmn3 \\
\hline Slitrk2 & Ahsa1 \\
\hline Elovl5 & Ptx3 \\
\hline \multirow[t]{2}{*}{ Emc3 } & Trmt112 \\
\hline & tinued) \\
\hline
\end{tabular}

Table 2: Continued

\begin{tabular}{|c|c|}
\hline $\begin{array}{l}\text { Astr-enriched genes in V-SVZ } \\
+ \text { SGZ }\end{array}$ & $\begin{array}{l}\text { NSC-enriched genes in V-SVZ } \\
+ \text { SGZ }\end{array}$ \\
\hline$\overline{\text { Tnik }}$ & Hmgn2 \\
\hline Saraf & Eef1b2 \\
\hline Cntfr & Creb5 \\
\hline Aco2 & Sf3b2 \\
\hline Ubc & Cfdp1 \\
\hline Chst10 & Tspan13 \\
\hline Plcd4 & Park7 \\
\hline Hmgcr & $\mathrm{Ei} 24$ \\
\hline Tmem229a & Sec61g \\
\hline Gstm5 & Fkbp3 \\
\hline Wscd1 & Tmem107 \\
\hline Gpi1 & Tbca \\
\hline Stt3b & Snrpf \\
\hline Hepacam & Anp32b \\
\hline $\mathrm{Cd} 47$ & Atp5e \\
\hline Ednrb & Nudc \\
\hline Mdga2 & Psmg4 \\
\hline Сyp2j6 & Pkig \\
\hline Akt2 & Sumo2 \\
\hline Pgm2 & Erh \\
\hline Nebl & Hcf.c1r1 \\
\hline Olig1 & 2810459M11Rik \\
\hline Mfn1 & Tmem258 \\
\hline Ddhd1 & Pfdn2 \\
\hline Trp53bp2 & Maf1 \\
\hline Rapgef3 & Bnip3l \\
\hline Crot & Akr1a1 \\
\hline Adk & Rpa2 \\
\hline Rasa2 & Rhcg \\
\hline Ckb & Kif21a \\
\hline Rnf13 & Oaz1 \\
\hline Slc20a1 & Sumo3 \\
\hline Dner & 2700094K13Rik \\
\hline Slc27a1 & H2afy \\
\hline Irak2 & St13 \\
\hline mt-Nd3 & Cetn3 \\
\hline Osbpl1a & Hbb-bs \\
\hline Cst3 & Hint1 \\
\hline Chst2 & Efnb1 \\
\hline Nrcam & Tubb5 \\
\hline Tpp1 & Fos \\
\hline Fgf1 & Sfr1 \\
\hline Clptm1 & Eif1ax \\
\hline Tmem189 & Nedd8 \\
\hline Capn2 & Cdc26 \\
\hline Daam2 & Elof1 \\
\hline $\mathrm{Ndp}$ & Hsp90ab1 \\
\hline Dmd & Ptov1 \\
\hline Slc1a4 & Hnrnpc \\
\hline Hadhb & Rnaseh2c \\
\hline Nr1d1 & Txn1 \\
\hline Baalc & Rnf187 \\
\hline Psd2 & Psme1 \\
\hline Aldh1/1 & Ngfrap1 \\
\hline Hist1 h1c & Fam32a \\
\hline Itga6 & Nop10 \\
\hline Сyp2d22 & $\mathrm{Pbx} 1$ \\
\hline Aldoa & Eif3h \\
\hline Laptm4b & Gltscr2 \\
\hline Cnp & Tmpo \\
\hline \multirow[t]{2}{*}{ Kifc3 } & Efnb3 \\
\hline & tinued) \\
\hline
\end{tabular}


Table 2: Continued

\begin{tabular}{|c|c|}
\hline $\begin{array}{l}\text { Astr-enriched genes in V-SVZ } \\
+ \text { SGZ }\end{array}$ & $\begin{array}{l}\text { NSC-enriched genes in V-SVZ } \\
+ \text { SGZ }\end{array}$ \\
\hline$\overline{\text { Pcdh1 }}$ & Aprt \\
\hline Dnajb9 & Psme2 \\
\hline Asah1 & Mettl9 \\
\hline Mfap3l & Hmgb2 \\
\hline Camk2g & Rlbp1 \\
\hline Cpq & Slit2 \\
\hline Tank & Use1 \\
\hline Gpr146 & Hsd17b10 \\
\hline Pnkd & Hspe1 \\
\hline Mgll & Pter \\
\hline Arhgef26 & Cnpy2 \\
\hline Aifm3 & Hnrnpf \\
\hline Slc2a1 & Btg2 \\
\hline Slc41a1 & Ywhaq \\
\hline Fam213a & Psenen \\
\hline Igsf11 & Bri3 \\
\hline Fgfrl1 & Wbp5 \\
\hline Adgrl3 & Gsta4 \\
\hline Etv5 & Trip6 \\
\hline RP23-4H17.3 & Mdk \\
\hline Fut8 & Mrpl52 \\
\hline Jam2 & Rac3 \\
\hline Kif1b & Ran \\
\hline Usp54 & Eif3i \\
\hline Sash1 & Tma7 \\
\hline Tmbim1 & G3bp1 \\
\hline Vcl & Pax6 \\
\hline Рpp3ca & Npm1 \\
\hline Pon2 & Chchd7 \\
\hline Phka1 & Fkbp4 \\
\hline Chpt1 & Ccdc80 \\
\hline Mir124-2 hg & $\mathrm{Mbd} 3$ \\
\hline Abi1 & Hnrnpr \\
\hline Uqcr10 & Myl6 \\
\hline Stxbp3 & Set \\
\hline Ppp1r1b & Ranbp1 \\
\hline Prex2 & Golim4 \\
\hline mt-Nd5 & Gpx8 \\
\hline Acss2 & Arl3 \\
\hline Tmx2 & Bag2 \\
\hline Pid1 & Ntan1 \\
\hline Ten2 & Med28 \\
\hline Tfrc & Ddah2 \\
\hline Dio2 & Nhp2l1 \\
\hline Trib2 & Stk11 \\
\hline Slc15a2 & Gpx1 \\
\hline Itpr2 & Tsn \\
\hline Gm2a & Basp1 \\
\hline Npas3 & Msn \\
\hline Pttg1ip & Cers 4 \\
\hline Acap2 & Unc119 \\
\hline Insig1 & Paip2 \\
\hline Csgalnact1 & Srp14 \\
\hline Mcur1 & Ift22 \\
\hline Uqcr11 & Anapc5 \\
\hline S100a13 & Hnrnpa1 \\
\hline Retsat & Cnn3 \\
\hline Tmem47 & Sumo1 \\
\hline \multirow[t]{4}{*}{ Adgrg1 } & Gm8730 \\
\hline & Anp32a \\
\hline & Tceb2 \\
\hline & tinued) \\
\hline
\end{tabular}

Table 2: Continued

\begin{tabular}{ll}
\hline $\begin{array}{l}\text { Astr-enriched genes in V-SVZ } \\
+ \text { SGZ }\end{array}$ & $\begin{array}{l}\text { NSC-enriched genes in V-SVZ } \\
+ \text { SGZ }\end{array}$ \\
\hline & Myl12a \\
Cacybp \\
Emg1 \\
Ssrp1 \\
Polr3h \\
Nfix \\
Puf60 \\
Ppp1ca \\
Rpl23a-ps3 \\
Romo1 \\
Cfap20 \\
Gm17750 \\
Vgll4
\end{tabular}

Shown are genes that are differentially expressed (FWER $<0.05$ ) between NSCs and astrocytes in both the dentate gyrus and the V-SVZ. Genes identified as differentially expressed by V-SVZ NSCs versus astrocytes in Borrett et al. (2020) were interrogated for their expression in all SGZ NSCs (red cells in Fig. $1 B$ ) and all SGZ astrocytes (green and blue cells in Fig. 1B) in the combined dentate gyrus dataset. The left column indicates genes significantly enriched in astrocytes in both the V-SVZ and SGZ, and the right column indicates genes significantly enriched in NSCs in both the V-SVZ and SGZ. Of the astrocyte-enriched genes, 26 (indicated with asterisks in the table) were highly enriched relative to NSCs, and were used to define a shared forebrain niche astrocyte signature as shown in Figures 1G, $2 E$.

dimensional data (Korsunsky et al., 2019; Tran et al., 2020). With the lowest level of Harmony correction, one iteration, there was complete integration of $\mathrm{V}-\mathrm{SVZ}$ and SGZ endothelial and immune cells (Fig. $4 A, B$; see Materials and Methods).

Having established this protocol, we removed the endothelial and immune cells and analyzed only the RP/NSC transcriptomes, using one iteration of Harmony batch correction. UMAP visualization of these data (Fig. $3 B$ ) defined three groups of clusters, one including the juvenile and adult V-SVZ and SGZ NSCs, a second including the perinatal and postnatal NSCs of both origins and a third including the embryonic hippocampal, cortical and GE RPs. At any given developmental stage (adult, postnatal, or embryonic) there was some segregation between SGZ and V-SVZ NSCs suggesting that these two NSC populations were very similar but not identical (Fig. $3 B-D$ ).

One explanation for the differential clustering of developing and adult NSCs is that cell cycle genes associated with proliferation are partially responsible for driving this segregation. To test this idea, we removed 678 cell cyclerelated genes (see Materials and Methods) and redid the analysis. UMAP visualization (Fig. $4 C$ ) showed that results were similar with and without removal of these cell cycle genes. There were three groups of clusters containing embryonic, perinatal/postnatal, or juvenile/adult NSCs, and there was some segregation of V-SVZ and SGZ NSCs of the same age within these clusters. Thus, cell cycle genes are not major drivers of the differential clustering seen for NSCs of different ages.

The strong age-dependent segregation of NSCs in the cluster plot (Fig. 3B) suggests that there may be greater transcriptional differences between NSCs at different developmental stages than there are between V-SVZ and SGZ precursors at the same time point. This conclusion 

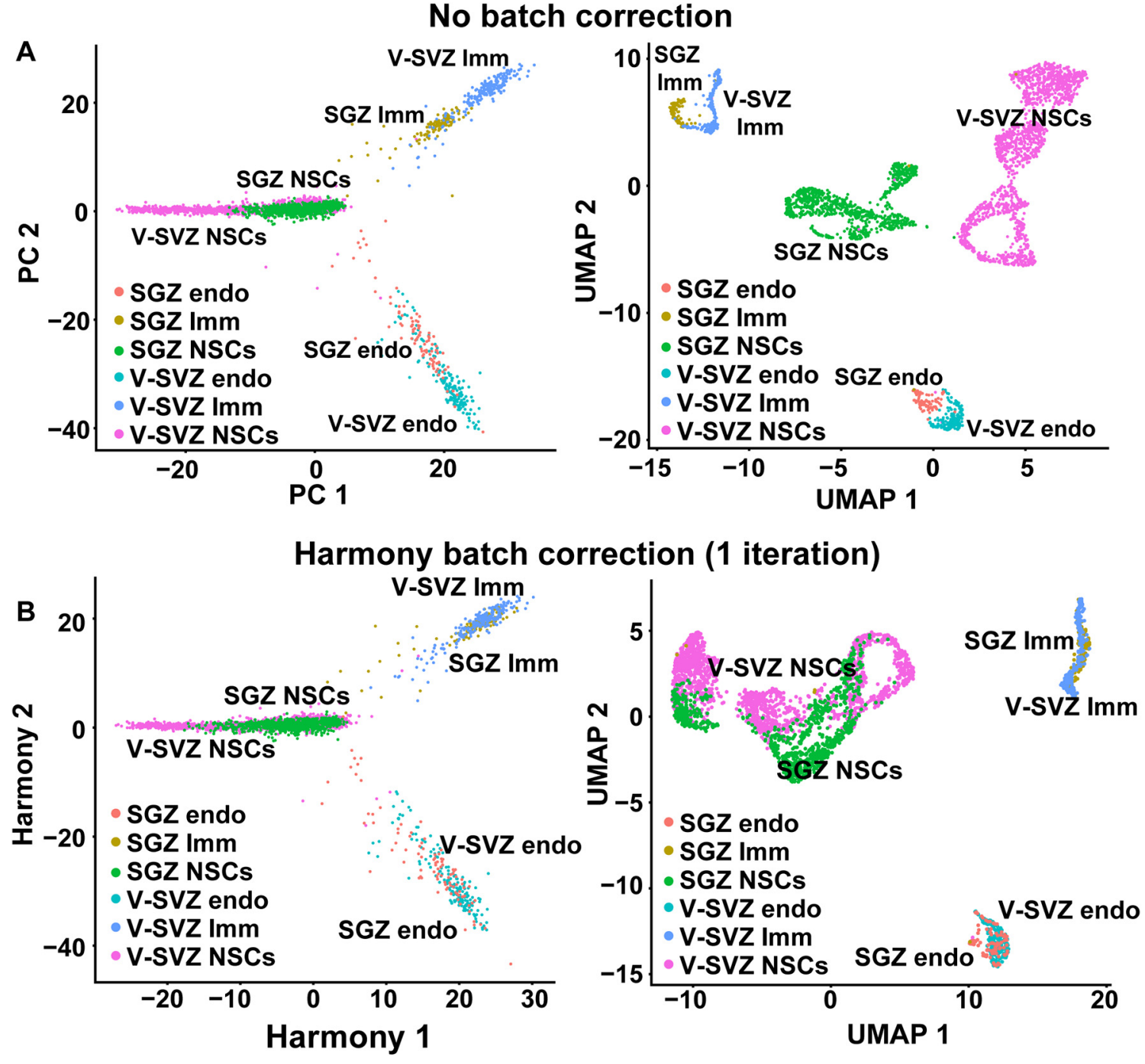

\section{V-SVZ + SGZ NSCs \\ Harmony batch correction (1 iteration) \\ Cell cycle regressed}
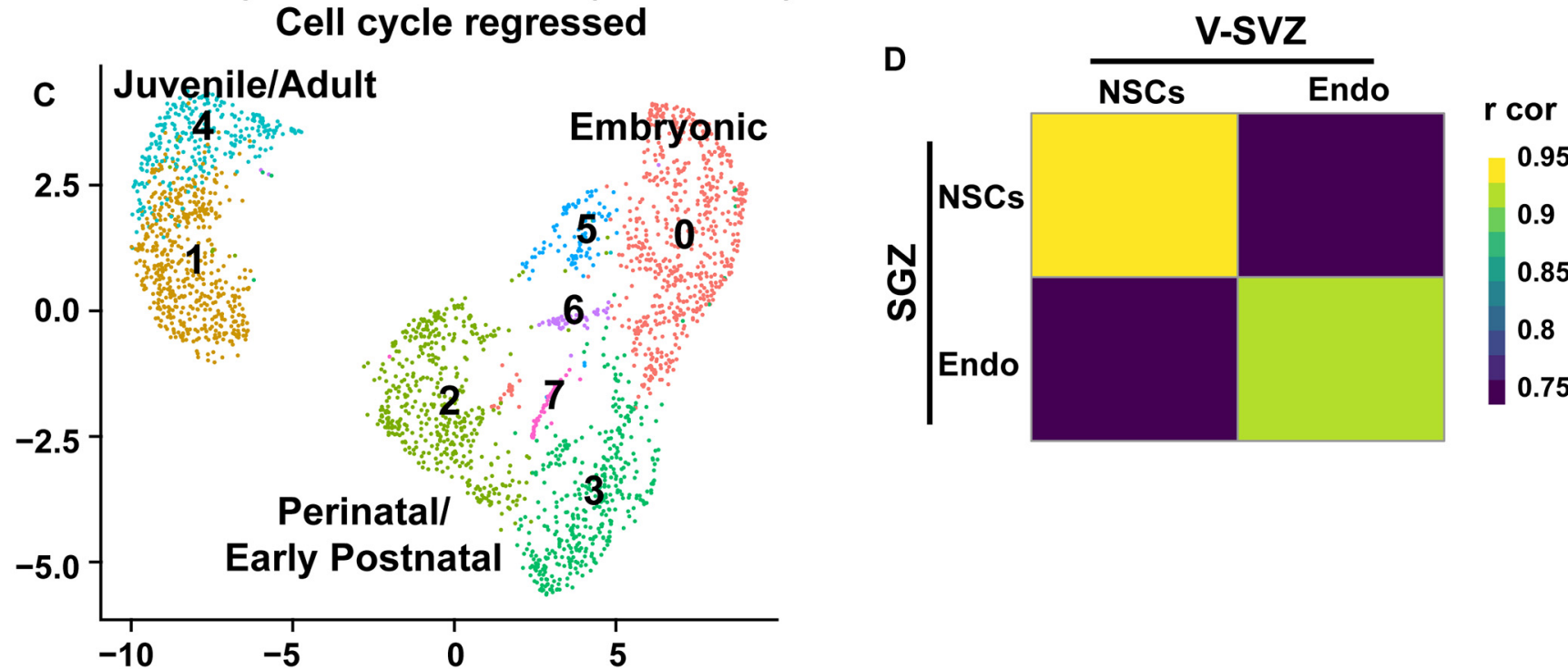

Figure 4. Batch correction and cell cycle regression for the combined V-SVZ and SGZ transcriptome analyses. A, As a control to 
continued

optimize the batch correction between V-SVZ and SGZ NSCs, raw transcriptomes from the dataset shown in Figure $3 B$ were merged with endothelial cells from the P19 dentate gyrus (SGZ endo), endothelial cells from the P20 V-SVZ (V-SVZ endo), microglia from the P23 dentate gyrus (SGZ Imm), and microglia from the P20 V-SVZ (V-SVZ Imm). PCA visualization (left) and UMAP visualization (right) of the total dataset without batch correction showed that endothelial and immune cells from the two regions did not cocluster well. Cells are colored based on cell type and region of origin. $\boldsymbol{B}$, The same dataset shown in $\boldsymbol{A}$ was batch corrected with one iteration of Harmony. The harmonized PCA visualization (left) and UMAP visualization (right) of the merged cells show that endothelial cells and immune cells were now well-clustered. Cells are colored based on cell type and region of origin. $\boldsymbol{C}$, Batch-corrected UMAP visualization of the merged V-SVZ NSC and SGZ NSC dataset shown in Figure 3B, where the cell cycle genes were regressed out as previously described (see Materials and Methods). Cells were grouped into color coded and numbered clusters based on gene expression profiles, and the NSCs of different ages are shown for direct comparison to Figure 3B. $\boldsymbol{D}$, Correlation heatmap showing Pearson correlation coefficients between averaged expression profiles of total NSCs (including all ages) and P19/ 20 V-SVZ and SGZ endothelial cells. Correlation coefficients are color coded as per the adjacent color key. Gene expression values were not batch-corrected.

was confirmed by performing two types of correlation analysis that do not involve any batch correction. The first was Pearson correlation analysis of average gene expression for V-SVZ and SGZ precursors at different timepoints (Fig. 3E). This analysis showed that at many timepoints, V-SVZ and SGZ precursors were more similar to each other than they were to any of the other precursor groups at different ages. For example, E14 V-SVZ and E16.5 SGZ RPs were correlated with a high value of $r=0.94$, while E14 V-SVZ RPs and P20 V-SVZ NSCs were only correlated with $r=0.78$. As predicted, all NSC populations were more similar to each other than they were to endothelial cells (Fig. 4D).

As a second approach, we performed a correlation analysis that compares single-cell transcriptomes rather than averaged gene expression (see Materials and Methods). To perform this single-cell correlation analysis, we first defined gene expression profiles for comparison to each individual cell transcriptome. As a first comparator, we determined average gene expression for E14 VSVZ RPs versus juvenile/adult V-SVZ NSCs (P20/34/61; Fig. $3 F, x$-axis) and as a second comparator we determined average gene expression for E16.5 nonproliferative SGZ RPs versus juvenile/adult SGZ NSCs (P18-P132; Fig. $3 F, y$-axis). We then correlated all V-SVZ and SGZ NSC single-cell transcriptomes from all timepoints with these averaged datasets and used these correlations to assign a two-dimensional coordinate for each cell. This analysis, which uses gene expression values that are not batch corrected, showed that during embryogenesis and the first postnatal week, the V-SVZ and SGZ precursors were very similar, with the E16.5-P5 SGZ precursors closely mingled with the E17-P6/7 V-SVZ precursors of the same approximate age (Fig. 3F). By contrast, the juvenile/adult V-SVZ and SGZ NSCs were more similar to each other than they were to the developing precursors of the same origin (Fig. 3F). Thus, SGZ and V-SVZ precursors follow similar transcriptional trajectories from active embryonic RPs to dormant adult NSCs.

\section{Embryonic dentate gyrus and cortex RPs but not GE RPs express genes associated with excitatory neurogenesis and a common pallial origin}

One explanation for the high similarity between SGZ and V-SVZ precursors is that they derive from RPs in adjacent lateral ventricle neuroepithelial regions during embryogenesis; dentate gyrus and cortical RPs are beside each other in the pallial region while GE RPs are immediately adjacent to cortical RPs in the subpallial region. We therefore directly compared E16.5 dentate gyrus RPs, E14 cortex RPs and E14 GE RPs, taking advantage of the fact that the V-SVZ cells were lineage traced so that cortex and GE-derived cells could be distinguished (see Borrett et al., 2020). We combined these different transcriptomes, put them through the pipeline together and used one round of Harmony batch correction. UMAP visualization of this combined dataset showed that the cortex, GE and dentate gyrus $\mathrm{RP}$ transcriptomes were largely but not completely segregated from each other (Fig. 5A), in good correspondence with the correlation analyses showing that these RPs were very similar to each other but not identical.

To more specifically identify differences between these RP populations, we focused on 117 genes that were previously-shown (Borrett et al., 2020) to be differentially expressed between cortical and GE RPs (average expression difference of $\geq 0.5$; adj. $p$ value $<0.05$; FWER). Fifty-four of these genes were expressed at higher levels in cortical than GE RPs, and of these about half (26) were also significantly enriched in dentate gyrus versus GE RPs (Table 3 ), as shown by UMAP gene expression overlays (Fig. 5B) and by a heatmap indicating mRNA expression levels in single cells (Fig. 5C). These included genes like Emx1, Tfap2c, Pax6, Fezf2, Neurog2, and Eomes. Notably, some of these shared enriched genes are associated with glutamatergic neurogenesis (Fezf2, Neurog2, and Eomes), while others are associated with a pallial origin (Emx1, Pax6, and Tfap2c). We also asked about the other 63 genes, which were expressed at higher levels in GE versus cortical RPs (average expression difference of $\geq 0.5$; adj. $p$ value $<0.05$; FWER). Of these, $49 \%$ were also higher in GE versus dentate gyrus RPs, as exemplified by $D / x 2$, Six3, and Gsx2, genes that are associated with GABAergic neurogenesis or GE identity (Fig. 5B,D; Table 3). Thus, the embryonic RP parents of V-SVZ and SGZ NSCs are all very similar to each, but are distinguished by expression of small cohorts of genes that are known to play important roles in determining regional identity and/or glutamatergic versus GABAergic neurogenesis. 

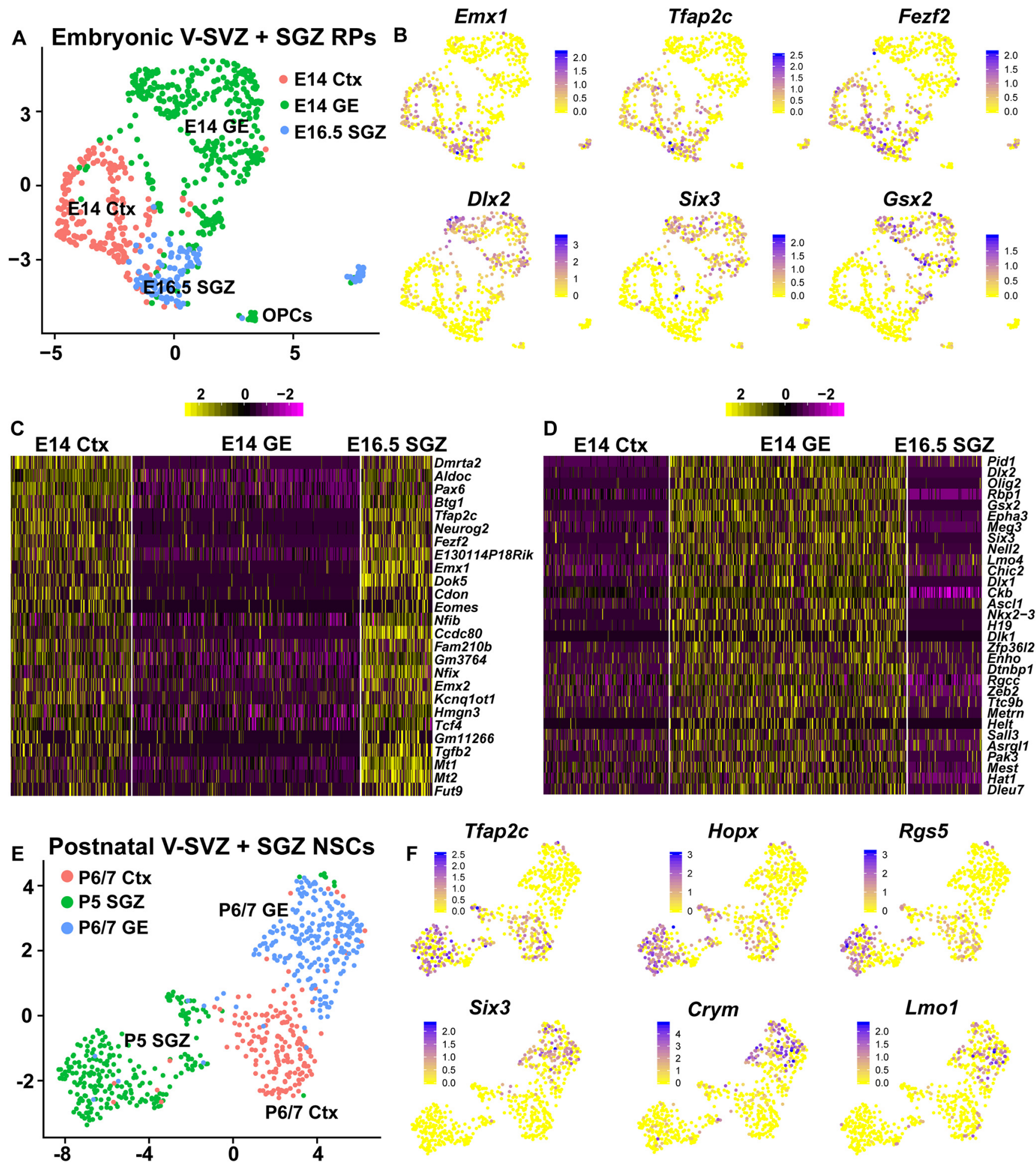

Figure 5. Embryonic dentate gyrus and cortex RPs express genes associated with excitatory neurogenesis and a common pallial origin. $\boldsymbol{A}$, Batch-corrected UMAP visualization of the transcriptomes of E16.5 dentate neuroepithelium RPs, E14 cortical RPs and E14 GE RPs, where transcriptomes are colored to indicate cell type. $\boldsymbol{B}$, UMAP marker gene expression overlays of the dataset in $\boldsymbol{A}$. Cells are color-coded for levels of gene expression as per the adjacent color keys. $\boldsymbol{C}, \boldsymbol{D}$, Heatmap illustrating common genes upregulated $(\boldsymbol{C})$ or downregulated $(\boldsymbol{D})$ in E14 cortical RPs and E16.5 SGZ RPs relative to E14 GE RPs. Genes are color-coded for levels of expression as per the adjacent color keys. Gene expression values are not batch-corrected. E, Batch-corrected UMAP visualization of transcriptomes of P5 SGZ NSCs, P6/7 cortically derived V-SVZ NSCs and P6/7 GE-derived V-SVZ NSCs, colored to indicate cell type. $\boldsymbol{F}$, UMAP visualizations as in $\boldsymbol{E}$, overlaid for expression of genes defined in Borrett et al. (2020) as being enriched in cortical versus GE-derived V-SVZ NSCs. Cells are color-coded for levels of expression as per the adjacent color keys. 
Table 3: Differential gene expression analysis between E16.5 DG/cortex RPs and E14 GE RPs (related to Fig. 5)

\begin{tabular}{|c|c|c|}
\hline DE gene & Average logFC & Adjusted $p$ value \\
\hline Dmrta2 & 0.63 & $6.00 \mathrm{E}-19$ \\
\hline Aldoc & 0.98 & $1.07 \mathrm{E}-15$ \\
\hline Pax6 & 0.68 & $5.02 \mathrm{E}-13$ \\
\hline Btg1 & 0.76 & $2.65 E-18$ \\
\hline Tfap2c & 0.73 & $1.45 \mathrm{E}-27$ \\
\hline Neurog2 & 1.08 & $6.34 \mathrm{E}-18$ \\
\hline Fezf2 & 0.65 & $4.26 \mathrm{E}-18$ \\
\hline E130114P18Rik & 0.87 & $3.97 \mathrm{E}-22$ \\
\hline Emx1 & 0.76 & 1.16E-29 \\
\hline Dok5 & 0.92 & $2.08 \mathrm{E}-37$ \\
\hline Cdon & 0.43 & 8.34E-04 \\
\hline Eomes & 0.40 & 3.94E-02 \\
\hline Nfib & 0.66 & $1.24 \mathrm{E}-14$ \\
\hline Ccdc80 & 1.22 & $9.16 \mathrm{E}-45$ \\
\hline Fam210b & 0.64 & 7.33E-07 \\
\hline Gm3764 & 0.68 & $1.43 \mathrm{E}-14$ \\
\hline Nfix & 1.05 & $3.33 E-23$ \\
\hline Emx2 & 0.55 & 2.61E-04 \\
\hline Kcnq1ot1 & 0.55 & $1.90 \mathrm{E}-06$ \\
\hline Hmgn3 & 0.65 & $2.46 \mathrm{E}-18$ \\
\hline Tcf.4 & 0.56 & $3.15 \mathrm{E}-12$ \\
\hline Gm11266 & 0.41 & $1.15 \mathrm{E}-06$ \\
\hline Tgfb2 & 0.64 & $4.88 \mathrm{E}-19$ \\
\hline Mt1 & 1.64 & 8.65E-38 \\
\hline Mt2 & 1.75 & 8.69E-29 \\
\hline Fut9 & 0.54 & $8.48 \mathrm{E}-10$ \\
\hline Pid1 & -0.56 & $1.30 \mathrm{E}-12$ \\
\hline Dlx2 & -1.20 & 4.90E-25 \\
\hline Olig2 & -0.82 & $2.76 \mathrm{E}-15$ \\
\hline Rbp1 & -1.92 & $1.43 E-38$ \\
\hline Gsx2 & -0.63 & $5.28 \mathrm{E}-14$ \\
\hline Epha3 & -0.77 & $2.77 \mathrm{E}-21$ \\
\hline Meg3 & -1.48 & $3.26 \mathrm{E}-26$ \\
\hline Six3 & -0.55 & $2.87 \mathrm{E}-13$ \\
\hline Nell2 & -0.67 & $5.69 \mathrm{E}-15$ \\
\hline Lmo4 & -0.43 & 6.56E-06 \\
\hline Chic2 & -0.45 & 2.30E-07 \\
\hline DIx1 & -0.87 & $6.63 \mathrm{E}-16$ \\
\hline Ckb & -1.11 & $4.64 \mathrm{E}-44$ \\
\hline Ascl1 & -0.73 & 9.94E-06 \\
\hline Nkx2-3 & -0.50 & $2.08 \mathrm{E}-11$ \\
\hline $\mathrm{H} 19$ & -0.58 & $2.12 \mathrm{E}-11$ \\
\hline Dlk1 & -0.35 & 2.93E-04 \\
\hline Zfp36l2 & -0.33 & 5.87E-05 \\
\hline Enho & -0.33 & $2.88 \mathrm{E}-04$ \\
\hline Dtnbp1 & -0.38 & $1.02 \mathrm{E}-05$ \\
\hline Rgcc & -0.88 & $1.15 \mathrm{E}-17$ \\
\hline Zeb2 & -0.53 & $4.91 \mathrm{E}-10$ \\
\hline Ttc9b & -0.29 & 2.04E-05 \\
\hline Metrn & -0.37 & 3.42E-05 \\
\hline Helt & -0.40 & 8.66E-03 \\
\hline Sall3 & -0.36 & 2.27E-05 \\
\hline Asrgl1 & -0.30 & 8.89E-03 \\
\hline Pak3 & $\begin{array}{l}-0.51 \\
\text { (Continued) }\end{array}$ & $1.74 \mathrm{E}-08$ \\
\hline
\end{tabular}

Table 3: Continued

\begin{tabular}{lll}
\hline DE gene & Average logFC & Adjusted $p$ value \\
\hline Mest & -0.95 & $5.72 \mathrm{E}-09$ \\
Hat1 & -0.70 & $9.08 \mathrm{E}-15$ \\
Dleu7 & -0.49 & $1.59 \mathrm{E}-05$ \\
\hline
\end{tabular}

A total of 117 genes was previously shown to be differentially expressed between E14 cortical RPs and E14 GE RPs (average difference > 0.5, FWER < 0.05 ) in Borrett et al. (2020). Of these, 54 were enriched in cortical RPs and 63 were enriched in GE RPs. These 117 genes were interrogated for their relative levels of expression in E16.5 DG RPs and E14 GE RPs (from the dataset shown in Fig. 5A). This analysis identified 26 (of 54) cortically enriched genes that were also significantly enriched in E16.5 SGZ RPs relative to E14 GE RPs, and 31 (of 63) GE-enriched genes that were also significantly enriched in E14 GE RPs relative to E16.5 SGZ RPs. These 57 genes are shown, as are the log fold changes in expression and adjusted $p$ values (FWER $<0.05$ ). Positive fold change values represent enriched expression in E16.5 SGZ RPs relative to E14 GE RPs and negative fold change values indicate enriched expression in E14 GE RPs relative to E16.5 SGZ RPs. These same 57 genes are depicted in the heatmaps in Figure 5C,D.

\section{Postnatal SGZ NSCs also express genes that may be associated with a pallial origin}

We asked whether postnatal SGZ NSCs might continue to express genes reflective of their embryonic origin, as was previously seen for postnatal V-SVZ NSCs (Borrett et al., 2020). To ask this, we compared P5 SGZ NSCs to lineage-traced P6/7 V-SVZ NSCs deriving from the cortex and GE. We put all the transcriptomes through the batchcorrected pipeline together and visualized clustering on a UMAP (Fig. 5E). This analysis showed that as seen for the embryonic cells, NSCs from the cortex, GE, and dentate gyrus were largely segregated from one another. Together with the Pearson correlation analysis (Fig. 3E), these results indicate that these different postnatal NSC populations are very similar but not identical. We then asked about genes previously-defined as differentially expressed in cortically-derived versus GE-derived postnatal V-SVZ NSCs (Borrett et al., 2020). UMAP gene expression overlays showed that genes that were enriched in cortical NSCs such as Hopx, Tfap2c, and Rgs5 were also enriched in dentate gyrus NSCs (Fig. 5F) and thus represented potential markers of their shared pallial origin. By contrast, genes that were enriched in GE NSCs and might be indicative of a subpallial origin, were largely not detectable in the SGZ NSCs, as exemplified by $L$ mo1, Six3, and Crym mRNAs (Fig. 5F). We validated one of the potential pallial NSC marker genes, Rgs5, by performing FISH on the P5 dentate gyrus. Rgs5 mRNA was expressed in Sox2-positive SGZ cells that also expressed the precursor gene Aldoc (Fig. 1E), likely NSCs. Thus, as seen during embryogenesis, cortically-derived and dentate neuroepithelium-derived NSCs, but not GE-derived NSCs, express potential marker genes for a pallial origin.

\section{The developmental transition to a dormant adult NSC occurs over a prolonged postnatal period in the SGZ as it does in the V-SVZ}

In the V-SVZ, the transition from an active embryonic RP to a dormant postnatal NSC occurs over a prolonged, largely postnatal timeframe (Borrett et al., 2020). We asked whether this was also true for the SGZ using trajectory analysis, an approach that orders cells based on 

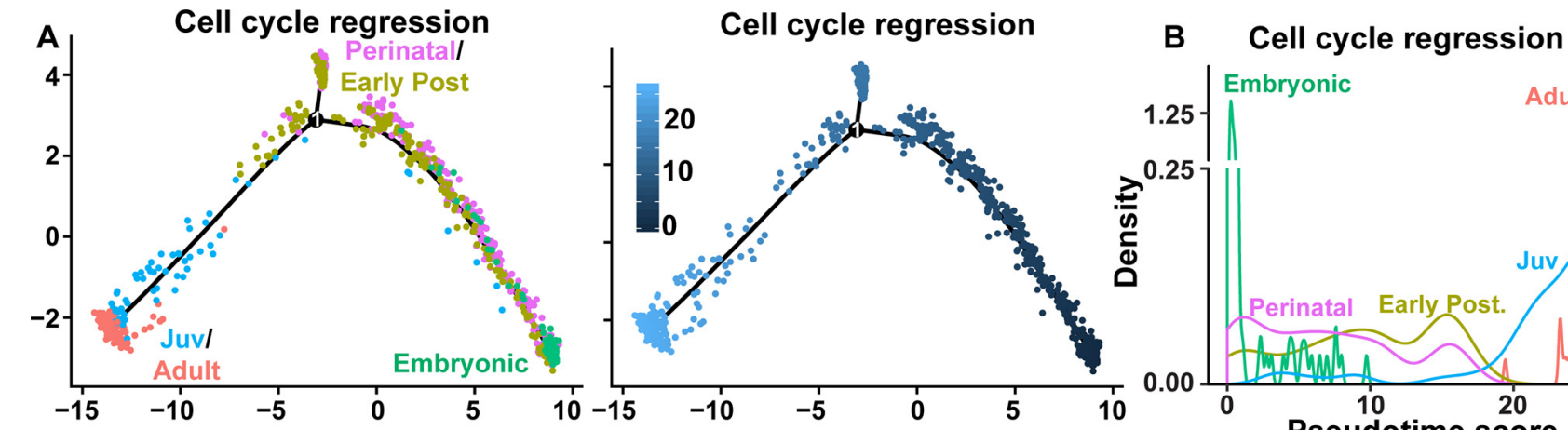

D
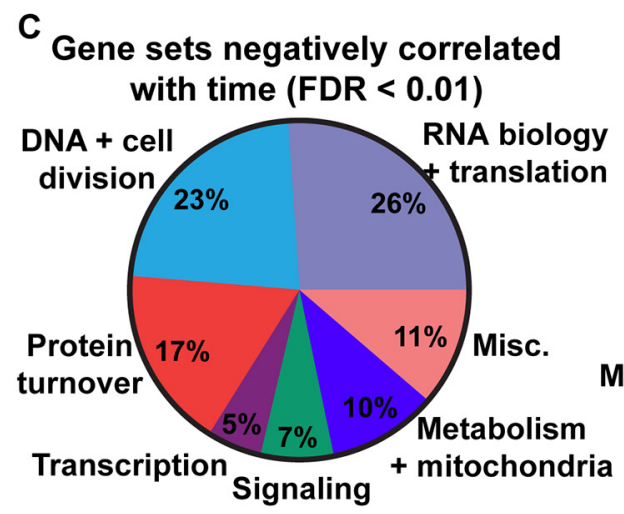

D Gene sets positively correlated

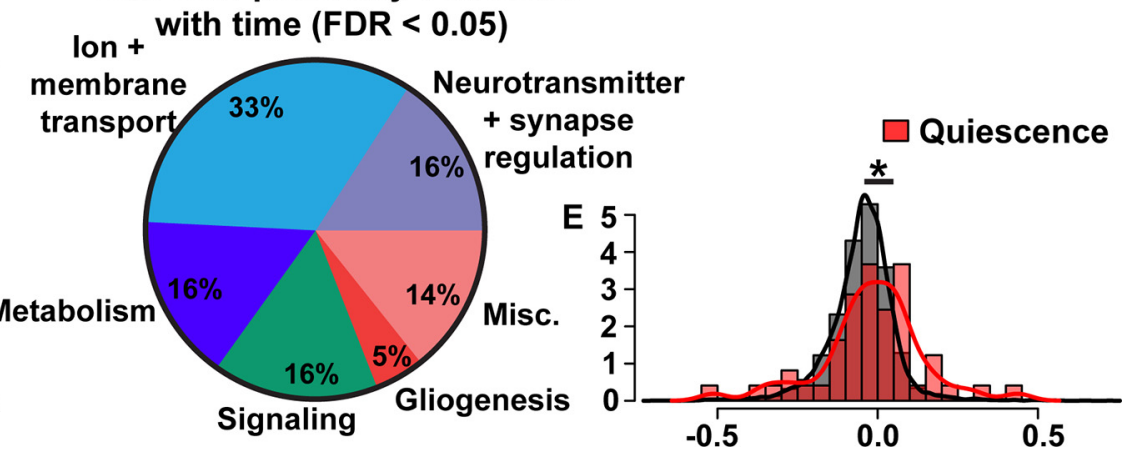

Figure 6. Mapping the trajectory from embryonic to adult SGZ NSCs with trajectory and GSEA analyses. $\boldsymbol{A}$, To understand the progression of SGZ NSCs from E16.5 to adulthood (P120/P132), SGZ NSCs at all ages (E16.5, P0, P5, P18, P19, P23, P120, P132) were ordered along a pseudotime trajectory using Monocle 2. To ensure cell cycle effects would not affect the ordering of the trajectory, we regressed out cell cycle genes (see Materials and Methods). SGZ NSCs along the trajectory are colored by age category (as defined in Fig. $3 A$, left) or by pseudotime ordering scores (right). These data are not batch corrected. B, Density plot showing the relative distribution of pseudotime ordering scores of SGZ NSCs in the trajectory depicted in $\boldsymbol{A}$ from each age category. $\boldsymbol{C}, \boldsymbol{D}$, GSEA analysis of the combined SGZ NSC dataset from E16.5 to P132, performed without batch correction. Pie chart shows broad categories of genes sets negatively correlated $(\boldsymbol{C})$ or positively correlated $(\boldsymbol{D})$ with time that fell into a number of broad categories (FDR cutoffs are indicated). Categories negatively correlated with time in $\boldsymbol{C}$ include DNA replication, DNA repair, chromosome stability and segregation and the cell cycle (DNA + cell division), transcription, epigenetics, and chromatin regulation (Transcription), RNA homeostasis, translation and tRNA and ribosome biogenesis (RNA biology + translation), general protein processing and trafficking including ubiquitination and sumoylation (Protein turnover), signaling pathways (Signaling), and metabolism, oxidative phosphorylation and mitochondrial activity (Metabolism + mitochondria). Other categories are termed as miscellaneous (Misc.). The detailed categorization is shown in Table 4. Categories positively correlated with time $(\boldsymbol{D})$ include neurotransmitter transport and synaptic regulation (Neurotransmitter + synapse regulation), lon regulation and membrane transport (Ion + membrane transport), signaling pathways (Signaling), gliogenesis and metabolism and lipid oxidation (Metabolism). Other categories are termed as miscellaneous (Misc.). The detailed categorization is shown in Table 5. E. Histogram of Spearman rank correlation coefficients of the combined SGZ NSC dataset for a signature of 49 quiescence genes described in Cheung and Rando (2013; red) versus all genes (gray). Correlations of $>0$ or $<0$ indicate expression increases or decreases over time; ${ }^{\star} p=0.024$, Wilcoxon rank-sum test.

changes in their transcriptomes over pseudo-time. To do this, we combined transcriptomes of all dentate gyrus nonproliferative RP/NSCs from E16.5 to adulthood and performed a trajectory analysis using Monocle (Fig. 6A,B). We did not use batch correction for this analysis and, to ensure that the trajectory was not driven by precursor proliferative status, we removed the aforementioned 678 cell cycle-related genes. We also excluded a small number of cells (31 of 885 total) that expressed genes consistent with activated NSCs. This analysis resulted in a trajectory that correctly reflected the developmental progression. The E16.5 RPs were ordered at one end, and the adult dormant NSCs were at the other end. Some of the P0 and P5 NSCs were mingled with the E16.5 RPs, but most perinatal cells extended to eventually meet the juvenile NSCs, which then extended further along the trajectory to meet and mingle with the adult dormant NSCs at the other end. This trajectory was very similar to an analogous Monocle trajectory analysis of the V-SVZ RP/ NSCs (Borrett et al., 2020), with the transition to an adult NSC state occurring gradually from birth until the third postnatal week.

These findings suggest that the transition from an active embryonic RP to a dormant adult NSC might be similar for the two major forebrain NSC populations. To further examine this idea and to determine what types of genes and/or cellular pathways are changed in SGZ NSCs at different ages, we performed a GSEA over SGZ developmental time from E16.5 to P132. We compared this GSEA to a previously-published (Borrett et al., 2020) analogous 
Table 4: Gene sets negatively correlated with time, as analyzed by GSEA for total SGZ NSCs from E16.5 to P132 (related to Fig. 6)

Pathway names
CYTOPLASMIC RIBOSOMAL PROTEINS\%WIKIPATHWAYS_20191210\%WP163\%MUS
MUSCULUS

FORMATION OF A POOL OF FREE 4OS SUBUNITS\%REACTOME DATABASE ID RELEASE $71 \% 72689$

VIRAL MRNA TRANSLATION\%REACTOME DATABASE ID RELEASE 71\%192823 L13A-MEDIATED TRANSLATIONAL SILENCING OF CERULOPLASMIN EXPRESSION\% REACTOME DATABASE ID RELEASE $71 \% 156827$

EUKARYOTIC TRANSLATION ELONGATION\%REACTOME\%R-HSA-156842.2 NONSENSE MEDIATED DECAY (NMD) INDEPENDENT OF THE EXON JUNCTION COMPLEX

(EJC)\%REACTOME\%R-HSA-975956.1

SELENOCYSTEINE SYNTHESIS\%REACTOME DATABASE ID RELEASE 71\%2408557 REGULATION OF EXPRESSION OF SLITS AND ROBOS\%REACTOME DATABASE ID

RELEASE $71 \% 9010553$

EUKARYOTIC TRANSLATION TERMINATION\%REACTOME\%R-HSA-72764.4

RESPONSE OF EIF2AK4 (GCN2) TO AMINO ACID DEFICIENCY\%REACTOME DATABASE ID

RELEASE $71 \% 9633012$

SRP-DEPENDENT COTRANSLATIONAL PROTEIN TARGETING TO MEMBRANE\%REACTOME

$\%$ R-HSA-1799339.2

ACTIVATION OF THE MRNA UPON BINDING OF THE CAP-BINDING COMPLEX AND EIFS,

AND SUBSEQUENT BINDING TO 43S\%REACTOME\%R-HSA-72662.3

HALLMARK_MYC_TARGETS_V1\%MSIGDB_C2\%HALLMARK_MYC_TARGETS_V1 SELENOAMINO ACID METABOLISM\%REACTOME DATABASE ID RELEASE $71 \% 2408522$ AUF1 (HNRNP DO) BINDS AND DESTABILIZES MRNA\%REACTOME DATABASE ID RELEASE $71 \% 450408$

REGULATION OF ORNITHINE DECARBOXYLASE (ODC)\%REACTOME\%R-HSA-350562.2

PROTEASOME DEGRADATION\%WIKIPATHWAYS_20191210\%WP519\%MUS MUSCULUS

THE ROLE OF GTSE1 IN G2 M PROGRESSION AFTER G2 CHECKPOINT\%REACTOME

DATABASE ID RELEASE $71 \% 8852276$

APC C:CDC20 MEDIATED DEGRADATION OF SECURIN\%REACTOME\%R-HSA-174154.2

CYTOPLASMIC TRANSLATION\%GOBP\%GO:0002181

ER-PHAGOSOME PATHWAY\%REACTOME DATABASE ID RELEASE $71 \% 1236974$

SCF(SKP2)-MEDIATED DEGRADATION OF P27 P21\%REACTOME\%R-HSA-187577.3

INFLUENZA VIRAL RNA TRANSCRIPTION AND REPLICATION\%REACTOME DATABASE ID

RELEASE $71 \% 168273$

INFLUENZA INFECTION\%REACTOME\%R-HSA-168254.2

ASSEMBLY OF THE PRE-REPLICATIVE COMPLEX\%REACTOME\%R-HSA-68867.4

REGULATION OF MITOTIC CELL CYCLE\%REACTOME\%R-HSA-453276.2

REGULATION OF MRNA STABILITY BY PROTEINS THAT BIND AU-RICH ELEMENTS\%

REACTOME\%R-HSA-450531.4

MAJOR PATHWAY OF RRNA PROCESSING IN THE NUCLEOLUS AND CYTOSOL\%

REACTOME\%R-HSA-6791226.3

SWITCHING OF ORIGINS TO A POST-REPLICATIVE STATE\%REACTOME DATABASE ID

RELEASE $71 \% 69052$

RUNX1 REGULATES TRANSCRIPTION OF GENES INVOLVED IN DIFFERENTIATION OF HSCS

\%REACTOME\%R-HSA-8939236.1

MITOCHONDRIAL TRANSLATION ELONGATION\%REACTOME\%R-HSA-5389840.1

HOST INTERACTIONS OF HIV FACTORS\%REACTOME\%R-HSA-162909.1

RIBOSOMAL LARGE SUBUNIT BIOGENESIS\%GOBP\%GO:0042273

NEGATIVE REGULATION OF RNA SPLICING\%GOBP\%GO:0033119

MRNA SPLICING\%REACTOME\%R-HSA-72172.3

RIBOSOME ASSEMBLY\%GOBP\%GO:0042255

RRNA PROCESSING\%GOBP\%GO:0006364

SYNTHESIS OF DNA\%REACTOME DATABASE ID RELEASE 71\%69239

COOPERATION OF PREFOLDIN AND TRIC CCT IN ACTIN AND TUBULIN FOLDING\%

REACTOME\%R-HSA-389958.2

UBIQUITIN PROTEASOME PATHWAY\%PANTHER PATHWAY\%P00060

TRANSLATION FACTORS\%WIKIPATHWAYS_20191210\%WP307\%MUS MUSCULUS

RIBOSOMAL SMALL SUBUNIT BIOGENESIS\%GOBP\%GO:0042274

RNA SPLICING\%GOBP\%GO:0008380

\begin{tabular}{|c|c|c|c|c|}
\hline $\begin{array}{l}\text { Adj. } p \text { value } \\
\text { (FDR) }\end{array}$ & $\begin{array}{l}\text { Norm. } \\
\text { Enr. Score }\end{array}$ & $\begin{array}{l}\text { nMore- } \\
\text { Extreme }\end{array}$ & Size & Category \\
\hline $2.29 \mathrm{E}-03$ & -2.73 & 0 & 80 & RNA translation + ribosomes \\
\hline $2.29 \mathrm{E}-03$ & -2.59 & 0 & 51 & RNA translation + ribosomes \\
\hline $2.29 \mathrm{E}-03$ & -2.57 & 0 & 39 & $\mathrm{IR}$ \\
\hline $2.29 \mathrm{E}-03$ & -2.57 & 0 & 61 & Miscellaneous \\
\hline $2.29 \mathrm{E}-03$ & -2.57 & 0 & 42 & RNA translation + ribosomes \\
\hline $2.29 \mathrm{E}-03$ & -2.56 & 0 & 45 & DNA + cell cycle \\
\hline $2.29 \mathrm{E}-03$ & -2.55 & 0 & 43 & Miscellaneous \\
\hline $2.29 \mathrm{E}-03$ & -2.54 & 0 & 111 & Signaling \\
\hline 2.29E-03 & -2.53 & 0 & 43 & RNA translation + ribosomes \\
\hline $2.29 \mathrm{E}-03$ & -2.51 & 0 & 50 & RNA translation + ribosomes \\
\hline $2.29 \mathrm{E}-03$ & -2.48 & 0 & 61 & Protein processing \\
\hline $2.29 \mathrm{E}-03$ & -2.42 & 0 & 43 & RNA translation + ribosomes \\
\hline $2.29 \mathrm{E}-03$ & -2.40 & 0 & 184 & DNA + cell cycle \\
\hline $2.29 \mathrm{E}-03$ & -2.39 & 0 & 62 & Metabolism \\
\hline $2.29 \mathrm{E}-03$ & -2.39 & 0 & 49 & RNA translation + ribosomes \\
\hline $2.29 \mathrm{E}-03$ & -2.37 & 0 & 48 & Miscellaneous \\
\hline $2.29 \mathrm{E}-03$ & -2.35 & 0 & 50 & Protein processing \\
\hline $2.29 \mathrm{E}-03$ & -2.35 & 0 & 53 & DNA + cell cycle \\
\hline $2.29 \mathrm{E}-03$ & -2.34 & 0 & 61 & IR \\
\hline $2.29 \mathrm{E}-03$ & -2.33 & 0 & 61 & RNA translation + ribosomes \\
\hline $2.29 \mathrm{E}-03$ & -2.31 & 0 & 69 & Protein processing \\
\hline 2.29E-03 & -2.29 & 0 & 56 & DNA + cell cycle \\
\hline $2.29 \mathrm{E}-03$ & -2.27 & 0 & 80 & IR \\
\hline $2.29 \mathrm{E}-03$ & -2.22 & 0 & 96 & IR \\
\hline $2.29 \mathrm{E}-03$ & -2.20 & 0 & 63 & DNA + cell cycle \\
\hline $2.29 \mathrm{E}-03$ & -2.20 & 0 & 78 & DNA + cell cycle \\
\hline $2.29 \mathrm{E}-03$ & -2.19 & 0 & 77 & RNA translation + ribosomes \\
\hline $2.29 \mathrm{E}-03$ & -2.19 & 0 & 124 & RNA translation + ribosomes \\
\hline $2.29 \mathrm{E}-03$ & -2.15 & 0 & 84 & DNA + cell cycle \\
\hline $2.29 \mathrm{E}-03$ & -2.14 & 0 & 72 & $\mathrm{IR}$ \\
\hline $2.29 \mathrm{E}-03$ & -2.13 & 0 & 83 & RNA translation + ribosomes \\
\hline $2.29 \mathrm{E}-03$ & -2.13 & 0 & 110 & $\mathrm{IR}$ \\
\hline $2.29 \mathrm{E}-03$ & -2.12 & 0 & 66 & RNA translation + ribosomes \\
\hline 2.29E-03 & -2.10 & 0 & 28 & RNA translation + ribosomes \\
\hline $2.29 \mathrm{E}-03$ & -2.09 & 0 & 176 & RNA translation + ribosomes \\
\hline $2.29 \mathrm{E}-03$ & -2.09 & 0 & 57 & RNA translation + ribosomes \\
\hline 2.29E-03 & -2.09 & 0 & 148 & RNA translation + ribosomes \\
\hline $2.29 \mathrm{E}-03$ & -2.07 & 0 & 113 & DNA + cell cycle \\
\hline $2.29 \mathrm{E}-03$ & -2.05 & 0 & 24 & Miscellaneous \\
\hline $2.29 \mathrm{E}-03$ & -2.05 & 0 & 39 & Protein processing \\
\hline $2.29 \mathrm{E}-03$ & -2.00 & 0 & 47 & RNA translation + ribosomes \\
\hline $2.29 \mathrm{E}-03$ & -2.00 & 0 & 63 & RNA translation + ribosomes \\
\hline $2.29 \mathrm{E}-03$ & -1.99 & 0 & 198 & RNA processing + translation \\
\hline
\end{tabular}


Table 4: Continued

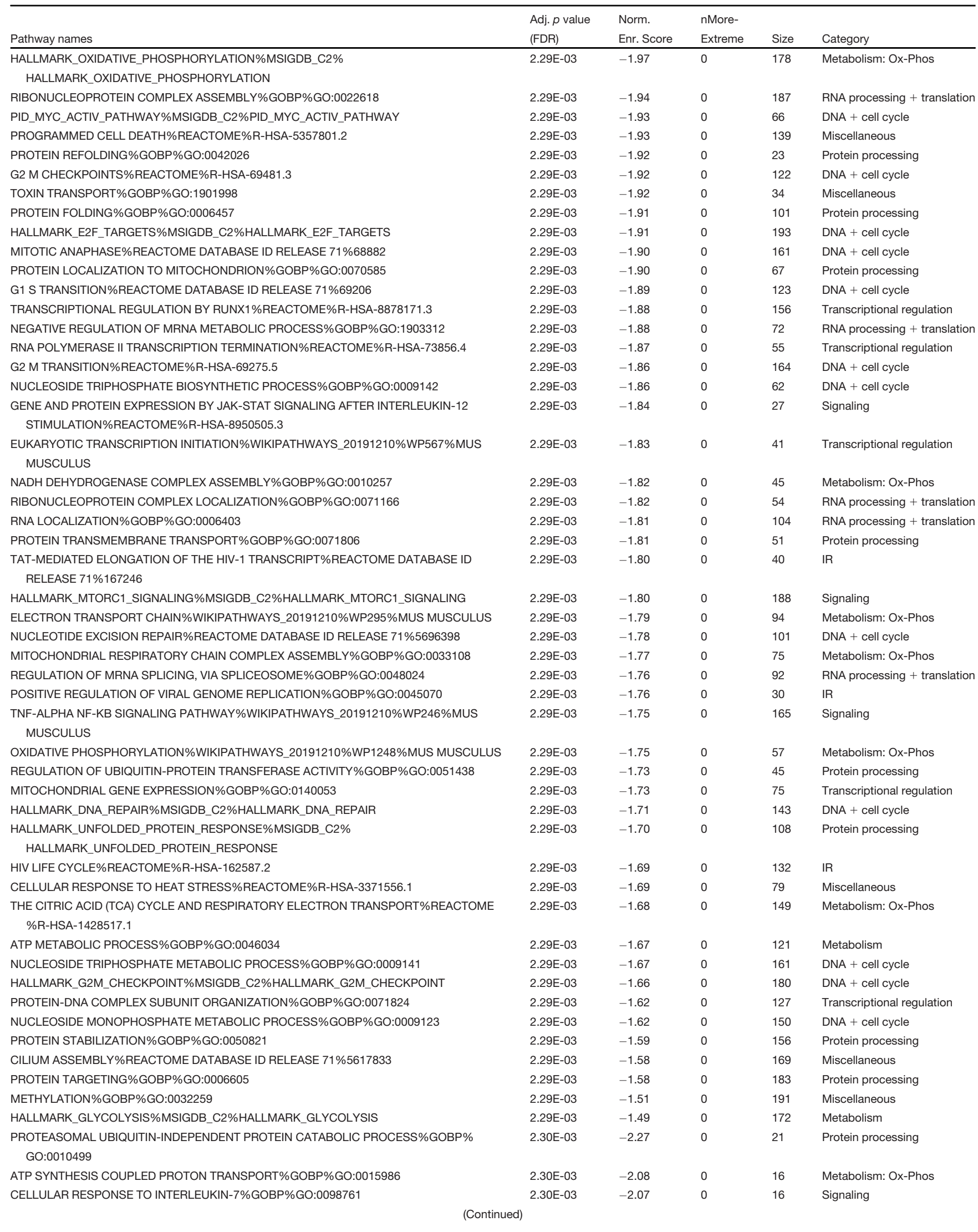


Table 4: Continued

\begin{tabular}{|c|c|c|c|c|c|}
\hline Pathway names & $\begin{array}{l}\text { Adj. } p \text { value } \\
\text { (FDR) }\end{array}$ & $\begin{array}{l}\text { Norm. } \\
\text { Enr. Score }\end{array}$ & $\begin{array}{l}\text { nMore- } \\
\text { Extreme }\end{array}$ & Size & Category \\
\hline $\begin{array}{l}\text { FORMATION OF TUBULIN FOLDING INTERMEDIATES BY CCT TRIC\%REACTOME\%R-HSA- } \\
389960.2\end{array}$ & 2.30E-03 & -2.03 & 0 & 17 & Miscellaneous \\
\hline CELLULAR RESPONSE TO INTERLEUKIN-4\%GOBP\%GO:0071353 & 2.30E-03 & -1.94 & 0 & 18 & Signaling \\
\hline SPERM-EGG RECOGNITION\%GOBP\%GO:0035036 & 2.30E-03 & -1.97 & 0 & 15 & IR \\
\hline ER TO GOLGI VESICLE-MEDIATED TRANSPORT\%GOBP\%GO:0006888 & $3.91 \mathrm{E}-03$ & -1.61 & 1 & 93 & Protein processing \\
\hline HALLMARK_MYC_TARGETS_V2\%MSIGDB_C2\%HALLMARK_MYC_TARGETS_V2 & 3.95E-03 & -1.75 & 1 & 56 & DNA + cell cycle \\
\hline $\begin{array}{l}\text { REGULATION OF SIGNAL TRANSDUCTION BY P53 CLASS MEDIATOR\%GOBP\% } \\
\text { GO:1901796 }\end{array}$ & 3.95E-03 & -1.72 & 1 & 58 & Signaling \\
\hline CELLULAR RESPONSE TO HEAT\%GOBP\%GO:0034605 & $3.98 \mathrm{E}-03$ & -1.69 & 1 & 46 & Miscellaneous \\
\hline CRISTAE FORMATION\%REACTOME DATABASE ID RELEASE $71 \% 8949613$ & 4.17E-03 & -1.83 & 1 & 24 & Miscellaneous \\
\hline RIBOSOMAL SMALL SUBUNIT ASSEMBLY\%GOBP\%GO:0000028 & 4.18E-03 & -1.89 & 1 & 18 & RNA processing + translation \\
\hline PROTEIN PEPTIDYL-PROLYL ISOMERIZATION\%GOBP\%GO:0000413 & 4.18E-03 & -1.83 & 1 & 18 & Protein processing \\
\hline $\begin{array}{l}\text { POSITIVE REGULATION OF TRANSCRIPTION INITIATION FROM RNA POLYMERASE II } \\
\text { PROMOTER\%GOBP\%GO:0060261 }\end{array}$ & $4.18 \mathrm{E}-03$ & -1.81 & 1 & 20 & Transcriptional regulation \\
\hline VIRAL GENE EXPRESSION\%GOBP\%GO:0019080 & 4.18E-03 & -1.81 & 1 & 20 & IR \\
\hline $\begin{array}{l}\text { BBSOME-MEDIATED CARGO-TARGETING TO CILIUM\%REACTOME DATABASE ID RELEASE } \\
71 \% 5620922\end{array}$ & 4.18E-03 & -1.79 & 1 & 21 & Miscellaneous \\
\hline MITOTIC PROMETAPHASE\%REACTOME\%R-HSA-68877.5 & $5.40 \mathrm{E}-03$ & -1.48 & 2 & 167 & DNA + cell cycle \\
\hline POSITIVE REGULATION OF TRANSLATION\%GOBP\%GO:0045727 & $5.40 \mathrm{E}-03$ & -1.62 & 2 & 104 & RNA processing + translation \\
\hline DNA REPLICATION\%GOBP\%GO:0006260 & $5.40 \mathrm{E}-03$ & -1.57 & 2 & 117 & DNA + cell cycle \\
\hline RNA CATABOLIC PROCESS\%GOBP\%GO:0006401 & $5.40 \mathrm{E}-03$ & -1.54 & 2 & 112 & RNA processing + translation \\
\hline MITOCHONDRIAL PROTEIN IMPORT\%REACTOME DATABASE ID RELEASE $71 \% 1268020$ & $5.50 \mathrm{E}-03$ & -1.69 & 2 & 57 & Miscellaneous \\
\hline $\begin{array}{l}\text { DEADENYLATION-DEPENDENT MRNA DECAY\%REACTOME DATABASE ID RELEASE 71\% } \\
\quad 429914\end{array}$ & $5.50 \mathrm{E}-03$ & -1.69 & 2 & 55 & RNA processing + translation \\
\hline NEGATIVE REGULATION OF PROTEIN POLYMERIZATION\%GOBP\%GO:0032272 & 5.52E-03 & -1.67 & 2 & 52 & Protein processing \\
\hline RNA MODIFICATION\%GOBP\%GO:0009451 & $6.86 \mathrm{E}-03$ & -1.55 & 3 & 114 & RNA processing + translation \\
\hline DNA RECOMBINATION\%GOBP\%GO:0006310 & $6.86 \mathrm{E}-03$ & -1.53 & 3 & 142 & DNA + cell cycle \\
\hline REGULATION OF NUCLEAR DIVISION\%GOBP\%GO:0051783 & $6.86 \mathrm{E}-03$ & -1.53 & 3 & 144 & DNA + cell cycle \\
\hline INTERSPECIES INTERACTION BETWEEN ORGANISMS\%GOBP\%GO:0044419 & $6.86 \mathrm{E}-03$ & -1.46 & 3 & 173 & IR \\
\hline CHROMOSOME MAINTENANCE\%REACTOME\%R-HSA-73886.2 & 6.97E-03 & -1.65 & 3 & 72 & DNA + cell cycle \\
\hline $\begin{array}{l}\text { SIG_REGULATION_OF_THE_ACTIN_CYTOSKELETON_BY_RHO_GTPASES\%MSIGDB_C2\% } \\
\text { SIG_REGULATION_OF_THE_ACTIN_CYTOSKELETON_BY_RHO_GTPASES }\end{array}$ & 7.29E-03 & -1.73 & 3 & 28 & Signaling \\
\hline $\begin{array}{l}\text { NEGATIVE REGULATION OF UBIQUITIN-PROTEIN TRANSFERASE ACTIVITY\%GOBP\% } \\
\text { GO:0051444 }\end{array}$ & 7.60E-03 & -1.76 & 3 & 16 & Protein processing \\
\hline TRNA METABOLIC PROCESS\%GOBP\%GO:0006399 & 8.03E-03 & -1.51 & 4 & 137 & RNA processing + translation \\
\hline REGULATION OF TP53 ACTIVITY\%REACTOME\%R-HSA-5633007.3 & $9.43 \mathrm{E}-03$ & -1.50 & 5 & 138 & Miscellaneous \\
\hline AUTOPHAGY\%REACTOME\%R-HSA-9612973.1 & $9.46 \mathrm{E}-03$ & -1.52 & 5 & 107 & Miscellaneous \\
\hline $\begin{array}{l}\text { NEGATIVE REGULATION OF PROTEOLYSIS INVOLVED IN CELLULAR PROTEIN CATABOLIC } \\
\text { PROCESS\%GOBP\%GO:1903051 }\end{array}$ & $9.65 \mathrm{E}-03$ & -1.62 & 5 & 67 & Protein processing \\
\hline
\end{tabular}

Shown are gene sets that are negatively correlated with time (decreasing in the transition from embryonic RPs to adult NSCs) where FDR $<0.01$, analyzed from the combined SGZ RP/NSC dataset (a total of 885 cells, highlighted in blue in Fig. $3 C$ ). Also shown are the adjusted $p$ values (adj. $p$ value; FDR), enrichment scores (Norm. Enr. score), the size of the gene set and the number of times a random gene set had a more extreme enrichment score than the gene set (nMoreExtreme). Gene sets are ordered from most to least significant from top to bottom. These gene sets were also categorized with regard to a number of broad categories, including DNA replication, DNA repair, chromosome stability and segregation and the cell cycle (DNA + cell cycle), transcription, epigenetics and chromatin regulation (transcriptional regulation), RNA homeostasis, translation and tRNA and ribosome biogenesis (RNA processing + translation), general protein processing and trafficking including ubiquitination and sumoylation (protein processing), signaling pathways (signaling), and metabolism, oxidative phosphorylation and mitochondrial activity (metabolism). Other categories are termed as miscellaneous (misc.) and irrelevant gene sets are termed as IR.

GSEA analysis for V-SVZ NSCs from E14 to P61. Notably, the SGZ analysis (Fig. 6C,D; Table 4) showed that 115 gene sets decreased significantly (adj. $p$ value $<0.01$; FDR) as the E16.5 SGZ RPs transitioned to dormant adult SGZ NSCs. Most of these gene sets involved basic cellular processes required to maintain an active, proliferative stem cell, including transcriptional programs required for cell division, DNA and chromosome replication, RNA biology, transcription, and protein synthesis and turnover, indicating that the predominant change that occurs over this timeframe is a transition to cellular dormancy. The developing NSCs were also enriched for gene sets involved with oxidative phosphorylation. Conversely, 63 gene sets were significantly enriched in dormant adult NSCs relative to their developing NSC counterparts (adj. $p$ value $<0.05$; FDR; Fig. $6 D$; Table 5). Notably, $65 \%$ of these were involved in regulating and/or sensing the niche environment, with a particular enrichment for sensing/handling neurotransmitters and ions like sodium and potassium. They also included gene sets involved in lipid metabolism and, of particular note, a quiescence gene set (Fig. 6E) that was shown to be significantly enriched as V-SVZ NSCs transitioned to dormancy (Borrett et al., 2020). Thus, as previously shown for adult V-SVZ NSCs, adult SGZ NSCs are transcriptionally quiet with regard to genes involved in maintaining an active state and instead selectively 
Table 5: Gene sets positively correlated with time, as analyzed by GSEA for total SGZ NSCs from E16.5 to P132 (related to Fig. 6)

\begin{tabular}{|c|c|c|c|c|c|}
\hline Pathway & $\begin{array}{l}\text { Adj. } \\
p \text { value (FDR) }\end{array}$ & $\begin{array}{l}\text { Norm. Enr. } \\
\text { score }\end{array}$ & $\begin{array}{l}\text { nMore- } \\
\text { Extreme }\end{array}$ & Size & Category \\
\hline \multicolumn{5}{|l|}{$\% \mathrm{GO}: 0035235$} & Neurotransmitter/synaptic regulation \\
\hline CELLULAR RESPONSE TO STEROL\%GOBP\%GO:0036315 & $9.84 \mathrm{E}-03$ & 2.46 & 0 & 15 & Signaling \\
\hline NEUROTRANSMITTER UPTAKE\%GOBP\%GO:0001504 & $1.01 \mathrm{E}-02$ & 2.49 & 0 & 16 & Neurotransmitter/synaptic regulation \\
\hline EXPORT ACROSS PLASMA MEMBRANE\%GOBP\%GO:0140115 & $1.01 \mathrm{E}-02$ & 2.23 & 0 & 16 & Membrane transport + ion balance \\
\hline $\begin{array}{l}\text { REGULATION OF MEMBRANE PROTEIN ECTODOMAIN PROTEOLYSIS } \\
\text { \%GOBP\%GO:0051043 }\end{array}$ & $1.03 \mathrm{E}-02$ & 2.32 & 0 & 17 & Miscellaneous \\
\hline $\begin{array}{l}\text { NEGATIVE REGULATION OF PEPTIDYL-THREONINE } \\
\text { PHOSPHORYLATION\%GOBP\%GO:0010801 }\end{array}$ & \multicolumn{3}{|c|}{ PHOSPHORYLATION\%GOBP\%GO:0010801 } & 17 & Miscellaneous \\
\hline ACIDIC AMINO ACID TRANSPORT\%GOBP\%GO:0015800 & $1.30 \mathrm{E}-02$ & 2.75 & 0 & 27 & Membrane transport + ion balance \\
\hline \multicolumn{6}{|l|}{ GO:0090207 } \\
\hline SODIUM ION TRANSMEMBRANE TRANSPORT\%GOBP\%GO:0035725 & $1.41 \mathrm{E}-02$ & 2.43 & 0 & 30 & Membrane transport + ion balance \\
\hline \multicolumn{5}{|l|}{ PATHWAY\%P00037 } & Neurotransmitter/synaptic regulation \\
\hline $\begin{array}{l}\text { NEUROTRANSMITTER RELEASE CYCLE\%REACTOME\%R-HSA- } \\
\quad 112310.5\end{array}$ & $1.51 \mathrm{E}-02$ & 2.46 & 0 & 34 & Neurotransmitter/synaptic regulation \\
\hline RESPONSE TO DIETARY EXCESS\%GOBP\%GO:0002021 & $1.68 \mathrm{E}-02$ & 2.25 & 1 & 15 & $\mathrm{IR}$ \\
\hline POSITIVE REGULATION OF ANION TRANSPORT\%GOBP\%GO:1903793 & $1.76 \mathrm{E}-02$ & 2.29 & 0 & 39 & Membrane transport + ion balance \\
\hline ZINC ION HOMEOSTASIS\%GOBP\%GO:0055069 & $1.78 \mathrm{E}-02$ & 2.09 & 1 & 18 & Membrane transport + ion balance \\
\hline SYNAPTIC_VESICLE_TRAFFICKING\%PANTHER PATHWAY\%P05734 & $1.78 \mathrm{E}-02$ & 2.09 & 1 & 18 & Neurotransmitter/synaptic regulation \\
\hline EXPLORATION BEHAVIOR\%GOBP\%GO:0035640 & $1.95 \mathrm{E}-02$ & 2.01 & 1 & 23 & $\mathrm{IR}$ \\
\hline REGULATION OF BONE RESORPTION\%GOBP\%GO:0045124 & $1.95 \mathrm{E}-02$ & 2.00 & 1 & 23 & IR \\
\hline MATING\%GOBP\%GO:0007618 & $1.95 \mathrm{E}-02$ & 1.94 & 1 & 23 & $\mathrm{IR}$ \\
\hline CYTOKINE SECRETION\%GOBP\%GO:0050663 & $1.95 \mathrm{E}-02$ & 1.92 & 1 & 23 & Membrane transport + ion balance \\
\hline \multicolumn{3}{|l|}{ GOBP\%GO:0051966 } & 0 & & Neurotransmitter/synaptic regulation \\
\hline IMPORT ACROSS PLASMA MEMBRANE\%GOBP\%GO:0098739 & $2.32 \mathrm{E}-02$ & 2.35 & 0 & 53 & Membrane transport + ion balance \\
\hline \multicolumn{6}{|l|}{ GO:0050885 } \\
\hline EFFECTS OF PIP2 HYDROLYSIS\%REACTOME\%R-HSA-114508.2 & $2.41 \mathrm{E}-02$ & 1.94 & 2 & 19 & Metabolism (lipid) \\
\hline OLIGODENDROCYTE DIFFERENTIATION\%GOBP\%GO:0048709 & $2.42 \mathrm{E}-02$ & 2.20 & 0 & 56 & Gliogenesis \\
\hline POSITIVE REGULATION OF AMINE TRANSPORT\%GOBP\%GO:0051954 & $2.48 \mathrm{E}-02$ & 2.17 & 1 & 34 & Membrane transport + ion balance \\
\hline POSTSYNAPTIC MEMBRANE ORGANIZATION\%GOBP\%GO:0001941 & $2.57 \mathrm{E}-02$ & 1.89 & 2 & 22 & Neurotransmitter/synaptic regulation \\
\hline $\begin{array}{l}\text { TRANSPORT OF INORGANIC CATIONS ANIONS AND AMINO ACIDS } \\
\text { OLIGOPEPTIDES\%REACTOME\%R-HSA-425393.2 }\end{array}$ & \multicolumn{5}{|c|}{ OLIGOPEPTIDES\%REACTOME\%R-HSA-425393.2 } \\
\hline ION HOMEOSTASIS\%REACTOME\%R-HSA-5578775.1 & $2.64 \mathrm{E}-02$ & 1.93 & 1 & 36 & Membrane transport + ion balance \\
\hline \multicolumn{5}{|l|}{ RELEASE $71 \% 936837$} & Membrane transport + ion balance \\
\hline \multicolumn{6}{|l|}{ GO:0046889 } \\
\hline $\begin{array}{l}\text { REGULATION OF COMPLEMENT CASCADE\%REACTOME DATABASE } \\
\text { ID RELEASE } 71 \% 977606\end{array}$ & $2.70 \mathrm{E}-02$ & 1.98 & 3 & 15 & Signaling \\
\hline \multicolumn{6}{|l|}{ GO:1903018 } \\
\hline REPRODUCTIVE BEHAVIOR\%GOBP\%GO:0019098 & $2.74 \mathrm{E}-02$ & 1.99 & 2 & 26 & IR \\
\hline $\begin{array}{l}\text { INTERACTION BETWEEN L1 AND ANKYRINS\%REACTOME\%R-HSA- } \\
\quad 445095.1\end{array}$ & $2.82 \mathrm{E}-02$ & 1.95 & 3 & 17 & Miscellaneous \\
\hline RESPONSE TO COPPER ION\%GOBP\%GO:0046688 & $2.82 \mathrm{E}-02$ & 1.89 & 3 & 17 & Membrane transport + ion balance \\
\hline CELLULAR POTASSIUM ION TRANSPORT\%GOBP\%GO:0071804 & $2.83 \mathrm{E}-02$ & 2.56 & 0 & 67 & Membrane transport + ion balance \\
\hline \multicolumn{6}{|l|}{ DATABASE ID RELEASE $71 \% 6794362$} \\
\hline \multicolumn{6}{|l|}{ GO:0001676 } \\
\hline \multicolumn{5}{|l|}{ SIGNALING PATHWAY\%GOBP\%GO:0007193 } & Signaling \\
\hline PID_UPA_UPAR_PATHWAY\%MSIGDB_C2\%PID_UPA_UPAR_PATHWAY & $2.90 \mathrm{E}-02$ & 1.89 & 3 & 20 & Signaling \\
\hline RESPONSE TO ZINC ION\%GOBP\%GO:0010043 & $2.90 \mathrm{E}-02$ & 1.89 & 3 & 20 & Membrane transport + ion balance \\
\hline $\begin{array}{l}\text { POSITIVE REGULATION OF STEROID METABOLIC PROCESS\%GOBP\% } \\
\text { GO:0045940 }\end{array}$ & $2.90 \mathrm{E}-02$ & 1.87 & 3 & 20 & Metabolism \\
\hline \multicolumn{6}{|c|}{ (Continued) } \\
\hline
\end{tabular}


Table 5: Continued

\begin{tabular}{|c|c|c|c|c|c|}
\hline Pathway & $\begin{array}{l}\text { Adj. } \\
p \text { value (FDR) }\end{array}$ & $\begin{array}{l}\text { Norm. Enr. } \\
\text { score }\end{array}$ & $\begin{array}{l}\text { nMore- } \\
\text { Extreme }\end{array}$ & Size & Category \\
\hline AMINO ACID TRANSPORT\%GOBP\%GO:0006865 & $2.96 \mathrm{E}-02$ & 2.54 & 0 & 72 & Membrane transport + ion balance \\
\hline $\begin{array}{l}\text { NEGATIVE REGULATION OF CELL-SUBSTRATE ADHESION\%GOBP\% } \\
\text { GO:0010812 }\end{array}$ & $3.09 \mathrm{E}-02$ & 1.85 & 1 & 44 & Miscellaneous \\
\hline NEUROTRANSMITTER METABOLIC PROCESS\%GOBP\%GO:0042133 & $3.15 \mathrm{E}-02$ & 1.83 & 1 & 45 & Neurotransmitter/synaptic regulation \\
\hline REGULATION OF BEHAVIOR\%GOBP\%GO:0050795 & $3.15 \mathrm{E}-02$ & 1.73 & 1 & 45 & $\mathrm{IR}$ \\
\hline GLYCOSPHINGOLIPID METABOLIC PROCESS\%GOBP\%GO:0006687 & $3.23 \mathrm{E}-02$ & 1.87 & 2 & 34 & Metabolism (lipid) \\
\hline REGULATION OF ANION TRANSPORT\%GOBP\%GO:0044070 & $3.27 \mathrm{E}-02$ & 2.02 & 0 & 76 & Membrane transport + ion balance \\
\hline DRUG TRANSPORT\%GOBP\%GO:0015893 & 3.37E-02 & 2.22 & 0 & 78 & Membrane transport + ion balance \\
\hline $\begin{array}{l}\text { OTHER INTERLEUKIN SIGNALING\%REACTOME DATABASE ID } \\
\text { RELEASE } 71 \% 449836\end{array}$ & $3.58 \mathrm{E}-02$ & 1.86 & 5 & 16 & Signaling \\
\hline $\begin{array}{l}\text { BIOCARTA_EDG1_PATHWAY\%MSIGDB_C2\% } \\
\text { BIOCARTA_EDG1_PATHWAY }\end{array}$ & $3.69 \mathrm{E}-02$ & 1.88 & 4 & 24 & Signaling \\
\hline OLIGOSACCHARIDE METABOLIC PROCESS\%GOBP\%GO:0009311 & $3.81 \mathrm{E}-02$ & 1.74 & 4 & 25 & Metabolism \\
\hline $\begin{array}{l}\text { PLASMA LIPOPROTEIN PARTICLE ORGANIZATION\%GOBP\% } \\
\text { GO:0071827 }\end{array}$ & $3.81 \mathrm{E}-02$ & 1.89 & 5 & 18 & Miscellaneous \\
\hline GLIAL CELL DEVELOPMENT\%GOBP\%GO:0021782 & $3.83 \mathrm{E}-02$ & 1.84 & 0 & 86 & Gliogenesis \\
\hline REGULATION OF CELL-MATRIX ADHESION\%GOBP\%GO:0001952 & $3.83 \mathrm{E}-02$ & 1.76 & 0 & 86 & Extracellular matrix \\
\hline ACYLGLYCEROL METABOLIC PROCESS\%GOBP\%GO:0006639 & $3.87 \mathrm{E}-02$ & 1.82 & 1 & 55 & Metabolism (lipid) \\
\hline $\begin{array}{l}\text { ADENYLATE CYCLASE-MODULATING G PROTEIN-COUPLED } \\
\text { RECEPTOR SIGNALING PATHWAY\%GOBP\%GO:0007188 }\end{array}$ & $3.87 \mathrm{E}-02$ & 1.71 & 0 & 83 & Signaling \\
\hline SIGNALING BY NTRK2 (TRKB)\%REACTOME\%R-HSA-9006115.2 & $3.96 \mathrm{E}-02$ & 1.85 & 5 & 21 & Signaling \\
\hline RESPONSE TO MECHANICAL STIMULUS\%GOBP\%GO:0009612 & 4.36E-02 & 1.53 & 0 & 91 & $\mathrm{IR}$ \\
\hline MYELINATION\%GOBP\%GO:0042552 & 4.42E-02 & 1.98 & 0 & 94 & Gliogenesis \\
\hline MULTICELLULAR ORGANISMAL SIGNALING\%GOBP\%GO:0035637 & 4.43E-02 & 1.63 & 1 & 66 & Signaling \\
\hline $\begin{array}{l}\text { UNSATURATED FATTY ACID METABOLIC PROCESS\%GOBP\% } \\
\text { GO:0033559 }\end{array}$ & 4.51E-02 & 1.81 & 4 & 33 & Metabolism (lipid) \\
\hline MEMBRANE ASSEMBLY\%GOBP\%GO:0071709 & $4.58 \mathrm{E}-02$ & 1.88 & 5 & 28 & Miscellaneous \\
\hline RESPONSE TO AMINO ACID\%GOBP\%GO:0043200 & $4.58 \mathrm{E}-02$ & 1.68 & 1 & 68 & Miscellaneous \\
\hline ANION TRANSMEMBRANE TRANSPORT\%GOBP\%GO:0098656 & 4.71E-02 & 2.01 & 0 & 97 & Membrane transport + ion balance \\
\hline SYNAPSE ASSEMBLY\%GOBP\%GO:0007416 & 4.71E-02 & 1.66 & 1 & 70 & Neurotransmitter/synaptic regulation \\
\hline $\begin{array}{l}\text { ION CHANNEL TRANSPORT\%REACTOME DATABASE ID RELEASE 71\% } \\
\quad 983712\end{array}$ & $4.78 \mathrm{E}-02$ & 1.65 & 0 & 96 & Membrane transport + ion balance \\
\hline REGULATION OF CELL JUNCTION ASSEMBLY\%GOBP\%GO:1901888 & 4.94E-02 & 1.71 & 1 & 73 & Miscellaneous \\
\hline RESPONSE TO CADMIUM ION\%GOBP\%GO:0046686 & 4.96E-02 & 1.86 & 6 & 27 & Membrane transport + ion balance \\
\hline RECEPTOR-MEDIATED ENDOCYTOSIS\%GOBP\%GO:0006898 & 4.96E-02 & 1.82 & 0 & 101 & Membrane transport + ion balance \\
\hline GPCRS, OTHER\%WIKIPATHWAYS_20191210\%WP41\%MUS & 4.96E-02 & 1.79 & 6 & 27 & Signaling \\
\hline
\end{tabular}

Shown are gene sets that are positively correlated with time (increasing in the transition from embryonic RPs to adult NSCs) where FDR $<0.05$, analyzed from the combined SGZ RP/NSC dataset (a total of 885 cells, cells highlighted in blue in Fig. $3 C$ ). Also shown are the adjusted $p$ values (adj. $p$ value; FDR), enrichment scores (Norm. Enr. score), the size of the gene set and the number of times a random gene set had a more extreme enrichment score than the gene set (nMoreExtreme). Gene sets are ordered from most to least significant from top to bottom. These gene sets were also categorized with regard to a number of broad categories, including neurotransmitter transport and synaptic regulation (neurotransmitter/synaptic regulation), ion regulation and membrane transport (ion balance + membrane transport), signaling pathways (signaling), gliogenesis and metabolism and lipid oxidation (metabolism). IR indicates they were not considered relevant to the NSCs and miscellaneous includes gene sets that do not fit into these categories.

express gene sets that allow them to sense and maintain themselves in a dynamic neuronal environment and to perform lipid metabolism.

\section{Upon activation, adult SGZ NSCs reacquire a development-like state that includes re-expression of proneurogenic genes}

Previous work (Borrett et al., 2020) showed that adult VSVZ transit-amplifying cells (TAPs) exhibited an embryonic RP-like transcriptional program, implying that adult dormant NSCs reverted to an earlier developmental state when activated for cell genesis. To ask whether this was also true for adult SGZ NSCs, we performed a single-cell correlation analysis comparing dormant NSCs and their downstream activated NSC and TAP/IP progeny from the
V-SVZ and SGZ (Fig. 7A). To perform this analysis, we determined average gene expression for E16.5 nonproliferative dentate gyrus RPs and juvenile/adult SGZ NSCs (P18-P132) as a first comparator (Fig. 7A, y-axis). As a second comparator, we determined average gene expression for E14 V-SVZ RPs and juvenile/adult V-SVZ dormant NSCs (P20/34/61; Fig. 7A, $x$-axis). We then correlated these average transcriptomes with single-cell transcriptomes from the E16.5 dentate gyrus RPs, adult SGZ NSCs and adult SGZ IPs. To enable a direct comparison, we also correlated single-cell transcriptomes from the V-SVZ dataset, including E14 cortical and GE RPs, adult dormant NSCs, adult activated NSCs and adult TAPs (all as defined in Borrett et al., 2020). This analysis showed that the various RP populations were largely but not completely intermingled, confirming that they were 
A
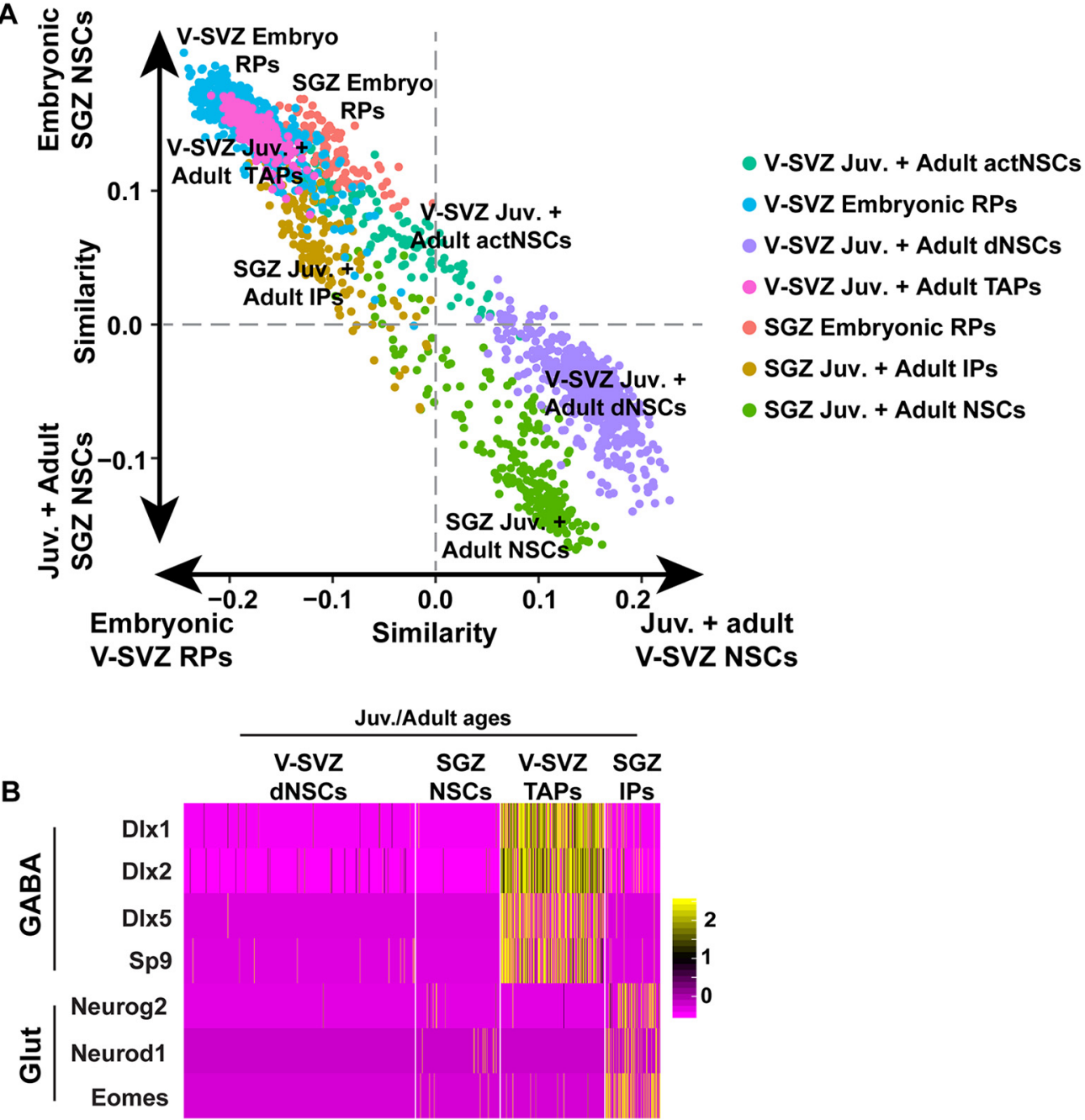

Figure 7. Upon activation, adult SGZ NSCs reacquire a development-like state that includes re-expression of proneurogenic genes. $\boldsymbol{A}$, Raw transcriptomes from the V-SVZ and SGZ NSC dataset shown in Figure $3 B$ were merged with V-SVZ activated NSCs (actNSCs) and V-SVZ TAPs from juvenile and adult ages (P20/P34/P61; as defined in Borrett et al., 2020) as well as SGZ IPs from juvenile and adult ages (P18/P19/P23/P120/P132; as shown in Fig. 1A). Scatterplot shows single-cell correlation analysis of different V-SVZ and SGZ populations (color coded by cell type and age as defined in Fig. $3 A$ ), where individual transcriptomes were each correlated with averaged gene expression for E14 V-SVZ RPs versus juvenile/adult V-SVZ dormant NSCs (P20/P34/P61; $x$-axis), and with averaged gene expression for E16.5 SGZ RPs versus juvenile/adult SGZ NSCs (P18/P19/P23/P120/P132; $y$-axis). Gene expression values are not batch-corrected. $\boldsymbol{B}$, Single-cell heatmap illustrating expression of genes involved in GABAergic and glutamatergic neurogenesis in the juvenile and adult SGZ and V-SVZ precursor populations shown in panel $\boldsymbol{A}$. Genes are color-coded for levels of expression as per the adjacent color keys. Gene expression values are not batch-corrected.

very similar to each other. Moreover, as previously published (Borrett et al., 2020), the adult V-SVZ TAPs were closely intermingled with the cortical and GE RPs. Notably, the adult SGZ IPs were closely mingled with the adult V-SVZ activated NSCs and were more highly correlated to embryonic RPs than to adult SGZ or V-SVZ dormant NSCs.

These data suggest that dormant SGZ and V-SVZ adult NSCs reacquire a development-like state when activated. We asked whether this was also true with regard to neurogenesis by examining genes associated with GABAergic (D/x1,D/x2, D/x5, Sp9) and glutamatergic (Neurog2, Neurod1, Eomes) neurogenesis. We analyzed expression of these proneurogenic mRNAs in adult dormant SGZ and V-SVZ NSCs and in their TAP progeny, TAPs and IPs (the same adult transcriptomes included in Fig. 7A; V-SVZ activated NSCs at juvenile and adult ages were not included in this analysis). This analysis, shown as a single-cell heatmap (Fig. 7B) demonstrated that the proneurogenic mRNAs were detectably expressed in few of the dormant NSCs. However, many of the V-SVZ TAPs detectably expressed the GABAergic but not glutamatergic mRNAs, while many of the SGZ IPs expressed the glutamatergic but not GABAergic mRNAs. Thus, dormant postnatal V-SVZ and SGZ NSCs are not apparently transcriptionally primed for generating specific types of neurons. Instead, this proneurogenic priming, which 
is also observed in embryonic RPs (Fig. 5B-D), apparently only occurs in their downstream activated progeny.

\section{Identification of shared genes that are selectively increased in dormant adult NSCs}

These findings support a model where V-SVZ and SGZ precursors share many commonalities with regard to their transcriptional identity, developmental progression to dormancy and subsequent activation to make adult-born progeny. To further define their shared adult transcriptional state, we analyzed SGZ NSCs for mRNAs that were upregulated developmentally from embryogenesis to adulthood but then downregulated in activated adult IPs (Table 6). Notably, of 105 SGZ NSC mRNAs that fulfilled these criteria, 94 (90\%) were also identified in a previous similar analysis of $\mathrm{V}-\mathrm{SVZ}$ NSCs (Borrett et al., 2020). A single-cell heatmap confirmed that all 94 mRNAs were upregulated in V-SVZ and SGZ NSCs as they transitioned to dormancy postnatally and were then downregulated in the activated TAPs/IPs (Fig. 8A). Many of these genes were involved in sensing and responding to the adult niche environment, including genes for transport and buffering of neurotransmitters and ions, and for cell:cell and cell: extracellular matrix interactions (see Table 7 for functional annotations). They also included genes important for protecting these long-lived cells from adverse environmental events, such as genes involved in detoxification and lysosome function, as well as many genes involved in lipid metabolism. Examples include mRNAs encoding the sodium-potassium ATPase subunit Atp1a2 and the secreted inhibitor of cysteine proteases Cst3 (Fig. 8B). Notably, three of the 94 mRNAs encode proteins that functionally interact with the GABA neurotransmitter. These include the two GABA transporter mRNAs S/c6a11 and S/c6a1 and the GABA-A receptor subunit mRNA Gabrb1 (Fig. 8C). These findings reinforce the idea that adult dormant NSCs are specialized for sensing and regulating their niche environments, and suggest that NSCs of both origins may alter their responses to GABA as they progress to a dormant state.

We asked whether this group of differentially-enriched genes would specifically identify adult dormant NSCs. To do this, we combined transcriptomes for all V-SVZ and SGZ NSC populations with those of the adult IPs/TAPs, removed the cell cycle genes, and then ran them through the Harmony batch-corrected pipeline together. UMAP visualization identified four main groups of transcriptomes that were segregated by developmental stage and/or activation state; embryonic RPs, perinatal NSCs, juvenile/ adult NSCs, and IPs/TAPs (Fig. 9A-D). Each group included cells of both V-SVZ and SGZ origin that were closely-associated, but only partially intermingled, consistent with the conclusion that they were very similar but not identical. We then used the 94 enriched dormant NSC genes (Table 7) to compute single-cell gene signature scores for these transcriptomes. This gene signature was very specific to the dormant NSCs from P6/7 through to adulthood (Fig. 9E,F).

These gene enrichment studies provide insights into the common transcriptional ground-state of dormant postnatal NSCs. However, further analysis showed that, with the exception of Riiad1, all of the mRNAs in this enriched dataset were also expressed by niche astrocytes (Table 7). We therefore asked whether we could combine the dormant NSC signature with the astrocyte gene signature (Fig. 1G) to specifically identify dormant adult NSCs in the V-SVZ and SGZ. To do this, we overlaid both gene signatures on the complete dentate gyrus dataset (shown in Fig. $1 A$ ) and on the juvenile/adult V-SVZ neural cell dataset (shown in Fig. 2E), as visualized by UMAPs. As predicted, in both the SGZ and V-SVZ datasets the adult dormant NSCs were identified by the NSC but not the astrocyte gene signature, while the niche astrocytes were positive for both (Fig. 10A-D). These findings provide a way to definitively identify dormant adult NSCs in the VSVZ and SGZ from other niche cell types and reinforce the conclusion that while adult dormant NSCs and niche astrocytes are very similar they can be distinguished transcriptionally.

\section{Discussion}

Analyses presented here provide insights into the identity and genesis of the two best-characterized NSC populations in the mammalian brain, forebrain V-SVZ NSCs that generate inhibitory $\mathrm{OB}$ interneurons and hippocampal SGZ NSCs that make excitatory dentate granule neurons. Our analyses support the conclusion that while these two NSC populations are not transcriptionally identical to each other, they are nonetheless very similar and share a common dormant adult NSC transcriptional ground state. Moreover, the transcriptional similarities between these two populations are seen throughout their lifespans, commencing when they are embryonic RP populations residing in adjacent regions around the lateral ventricle and being maintained as they progress over an extended postnatal period to become dormant adult NSCs. These findings are particularly important in light of previous work showing that transplantation of embryonic or postnatal NSCs from one niche to the other or one time point to the other is apparently sufficient for them to start making cells appropriate to their new environment (Fishell, 1995; Suhonen et al., 1996; Hitoshi et al., 2002; Sequerra et al., 2010). Our own computational analyses together with these previous transplant studies provide support for a model where V-SVZ and SGZ NSCs share a common ground state and where the cellular progeny they generate may be largely determined by their niche environment. While this model requires further experimental validation, it has important implications for attempts to regulate and environmentally reprogram endogenous cell genesis as a therapeutic strategy.

One of the key findings described here involves the NSC transition into and out of a dormant adult state. With regard to the developmental transition to dormancy, our analyses here build on previous work by Borrett et al. 
Table 6: Identification of a shared NSC gene signature enriched in juvenile/adult SGZ NSCs relative to embryonic SGZ RPs and juvenile/adult SGZ IPs (related to Fig. 8-10)

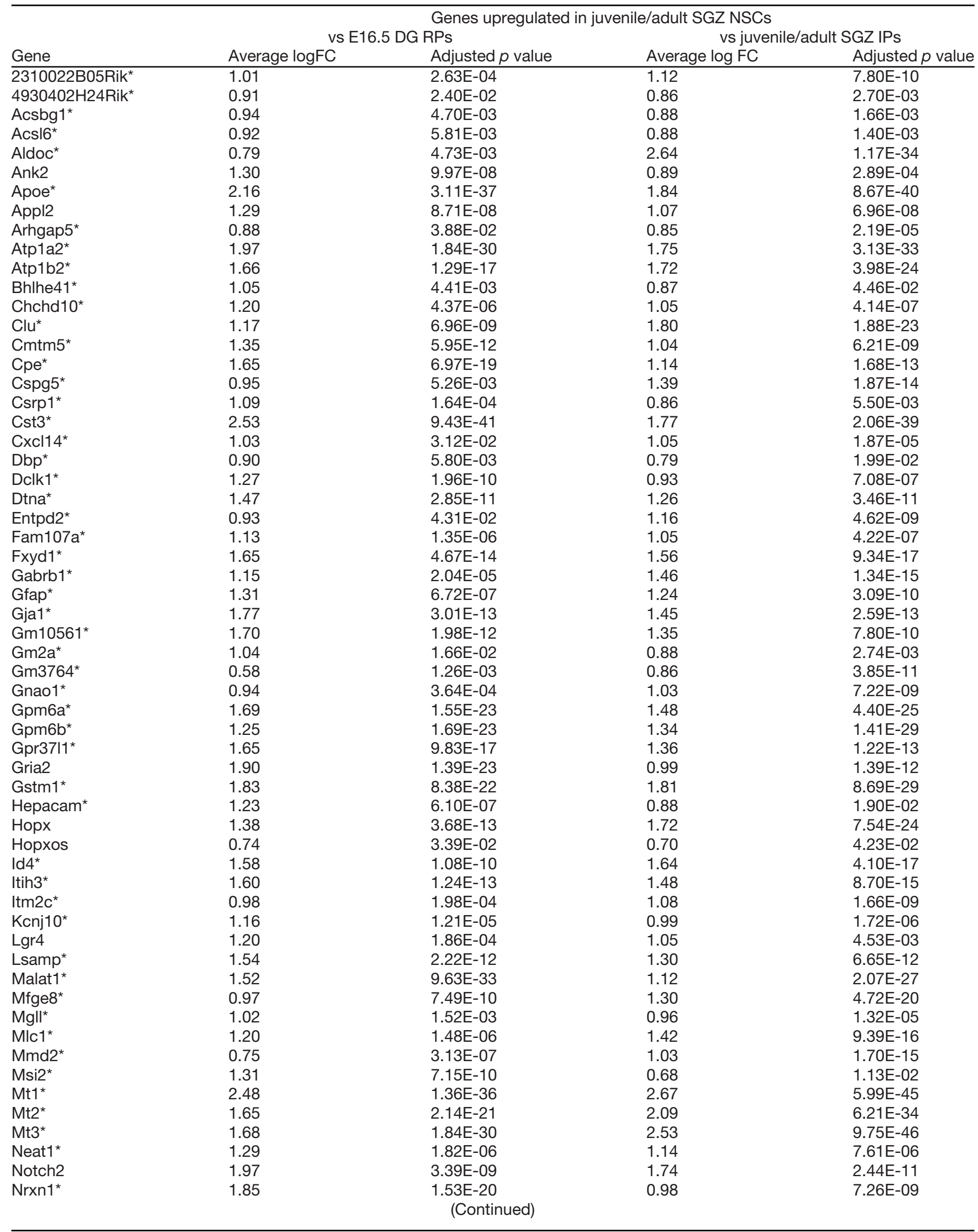


Table 6: Continued

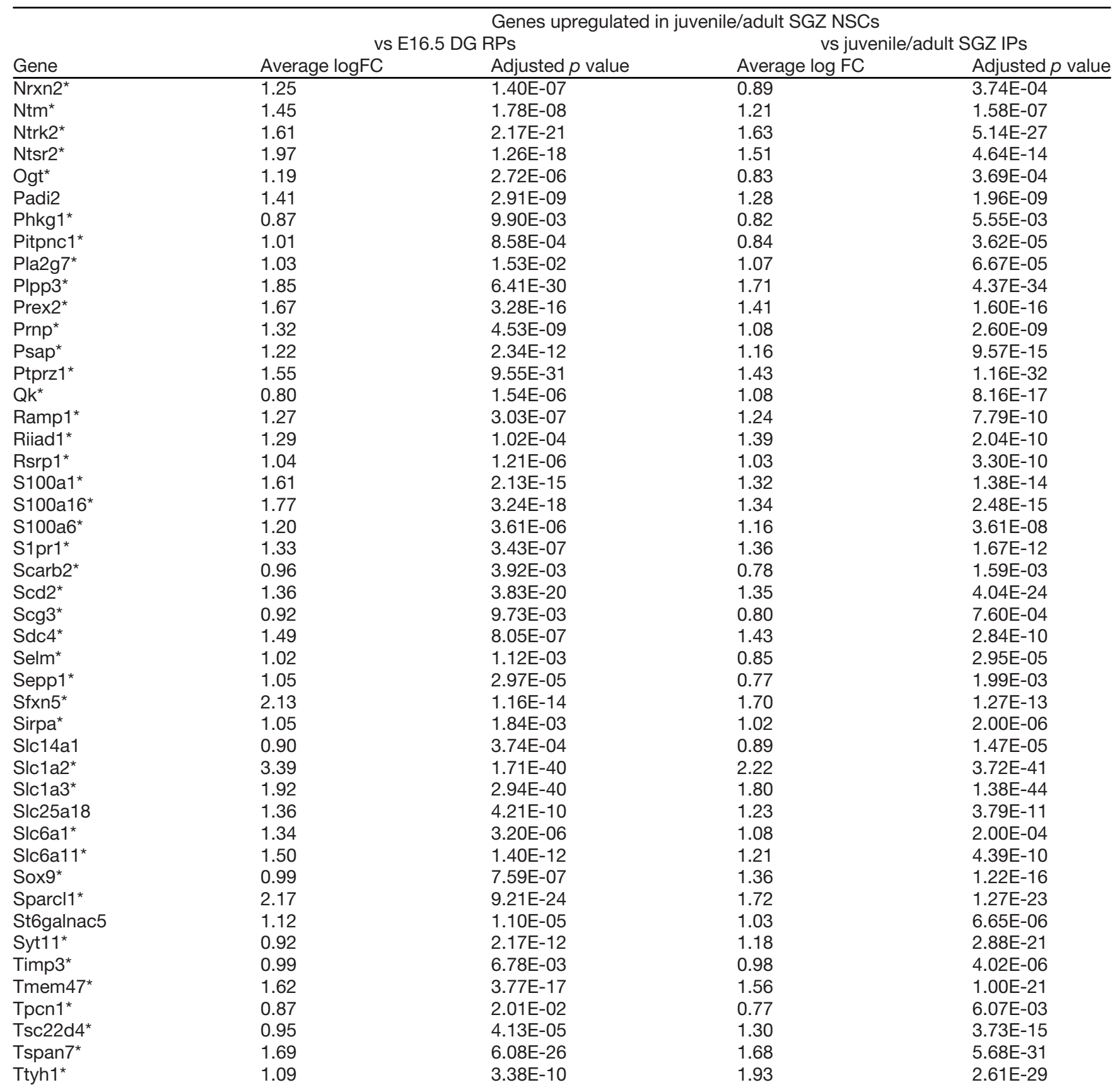

Differential gene expression was performed for (1) juvenile/adult SGZ NSCs (P18-P132; blue cells in two final right panels in Fig. 3C) versus E16.5 SGZ RPs (blue cells in left panel in Fig. 3C) and (2) juvenile/adult SGZ NSCs versus juvenile/adult SGZ IPs (P18-P132; 139 cells). This analysis identified 105 genes that were significantly enriched in juvenile/adult SGZ NSCs relative to both E16.5 SGZ RPs and juvenile/adult SGZ IPS (log fold change > 0.5, adj. $p$ value < 0.05; FWER). These 105 genes are shown along with their fold change in expression and adjusted $p$ values. Also indicated with an asterisk are 94 of these genes that were also enriched in juvenile/adult V-SVZ dormant NSCs relative to E14 V-SVZ RPs and juvenile/adult V-SVZ TAPs, as identified in Borrett et al. (2020). These 94 genes were used to define a shared adult dormant NSC gene signature. Analysis using this 94 gene signature is described in Figures 8-10.

(2020) and demonstrate that V-SVZ and SGZ NSCs share a similar, temporally aligned trajectory of transcriptional shut-down. In the V-SVZ this transition to dormancy is a prolonged process that commences during late embryogenesis and extends into the third postnatal week, with the early postnatal NSCs displaying an intermediary transcriptional state (Borrett et al., 2020). Our analyses here indicate that the transition occurs over a similar timeframe in the SGZ, with early postnatal hippocampal NSCs in a transition state, and near complete acquisition of the adult dormant state occurring by the third postnatal week. What then is the dormant forebrain NSC state? For adult V-SVZ and SGZ NSCs, this dormancy state predominantly involves a downregulation 


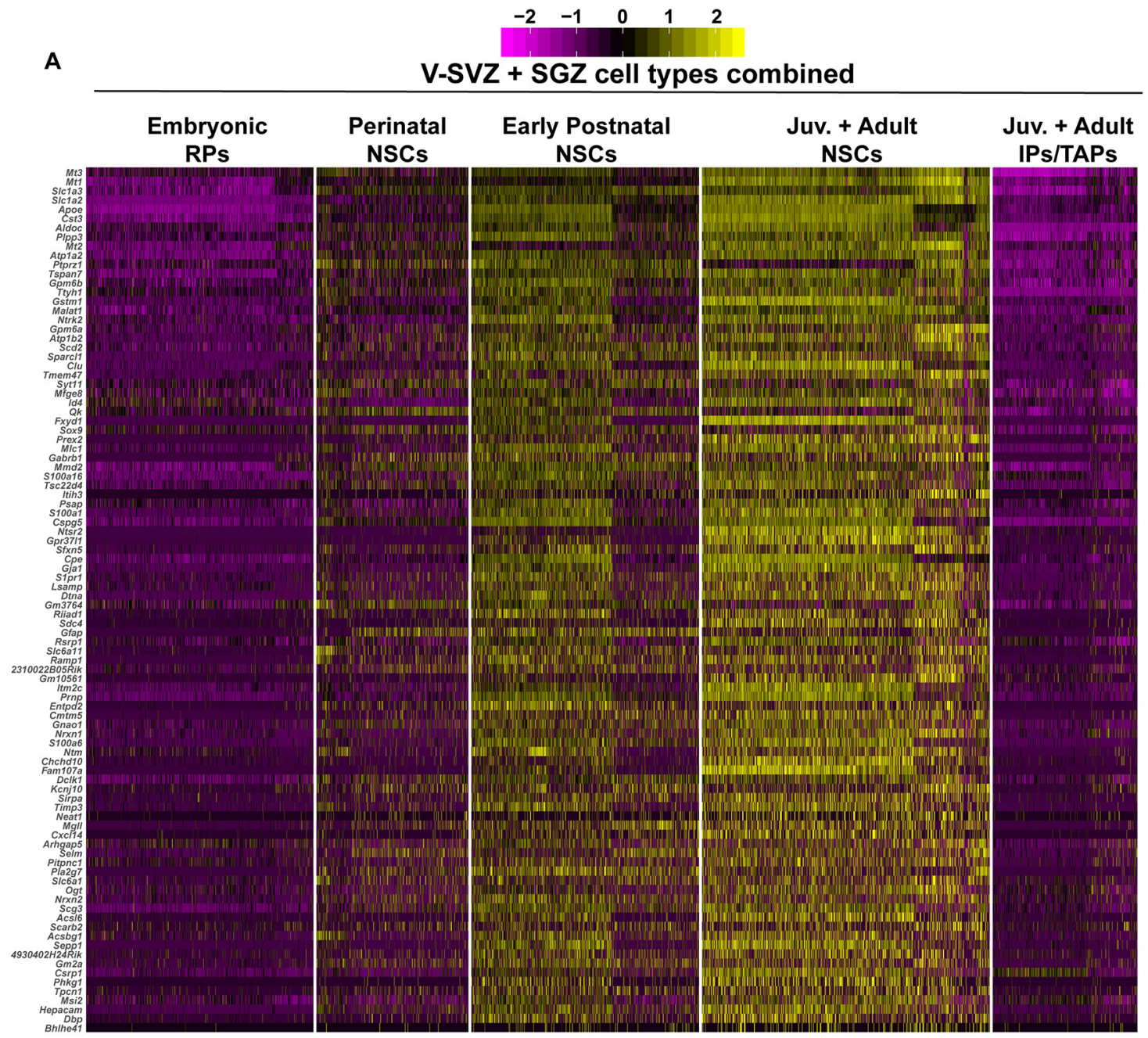

B
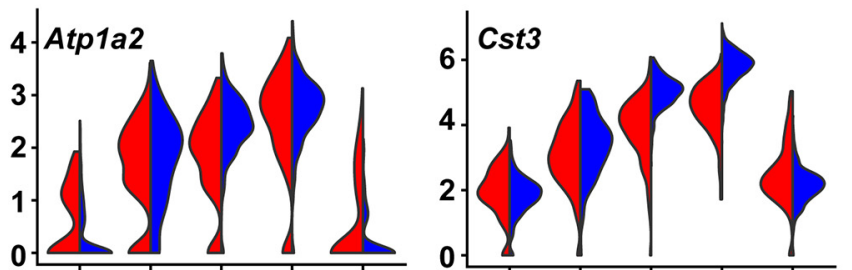

V-SVZ

SGZ

C
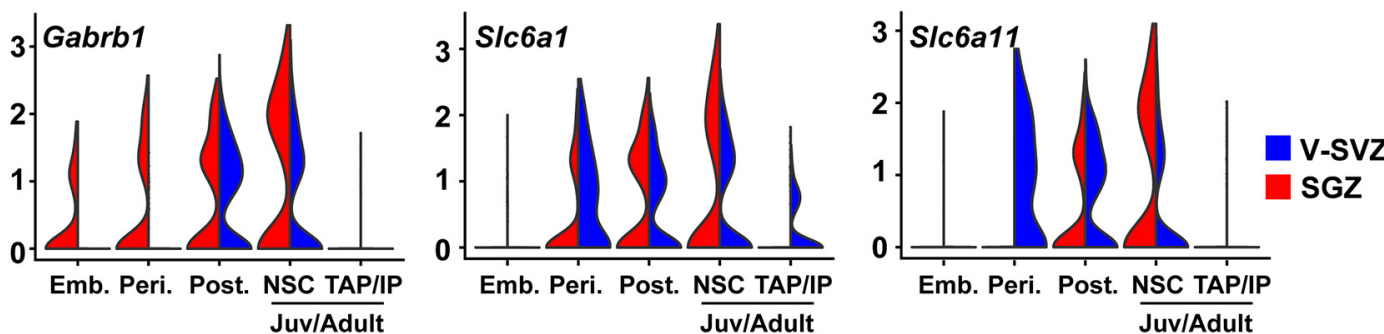

Figure 8. Identification of shared genes selectively enriched in dormant adult NSCs. $\boldsymbol{A}$, Single-cell heatmap showing the expression profiles of 94 genes selectively enriched in juvenile/adult V-SVZ and SGZ NSCs relative to embryonic NSCs and juvenile/adult V-SVZ transit-amplifying cells (TAPs) and SGZ IPs (same dataset as in Fig. 7A without the activated juvenile/adult V-SVZ NSCs). Each column line represents the level of expression in a single cell. Gene expression represents scaled expression and is color-coded as per the adjacent color key, where pink/purple represents no or low expression, and yellow the highest expression. Gene expression values are not batch-corrected. $\boldsymbol{B}$, Violin plots showing gene expression profiles of two selected mRNAs from $\boldsymbol{A}$, Atp1a2 and Cst3, in the same populations as shown in $\boldsymbol{A}$. SGZ expression profiles are shown in red and V-SVZ profiles in blue. Gene expression values are not batch-corrected. $\boldsymbol{C}$, Violin plots showing gene expression profiles of three selected mRNAs from A, Gabrb1, S/c6a1, and Slc6a11, all of which are involved with NSC responsiveness to GABA. Gene expression values are not batch-corrected. 
Table 7: Categorization and expression of the shared adult dormant NSC signature genes in juvenile/adult V-SVZ and SGZ NSCs and astrocytes (related to Fig. 8-10)

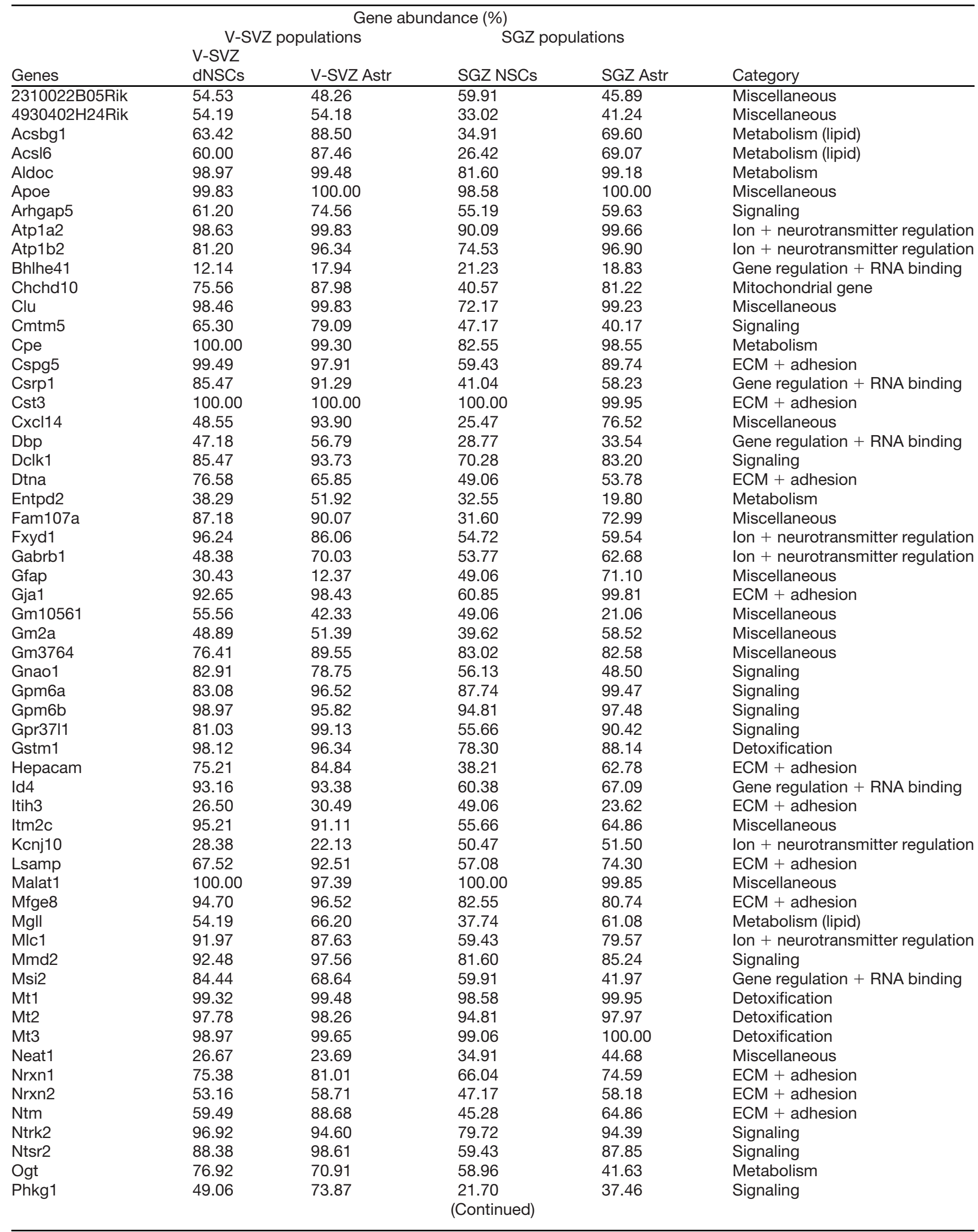


Table 7: Continued

\begin{tabular}{|c|c|c|c|c|c|}
\hline \multirow[b]{3}{*}{ Genes } & \multicolumn{4}{|c|}{ Gene abundance (\%) } & \multirow[b]{3}{*}{ Category } \\
\hline & \multicolumn{2}{|c|}{ V-SVZ populations } & \multicolumn{2}{|c|}{ SGZ populations } & \\
\hline & dNSCs & V-SVZ Astr & SGZ NSCs & SGZ Astr & \\
\hline Pla2g7 & 43.76 & 86.24 & 33.96 & 73.23 & Metabolism (lipid) \\
\hline Plpp3 & 98.29 & 98.78 & 92.45 & 98.69 & $\mathrm{ECM}+$ adhesion \\
\hline Prex2 & 68.89 & 77.18 & 60.85 & 62.00 & Signaling \\
\hline Ptprz1 & 85.13 & 93.38 & 96.70 & 94.29 & Signaling \\
\hline Qk & 76.92 & 70.56 & 83.02 & 92.21 & Gene regulation + RNA binding \\
\hline Ramp1 & 57.26 & 75.09 & 41.98 & 43.76 & Signaling \\
\hline Riiad1 & 50.09 & 11.15 & 41.98 & 3.19 & Signaling \\
\hline Rsrp1 & 95.73 & 90.77 & 69.34 & 70.04 & Miscellaneous \\
\hline S100a1 & 86.84 & 80.14 & 60.85 & 71.10 & Ion + neurotransmitter regulation \\
\hline Scd2 & 92.65 & 78.92 & 88.68 & 96.85 & Metabolism (lipid) \\
\hline $\operatorname{Scg} 3$ & 86.32 & 95.47 & 50.47 & 81.99 & Miscellaneous \\
\hline Sdc4 & 59.66 & 67.07 & 45.28 & 73.86 & $\mathrm{ECM}+$ adhesion \\
\hline Selm & 66.32 & 44.60 & 54.25 & 42.55 & Miscellaneous \\
\hline Sepp1 & 80.68 & 95.64 & 33.96 & 84.27 & Detoxification \\
\hline Sfxn5 & 65.64 & 58.71 & 64.15 & 67.42 & Ion + neurotransmitter regulation \\
\hline Sirpa & 60.17 & 46.34 & 34.91 & 47.53 & Signaling \\
\hline Slc1a2 & 99.32 & 99.48 & 96.23 & 100.00 & lon + neurotransmitter regulation \\
\hline Slc1a3 & 98.12 & 99.13 & 99.06 & 99.56 & Ion + neurotransmitter regulation \\
\hline Slc6a1 & 48.72 & 74.04 & 44.81 & 77.44 & lon + neurotransmitter regulation \\
\hline Slc6a11 & 35.21 & 62.89 & 47.64 & 76.86 & lon + neurotransmitter regulation \\
\hline Sox9 & 75.21 & 64.81 & 73.58 & 76.23 & Gene regulation + RNA binding \\
\hline Sparcl1 & 76.75 & 99.65 & 71.70 & 97.10 & $\mathrm{ECM}+$ adhesion \\
\hline
\end{tabular}

Shown are the 94 shared adult dormant NSC genes, and the relative proportions of juvenile/adult V-SVZ and SGZ NSCs and astrocytes that detectably express these genes. The astrocytes in this analysis included the green cells in Figures $1 B$ (SGZ) and 2E (V-SVZ). The shared genes were also categorized with regard to a number of broad cellular processes including metabolism, cell signaling, ion and neurotransmitter regulation, cell adhesion and the extracellular matrix (ECM), gene regulation and RNA binding, and detoxification.

of basic cellular processes such as those required for DNA replication and transcription, RNA processing and translation, ribosome biogenesis, and protein synthesis and folding, in good agreement with what has been described in other studies (Llorens-Bobadilla et al., 2015; Shin et al., 2015; Dulken et al., 2017; Berg et al., 2019; Xie et al., 2020). However, the dormant NSC state involves more than just this shut-down. The gene set enrichment analyses presented here and in Borrett et al. (2020) show that it also includes upregulation of transcriptional programs involved in sensing the niche environment, including membrane transport, ion balance regulation, neurotransmitter regulation, and cell surface receptor signaling. Intriguingly, our comparison of adult dormant NSCs with TAP/IPs demonstrated that many of these same genes are turned-off again when dormant NSCs are reactivated to generate their adult-born progeny. Intriguingly, at least some of these genes and processes are important for the maintenance of adult quiescent-like NSCs (Zhou et al., 2018; Obernier and Alvarez-Buylla, 2019; Kjell et al., 2020). Thus, dormancy is normally thought of as a "silent" stem cell state, but our analyses suggest that while adult NSCs are metabolically quiet, they are nonetheless actively monitoring and responding to their niche environments as previously suggested (Shin et al., 2015).

Our studies emphasize commonalities between SGZ and V-SVZ NSCs, but these are clearly distinct stem cell populations that make different types of neurons. Do our analyses provide insights into this differential neurogenesis? In the postnatal brain, V-SVZ NSCs make GABAergic interneurons, but they derive, in part, from cortical RPs that make excitatory glutamatergic neurons during 

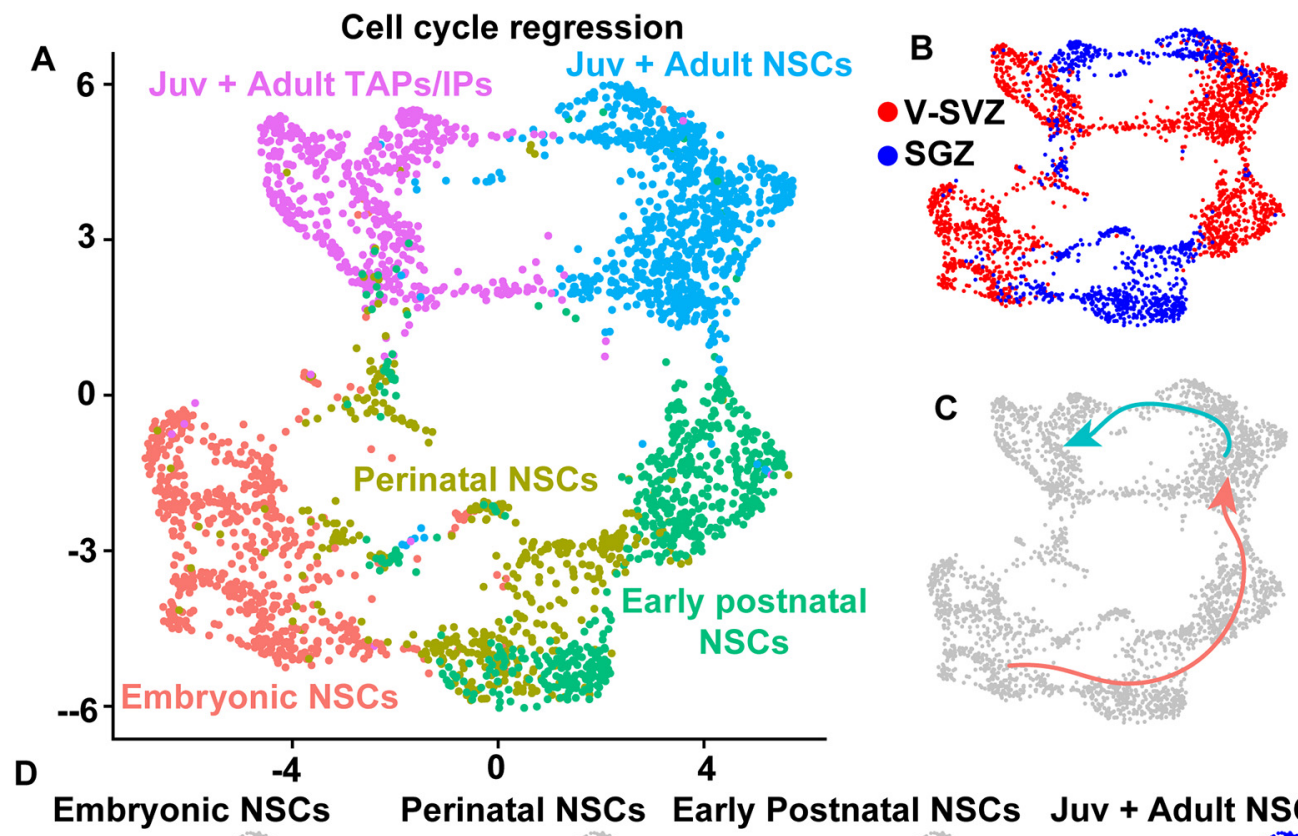

\section{Forebrain dormant NSC state acquisition}

\section{Forebrain dormant NSC} activation
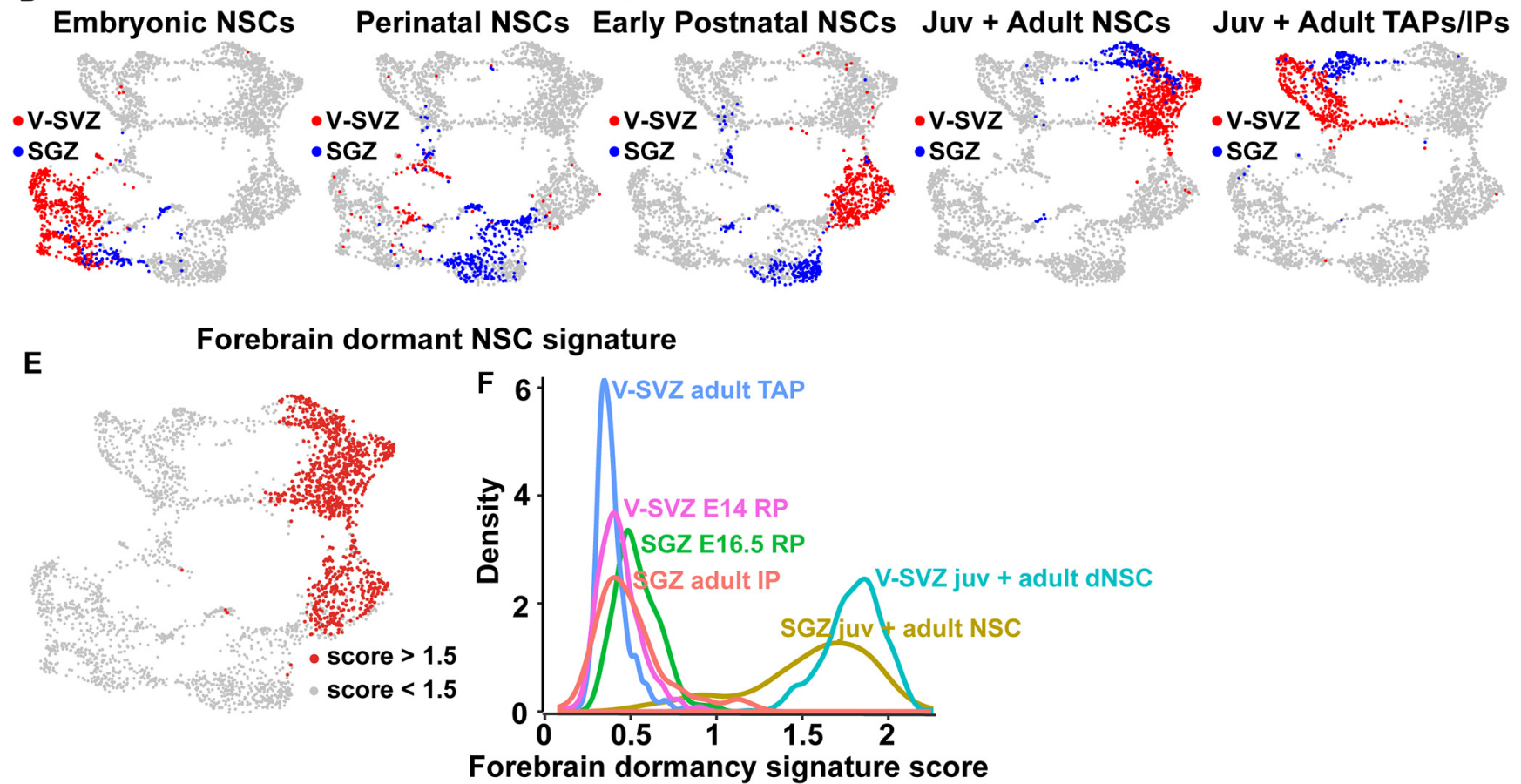

Figure 9. Identification of a shared adult dormant NSC gene signature. $\boldsymbol{A}$, Transcriptomes of embryonic, perinatal, early postnatal, juvenile and adult V-SVZ and SGZ NSCs were combined with those of juvenile and adult V-SVZ and SGZ TAPS/IPS (same dataset as shown in Fig. 7A), cell cycle genes were regressed, and the dataset was run through the batch-corrected pipeline. Shown is a UMAP visualization where cells are color-coded and labeled based on cell type. Note here that the Juv + Adult TAPs/IPs group shown in purple include V-SVZ activated NSCs at juvenile and adult ages. $\boldsymbol{B}$, UMAP plot as in $\boldsymbol{A}$ with cells color coded based on region of origin (V-SVZ or SGZ). C, UMAP plot as in $\boldsymbol{A}$ annotated to depict two distinct trajectories. The first trajectory describes the progression from embryonic RP to adult NSC in the V-SVZ and SGZ (pink). The second trajectory describes the progression from dormant juvenile/adult NSCs to activated, differentiating TAPS/IPs (light blue). $\boldsymbol{D}$, UMAP visualizations as in $\boldsymbol{A}$ overlaid with V-SVZ and SGZ cell types from different ages, as defined in Figure $3 A$. V-SVZ cells are shown in red and SGZ cells in blue. $\boldsymbol{E}$, UMAP as in $\boldsymbol{A}$ overlaid with gene expression scores for a shared adult dormant NSC signature consisting of the 94 genes shown in the heatmap in Figure $8 A$ and in Table 7. Red denotes cells with scores $>1.5$. F, Density plot showing the distribution of the shared adult dormant NSC signature scores in V-SVZ juvenile/adult TAPs (P20/P34/P61; blue), SGZ juvenile/adult IPs (P18/P19/P23/P120/P132; orange), V-SVZ E14 RPs (pink), E16.5 SGZ RPs (green), V-SVZ juvenile/adult dormant NSCs (dNSCs; turquoise), and juvenile/adult SGZ NSCs (yellow). 
Embryonic to Adult Dentate Gyrus

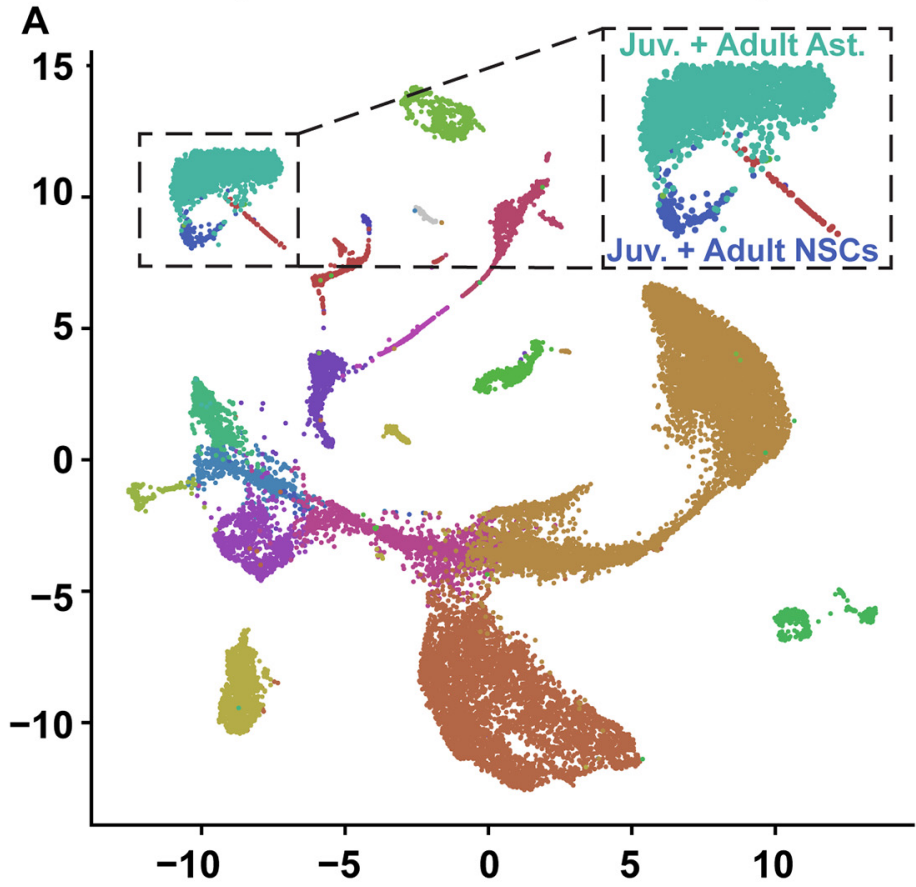

B

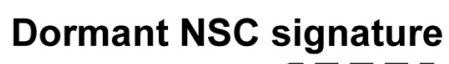

Dormant NSC signature

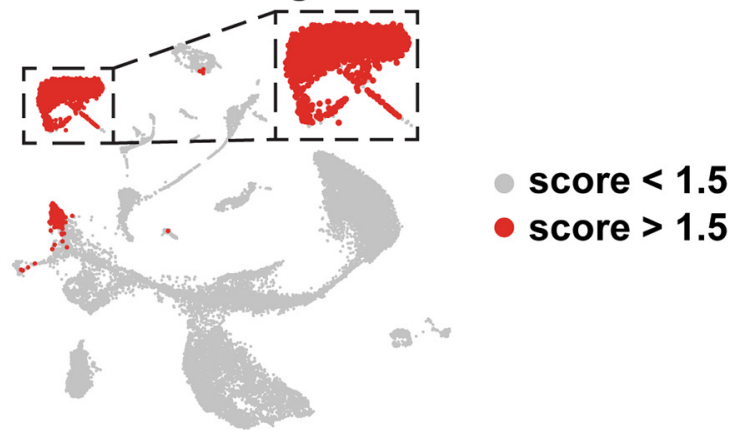

\section{Astrocyte signature}

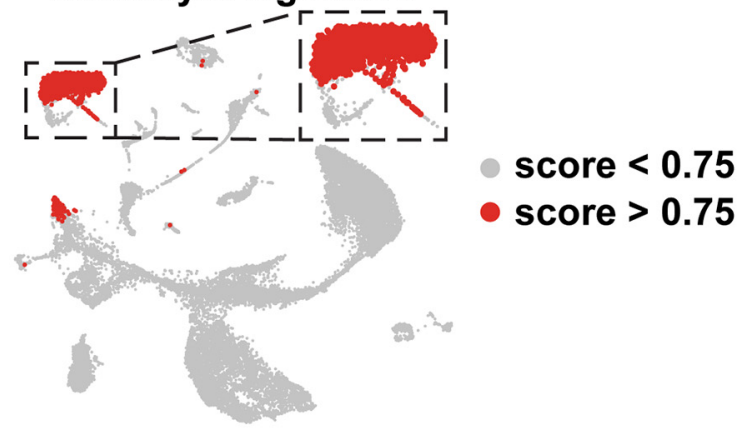

D Dormant NSC signature
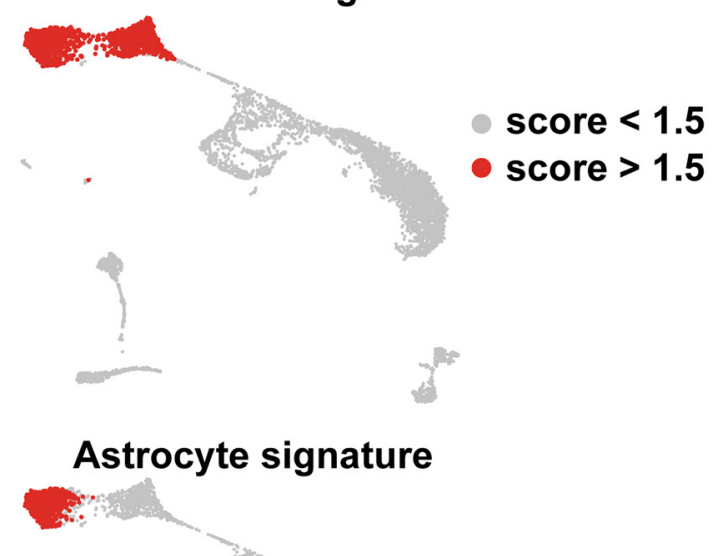

score $<0.75$

score $>0.75$

\section{Juvenile + Adult V-SVZ neural cell types}
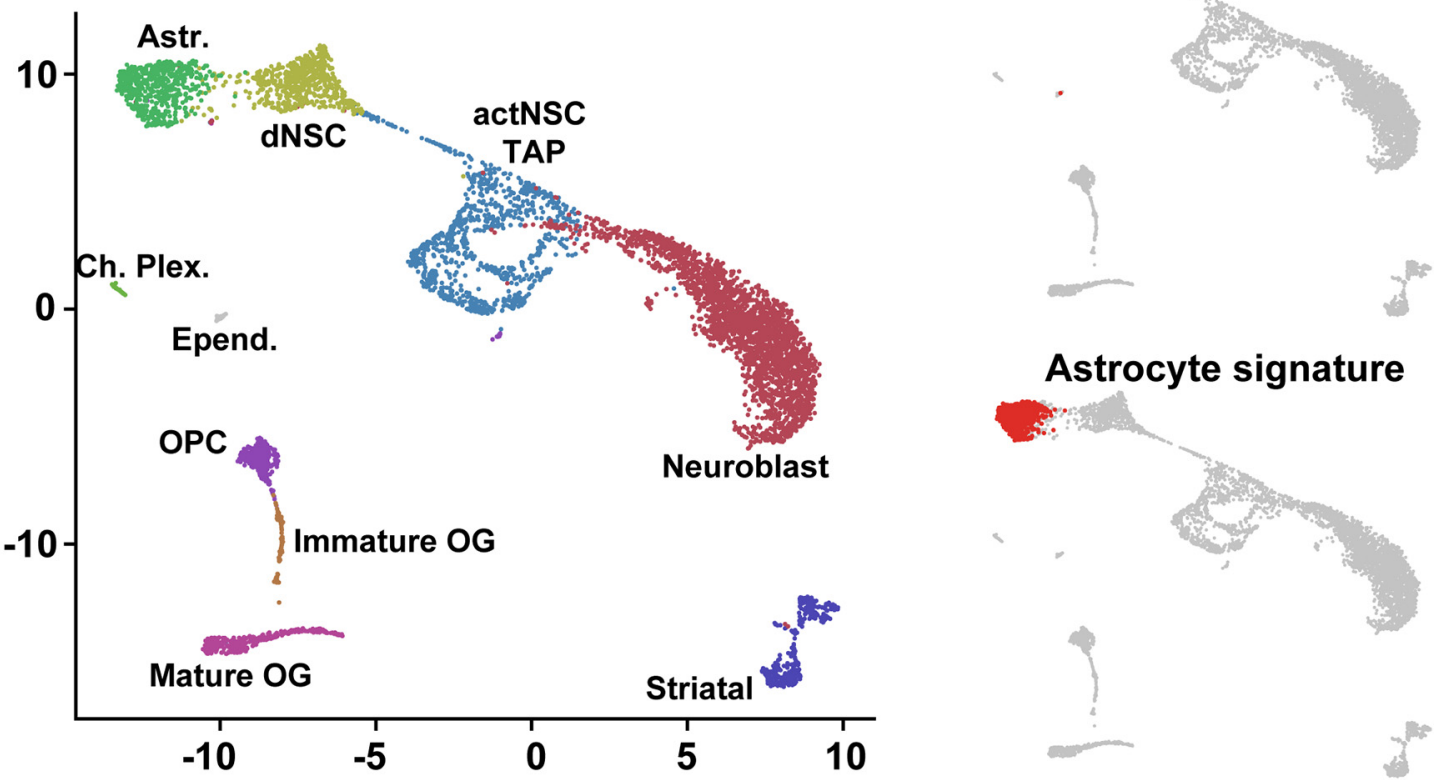

Figure 10. Analysis of the shared adult dormant NSC gene signature in all V-SVZ and SGZ cells. $\boldsymbol{A}, \boldsymbol{B}$, UMAP visualization of dentate gyrus cells as in Figure $1 A$ overlaid with expression scores for two different gene signatures, the shared 94 gene dormant adult NSC signature (panel $\boldsymbol{B}$, top) and the shared 26 gene niche astrocyte signature (panel $\boldsymbol{B}$, bottom). The region shown in the hatched boxes includes juvenile/adult astrocytes and NSCs as identified in Figure $1 B$ and is shown at a larger size to the right in each case. Red denotes cells with scores $>1.5$ (top) or 0.75 (bottom). Data are not batch-corrected. $\boldsymbol{C}, \boldsymbol{D}$, Annotated UMAP visualization of juvenile/adult V-SVZ neural cells (P20, P34, P61 combined) as shown in Figure 2E, overlaid with expression scores for two different gene signatures, the shared 94 gene dormant NSC signature (panel $\boldsymbol{D}$, top) and the shared 26 gene niche astrocyte signature (panel $D$, bottom). Red denotes cells with scores $>1.5$ (top) or 0.75 (bottom). Data are not batch-corrected. 
embrogenesis (Kohwi et al., 2007; Ventura and Goldman, 2007; Fuentealba et al., 2015; Borrett et al., 2020; Zhang et al., 2020). These cortical RPs are located immediately adjacent to the dentate neuroepithelial RP parents of SGZ NSCs that make excitatory granule neurons. By contrast, most V-SVZ NSCs derive from subpallial GE RPs that make GABAergic neurons throughout life. Somewhat surprisingly, despite these differences in neurogenesis, our analyses, together with those previously published in Borrett et al. (2020), indicate that all three embryonic RP populations are very similar. Nonetheless, they are not identical, and both cortical and dentate neuroepithelial RPs are highly enriched for a small group of genes important for their pallial identity and embryonic excitatory neurogenesis. Conversely, the GE RPs are instead enriched for genes that are associated, in part, with a subpallial identity and GABAergic neurogenesis. Thus, a small cohort of genes is apparently sufficient to drive functional differences in embryonic neurogenesis.

Data presented here indicate, however, that the situation is different in the postnatal brain. Specifically, data presented here and in Borrett et al. (2020) show that postnatal dormant V-SVZ and SGZ NSCs do maintain a transcriptional memory of their embryonic origin, but also show that they do not detectably express proneurogenic genes. Instead, these genes become re-expressed when dormant NSCs are reactivated. Thus, while embryonic RPs are transcriptionally-primed to make the appropriate types of neurons (for example, see Zahr et al., 2018), dormant postnatal NSCs are apparently in an unbiased transcriptional state. A key question, then, is whether this means that postnatal NSCs are malleable with regard to the types of neurons they can generate. This possibility is suggested by the aforementioned transplant studies (Suhonen et al., 1996; Sequerra et al., 2010), by a number of developmental studies showing flexibility in GABAergic versus glutamatergic neurogenesis in embryonic forebrain precursors depending on their local environment (Machon et al., 2005; Willaime-Morawek et al., 2006; Azim et al., 2014; Zhang et al., 2020), and by previous work demonstrating adult genesis of neurons other than GABAergic OB neurons and dentate gyrus granule cells following injury (Magavi et al., 2000; Nakatomi et al., 2002; Chen et al., 2004; Brill et al., 2009). However, it is also possible that dormant NSCs maintain a neurogenic memory at the chromatin level and that, like many other facets of their cell biology, this transcription is silenced during dormancy. Definitively distinguishing these alternatives will require further experimentation.

Our analyses also indicate that, as seen for V-SVZ NSCs (Borrett et al., 2020), SGZ NSCs acquire a global development-like transcriptional state when they are reactivated to make adult-born neurons. In both cases the transition from a dormant to an active NSC involves an increase in metabolic genes/processes associated with an active, ultimately proliferative cell state, induction of gene sets associated with translation and adult cell genesis, and a coincident transcriptional shut-down of dormancyassociated genes. This recapitulation of a developmental state supports the idea that embryonic RPs and adult
NSCs may be similar cells that are simply in different states of activation. Notably, one prediction of this model is that cues known to regulate embryonic RPs might have the same effect on adult NSCs, although this relatively straightforward prediction is somewhat complicated by the fact that niche environments differ and signaling is context-dependent.

One final conclusion involves the transcriptional commonalities between adult dormant NSCs and niche astrocytes. Analyses here and in Borrett et al. (2020) show that these two cell types can be readily distinguished on a transcriptional level. However, almost all of the genes enriched in adult dormant NSCs relative to developing and reactivated precursors were also enriched in astrocytes. What is the explanation for this latter finding? One previously-described hypothesis is that astrocytes may possess latent precursor-like properties. In support of this concept, it has previously been shown that parenchymal astrocytes can acquire a neurogenic potential following genetic or environmental alterations. For example, astrocytes can be reprogrammed to make neurons following overexpression of neuronal specifiers such as NeuroD, Ascl1, and Neurog2 (Guo et al., 2014; Liu et al., 2015; Gascón et al., 2016). Moreover, blocking Notch signaling in parenchymal astrocytes following cortical injury is sufficient to induce a neurogenic program that resembles V-SVZ neurogenesis (Zamboni et al., 2020). A second hypothesis comes from our observation that most of the shared astrocyte/dormant NSC genes are involved in cell adhesion, the extracellular matrix, and ion and neurotransmitter sensing and regulation. Thus, we posit that perhaps astrocytes and dormant NSCs share a requirement for adhering within their niches, and then sensing, detoxifying and responding to those environments in unique ways. Perhaps, as has been suggested for astrocytes in the gray matter (Freeman and Rowitch, 2013), dormant NSCs must act to ensure that the V-SVZ and SGZ niches are favorable environments for their newborn neuroblast progeny. While this is not a function normally ascribed to NSCs, it might in part explain the degradation of these two niches that occurs when NSCs become depleted during aging (Conover and Shook, 2011).

\section{References}

Azim K, Fischer B, Hurtado-Chong A, Draganova K, Cantù C, Zemke M, Sommer L, Butt A, Raineteau O (2014) Persistent Wnt/ $\beta$-catenin signaling determines dorsalization of the postnatal subventricular zone and neural stem cell specification into oligodendrocytes and glutamatergic neurons. Stem Cells 32:1301-1312.

Berg DA, Bond AM, Ming G, Song H (2018) Radial glial cells in the adult dentate gyrus: what are they and where do they come from? F1000Res 7:277.

Berg DA, Su Y, Jimenez-Cyrus D, Patel A, Huang N, Morizet D, Lee S, Shah R, Ringeling FR, Jain R, Epstein JA, Wu Q, Canzar S, Ming G, Song H, Bond AM (2019) A common embryonic origin of stem cells drives developmental and adult neurogenesis. Cell 177:654668.e15.

Bonaguidi MA, Wheeler MA, Shapiro JS, Stadel RP, Sun GJ, Ming G, Song $H$ (2011) In vivo clonal analysis reveals self-renewing and multipotent adult neural stem cell characteristics. Cell 145:11421155. 
Borrett MJ, Innes BT, Jeong D, Tahmasian N, Storer MA, Bader GD, Kaplan DR, Miller FD (2020) Single-cell profiling shows murine forebrain neural stem cells reacquire a developmental state when activated for adult neurogenesis. Cell Rep 32:108022.

Brandt MD, Jessberger S, Steiner B, Kronenberg G, Reuter K, BickSander A, von der Behrens W, Kempermann G (2003) Transient calretinin expression defines early postmitotic step of neuronal differentiation in adult hippocampal neurogenesis of mice. Mol Cell Neurosci 24:603-613.

Brill MS, Ninkovic J, Winpenny E, Hodge RD, Ozen I, Yang R, Lepier A, Gascón S, Erdelyi F, Szabo G, Parras C, Guillemot F, Frotscher M, Berninger B, Hevner RF, Raineteau O, Götz M (2009) Adult generation of glutamatergic olfactory bulb interneurons. Nat Neurosci 12:1524-1533.

Carr MJ, Toma JS, Johnston APW, Steadman PE, Yuzwa SA, Mahmud N, Frankland PW, Kaplan DR, Miller FD (2019) Mesenchymal precursor cells in adult nerves contribute to mammalian tissue repair and regeneration. Cell Stem Cell 24:240-256. e9.

Chen J, Magavi SSP, Macklis JD (2004) Neurogenesis of corticospinal motor neurons extending spinal projections in adult mice. Proc Natl Acad Sci USA 101:16357-16362.

Cheung TH, Rando TA (2013) Molecular regulation of stem cell quiescence. Nat Rev Mol Cell Biol 14:329-340.

Conover JC, Shook BA (2011) Aging of the subventricular zone neural stem cell niche. Aging Dis 2:49-63.

Dulken BW, Leeman DS, Boutet SC, Hebestreit K, Brunet A (2017) Single-cell transcriptomic analysis defines heterogeneity and transcriptional dynamics in the adult neural stem cell lineage. Cell Rep 18:777-790.

Freeman MR, Rowitch DH (2013) Evolving concepts of gliogenesis: a look way back and ahead to the next 25 years. Neuron 80:613623.

Fishell G (1995) Striatal precursors adopt cortical identities in response to local cues. Development 121:803-812.

Fuentealba LC, Rompani SB, Parraguez Jl, Obernier K, Romero R, Cepko CL, Alvarez-Buylla A (2015) Embryonic origin of postnatal neural stem cells. Cell 161:1644-1655.

Furutachi S, Miya H, Watanabe T, Kawai H, Yamasaki N, Harada Y, Imayoshi I, Nelson M, Nakayama KI, Hirabayashi Y, Gotoh Y (2015) Slowly dividing neural progenitors are an embryonic origin of adult neural stem cells. Nat Neurosci 18:657-665.

Gascón S, Murenu E, Masserdotti G, Ortega F, Russo GL, Petrik D, Deshpande A, Heinrich C, Karow M, Robertson SP, Schroeder T, Beckers J, Irmler M, Berndt C, Friedmann Angeli JP, Conrad M, Berninger B, Götz M (2016) Identification and successful negotiation of a metabolic checkpoint in direct neuronal reprogramming. Cell Stem Cell 18:396-409.

Guo Z, Zhang L, Wu Z, Chen Y, Wang F, Chen G (2014) In vivo direct reprogramming of reactive glial cells into functional neurons after brain injury and in an Alzheimer's disease model. Cell Stem Cell 14:188-202.

Hitoshi S, Tropepe V, Ekker M, van der Kooy D (2002) Neural stem cell lineages are regionally specified, but not committed, within distinct compartments of the developing brain. Development 129:233-244.

Hochgerner H, Zeisel A, Lönnerberg P, Linnarsson S (2018) Conserved properties of dentate gyrus neurogenesis across postnatal development revealed by single-cell RNA sequencing. Nat Neurosci 21:290-299.

Kjell J, Fischer-Sternjak J, Thompson AJ, Friess C, Sticco MJ, Salinas F, Cox J, Martinelli DC, Ninkovic J, Franze K, Schiller HB, Götz M (2020) Defining the adult neural stem cell niche proteome identifies key regulators of adult neurogenesis. Cell Stem Cell 26:277-293.e8.

Kohwi M, Petryniak MA, Long JE, Ekker M, Obata K, Yanagawa Y, Rubenstein JLR, Alvarez-Buylla A (2007) A subpopulation of olfactory bulb GABAergic interneurons is derived from Emx1- and DIx5/ 6-expressing progenitors. J Neurosci 27:6878-6891.
Korotkevich G, Sukhov V, Budin N, Shpak B, Artyomov MN, Sergushichev A (2021) Fast gene set enrichment analysis. bioRxiv e060012.

Korsunsky I, Millard N, Fan J, Slowikowski K, Zhang F, Wei K, Baglaenko Y, Brenner M, Loh P, Raychaudhuri S (2019) Fast, sensitive and accurate integration of single-cell data with Harmony. Nat Methods 16:1289-1296.

Kowalczyk MS, Tirosh I, Heckl D, Rao TN, Dixit A, Haas BJ, Schneider RK, Wagers AJ, Ebert BL, Regev A (2015) Single-cell RNA-seq reveals changes in cell cycle and differentiation programs upon aging of hematopoietic stem cells. Genome Res 25:1860-1872.

Liu Y, Miao Q, Yuan J, Han S, Zhang P, Li S, Rao Z, Zhao W, Ye Q, Geng J, Zhang X, Cheng L (2015) Ascl1 converts dorsal midbrain astrocytes into functional neurons in vivo. J Neurosci 35:93369355.

Llorens-Bobadilla E, Zhao S, Baser A, Saiz-Castro G, Zwadlo K, Martin-Villalba A (2015) Single-cell transcriptomics reveals a population of dormant neural stem cells that become activated upon brain injury. Cell Stem Cell 17:329-340.

Lois C, Alvarez-Buylla A (1994) Long-distance neuronal migration in the adult mammalian brain. Science 264:1145-1148.

Lois C, García-Verdugo JM, Alvarez-Buylla A (1996) Chain migration of neuronal precursors. Science 271:978-981.

Machon O, Backman M, Krauss S, Kozmik Z (2005) The cellular fate of cortical progenitors is not maintained in neurosphere cultures. Mol Cell Neurosci 30:388-397.

Magavi SS, Leavitt BR, Macklis JD (2000) Induction of neurogenesis in the neocortex of adult mice. Nature 405:951-955.

Menn B, Garcia-Verdugo JM, Yaschine C, Gonzalez-Perez O, Rowitch D, Alvarez-Buylla A (2006) Origin of oligodendrocytes in the subventricular zone of the adult brain. J Neurosci 26:79077918.

Nakatomi H, Kuriu T, Okabe S, Yamamoto S, Hatano O, Kawahara N, Tamura A, Kirino T, Nakafuku M (2002) Regeneration of hippocampal pyramidal neurons after ischemic brain injury by recruitment of endogenous neural progenitors. Cell 110:429-441.

Obernier K, Alvarez-Buylla A (2019) Neural stem cells: origin, heterogeneity and regulation in the adult mammalian brain. Development 146:dev156059.

Reimand J, Isserlin R, Voisin V, Kucera M, Tannus-Lopes C, Rostamianfar A, Wadi L, Meyer M, Wong J, Xu C, Merico D, Bader GD (2019) Pathway enrichment analysis and visualization of omics data using g: profiler, GSEA, cytoscape and EnrichmentMap. Nat Protoc 14:482-517.

Scialdone A, Natarajan KN, Saraiva LR, Proserpio V, Teichmann SA, Stegle O, Marioni JC, Buettner F (2015) Computational assignment of cell-cycle stage from single-cell transcriptome data. Methods 85:54-61.

Sequerra EB, Miyakoshi LM, Fróes MM, L. Menezes JR, HedinPereira C (2010) Generation of glutamatergic neurons from postnatal and adult subventricular zone with pyramidal-like morphology. Cereb Cortex 20:2583-2591.

Shin J, Berg DA, Zhu Y, Shin JY, Song J, Bonaguidi MA, Enikolopov G, Nauen DW, Christian KM, Ming G, Song H (2015) Single-cell RNA-Seq with waterfall reveals molecular cascades underlying adult neurogenesis. Cell Stem Cell 17:360-372.

Storer MA, Mahmud N, Karamboulas K, Borrett MJ, Yuzwa SA, Gont A, Androschuk A, Sefton MV, Kaplan DR, Miller FD (2020) Acquisition of a unique mesenchymal precursor-like blastema state underlies successful adult mammalian digit tip regeneration. Dev Cell 52:509-524.e9.

Suhonen JO, Peterson DA, Ray J, Gage FH (1996) Differentiation of adult hippocampus-derived progenitors into olfactory neurons in vivo. Nature 383:624-627.

Toma JS, Karamboulas K, Carr MJ, Kolaj A, Yuzwa SA, Mahmud N, Storer MA, Kaplan DR, Miller FD (2020) Peripheral nerve single cell analysis identifies mesenchymal ligands that promote axonal growth. eNeuro 7:ENEURO.0066-20.2020. 
Tran HTN, Ang KS, Chevrier M, Zhang X, Lee NYS, Goh M, Chen J (2020) A benchmark of batch-effect correction methods for singlecell RNA sequencing data. Genome Biol 21:12.

Trapnell C, Cacchiarelli D, Grimsby J, Pokharel P, Li S, Morse M, Lennon NJ, Livak KJ, Mikkelsen TS, Rinn JL (2014) The dynamics and regulators of cell fate decisions are revealed by pseudotemporal ordering of single cells. Nat Biotechnol 32:381-386.

Ventura RE, Goldman JE (2007) Dorsal radial glia generate olfactory bulb interneurons in the postnatal murine brain. J Neurosci 27:4297-4302.

Willaime-Morawek S, Seaberg RM, Batista C, Labbé E, Attisano L, Gorski JA, Jones KR, Kam A, Morshead CM, van der Kooy D (2006) Embryonic cortical neural stem cells migrate ventrally and persist as postnatal striatal stem cells. J Cell Biol 175:159168.

Xie XP, Laks DR, Sun D, Poran A, Laughney AM, Wang Z, Sam J, Belenguer G, Fariñas I, Elemento O, Zhou X, Parada LF (2020) High-resolution mouse subventricular zone stem-cell niche transcriptome reveals features of lineage, anatomy, and aging. Proc Natl Acad Sci USA 117:31448-31458.

Young KM, Fogarty M, Kessaris N, Richardson WD (2007) Subventricular zone stem cells are heterogeneous with respect to their embryonic origins and neurogenic fates in the adult olfactory bulb. J Neurosci 27:8286-8296.

Yuzwa SA, Borrett MJ, Innes BT, Voronova A, Ketela T, Kaplan DR, Bader GD, Miller FD (2017) Developmental emergence of adult neural stem cells as revealed by single-cell transcriptional profiling. Cell Rep 21:3970-3986.

Zahr SK, Yang G, Kazan H, Borrett MJ, Yuzwa SA, Voronova A, Kaplan DR, Miller FD (2018) A translational repression complex in developing mammalian neural stem cells that regulates neuronal specification. Neuron 97:520-537.e6.

Zamboni M, Llorens-Bobadilla E, Magnusson JP, Frisén J (2020) A widespread neurogenic potential of neocortical astrocytes is induced by injury. Cell Stem Cell 27:605-617.e5.

Zhang Y, Liu G, Guo T, Liang XG, Du H, Yang L, Bhaduri A, Li X, Xu Z, Zhang Z, Li Z, He M, Tsyporin J, Kriegstein AR, Rubenstein JL, Yang Z, Chen B (2020) Cortical neural stem cell lineage progression is regulated by extrinsic signaling molecule sonic hedgehog. Cell Rep 30:4490-4504.e4.

Zhou Y, Bond AM, Shade JE, Zhu Y, Davis CO, Wang X, Su Y, Yoon K-J, Phan AT, Chen WJ, Oh JH, Marsh-Armstrong N, Atabai K, Ming G, Song H (2018) Autocrine Mfge8 signaling prevents developmental exhaustion of the adult neural stem cell pool. Cell Stem Cell 23:444-452.e4. 